\title{
ELEPHANT POACHING IN SPACE AND TIME
}


Graduation Committee:

\section{Chairman/Secretary}

Prof.dr.ir. A. Veldkamp

\section{Supervisor}

Prof.dr. A.K. Skidmore

University of Twente/ITC

\section{Co-supervisors}

Dr. T. Wang

University of Twente/ITC

Dr. R. Darvishzadeh Varchehi

University of Twente/ITC

\section{Members}

Prof.dr. P.Y. Georgiadou

University of Twente

Prof.dr. V.G. Jetten

University of Twente

Prof.dr. D. Siege

Utrecht University

A/ Prof.dr. rer. wet. W.D. Kissling

University of Amsterdam

ITC dissertation number 328

ITC, P.O. Box 217, 7500 AA Enschede, The Netherlands

ISBN 978-90-365-4615-7

DOI $10.3990 / 1.9789036546157$

Cover designed by Parinaz Rashidi

Printed by ITC Printing Department

Copyright @ 2018 by Parinaz Rashidi

TUC FACULTY OF GEO-INFORMATION SCIENCE AND EARTH OBSERVATION 


\title{
ELEPHANT POACHING IN SPACE AND TIME
}

\author{
DISSERTATION
}

to obtain

the degree of doctor at the University of Twente, on the authority of the rector magnificus, prof.dr. T.T.M. Palstra, on account of the decision of the graduation committee, to be publicly defended

on Tuesday 18 September 2018 at 14.45 hrs

by

Parinaz Rashidi

born on 31 July 1982

in Nahavand, Iran 
This thesis has been approved by

Prof. dr. A.K. Skidmore, supervisor

Dr. T. Wang, co-supervisor

Dr. R. Darvishzadeh Varchehi , co-supervisor 
To my sincere husband for his love and encouragement and to my beloved parents for their endless devotion 



\section{Acknowledgements}

This PhD research has been a challenging and enjoyable journey over these past few years. This work would not have been possible without the support of many people. Each member of my committee has supplied the tools, direction, and inspiration necessary for completing this research. In this space, I can't begin to thank my promoter Prof. Andrew Skidmore enough for all he has done for me. Prof. Skidmore has been an incredibly giving mentor. He has taught me much about research, but much more about being an honourable academic and a kind person. He has given me the opportunity to undertake a PhD and has made me feel welcome as part of the team. Thank you for your endless advice, guidance, and for allowing me to explore my research interests and providing me with opportunities to succeed. Working with you has been an absolute pleasure.

I am extremely grateful to my co-promoter and daily supervisor, Dr. Tiejun Wang, for his assistance and motivation from the very first day of my PhD until my last day at ITC. Thank you for your guidance, support, encouragement, and patience.

I would like to convey my heartfelt gratitude and sincere appreciation to my co-promoter, Dr. Roshanak Darvishzadeh for her assistance with this thesis. She always kindly encouraged me and shared her experiences with me when I felt frustrated during my studies. You inspired me during difficult times when I needed words of encouragement. You are a blessing in my life. Thanks for all your support and advice.

I would like to express my sincere thanks to $\mathrm{Dr}$ Anton Vrieling for his constructive comments, edits in my work and willingness to respond to my questions even when I asked them in wrong places.

My sincere gratitude goes to Dr. Shadrack Ngene, for his assistance in providing data and his support undertaking fieldwork in Kenya. Without your valuable support, this thesis would have been very difficult to complete.

I also thank Dr Albertus Toxopeus for his involvement and input in the papers.

Many thanks also go to Ms. Eva Skidmore and Ms. Jackie Senior for great assistance in English editing. Eva, I am impressed by the professionalism and quality of your editing. I will always remember your warm smile and your kindness.

I am also indebted to the European Commission's Erasmus Mundus program for awarding me a PhD scholarship and to the Faculty of Geo-information Science and Earth Observation (ITC) for their financial support. Without this support, it would not have been possible for me to undertake this research. 
I thank the Kenya Wildlife Service for providing the elephant poaching data and their support for doing field work.

I would like to thank everyone at ITC who supported me throughout my stay, in particular, Ms. Loes Colenbrander and Mr Willem Nieuwenhuis for always being so kind and helpful. My special thanks go to Ms. Esther Hondebrink, for the kind help in Dutch translation. Thank you for all the assistance you have provided me during my PhD. I would like to express my gratitude to Mr. Job Duim for his kind assistance in the thesis cover design. I would especially like to thank Prof Andy Nelson, Dr. Thomas Groen, Dr. Tom Rientjes, Mr Tonny Boeve, Ms. Theresa van den Boogaard, Mr. Benno Masselink, Ms Carla Gerritsen, and Mr. Roelof Schoppers.

I have been blessed with a large group of exceptional office mates. Dr. Elnaz Neinavaz, Dr John Wasige and Dr Amjad Ali were the first and remain the first in my heart. My cordial thanks also go to my officemates Dr Xi Zhu, Dr Maria Fernanda Buitrago and Dr Elias Nyandwi.

I have been lucky to come across many good friends, without whom life would be bleak. Thanks Dr Shariat Mobasser and Dr. Mitra Shariati Najafabadi, for the great friendship, and for always being so supportive and kind. My sincere thanks go to my friends, Mr Hamed Mehdi Poor, Dr Jamil Amanollahi, Dr Babak Naimi, Dr Marjan Mohamadzadeh, Mr Milad Mahour, Mr. Frederick Lala, Ms Adish Khezri, Ms Sara Alidoost, Ms Soodabeh Amininejhad, Dr Sanaz Salati, Mr Sam Khosravifard, Ms Linlin Li, Dr Zhihui Wang, Mr Peter Van Es, Mr Matthew Dimal, Mr Edward Opiyo Ouko, Dr Elahe Hadavi, Ms Sara Mehryar and Dr Anahita Khosravipour.

I am extremely grateful to my Master's supervisors, Dr Abdolrassoul Salman Mahiny, Professor Majid Makhdoum Farkhondeh, Dr Hossein Varasteh Moradi, Dr Alireza Mickaeili Tabrizi, Dr Hamidreza Rezaee and Dr Hamed Mirkarimi who supported and encouraged me to continue my education and had a positive influence on my life.

To my family, words are not enough to express my sincere gratitude and love. Thanks to my parents and parents-in-law for their unconditional love and patience. I also would like to thank my sister Parisa and my brothers Pouya and Pedram for unconditional love and support. I owe my deepest gratitude to my kind husband, Shahabedin Akbarian for supporting and loving me, and growing up with me all these years. 


\section{Table of Contents}

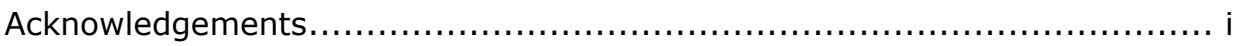

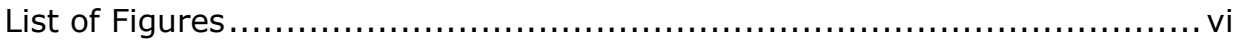

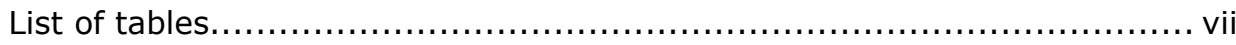

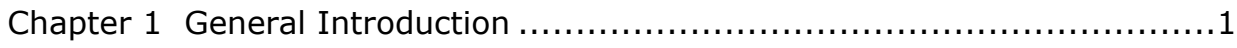

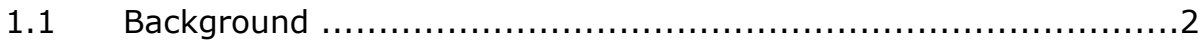

1.2 Elephant Poaching and Research Problem ............................ 3

1.2.1 Elephant Poaching in Kenya .......................................

1.2.2 Limitation in the Research and Knowledge Gap Regarding the

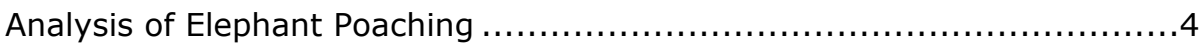

1.2.3 Innovative Application of Cluster Analysis and Bayesian Modelling Regarding Elephant Poaching Data.......................................4

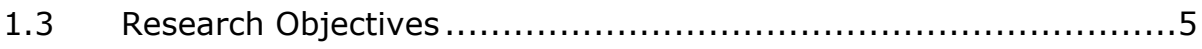

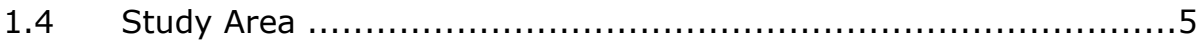

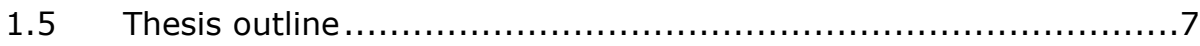

Chapter 2 Spatial and Spatiotemporal Clustering Methods for Detecting

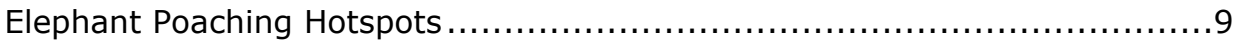

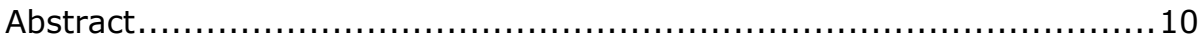

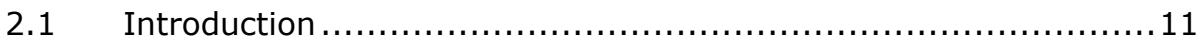

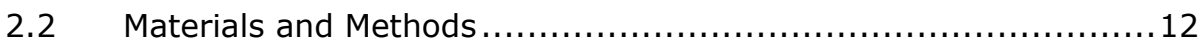

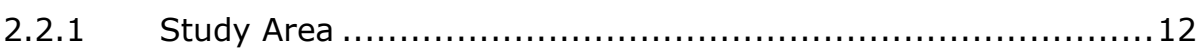

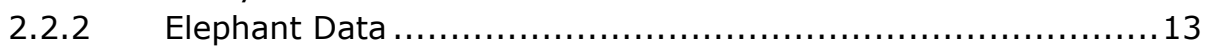

2.2.3 Block Design ................................................... 13

2.2.4 Spatial Clustering Methods....................................... 14

2.2.4.1 Kulldorff's Spatial Scan Statistic ............................... 14

2.2.4.2 Flexible Spatial Scan Statistic.............................. 14

2.2.5 Spatiotemporal Clustering Methods .............................. 15

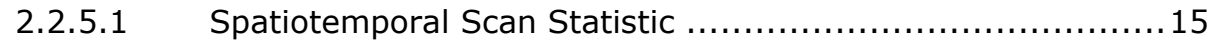

2.2.5.2 Spatiotemporal Permutation Scan Statistic.................... 15

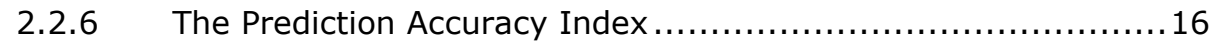

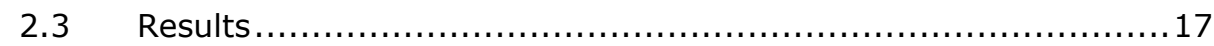

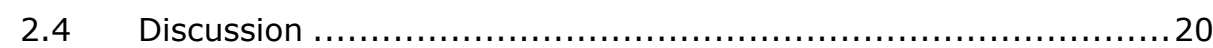

2.5 Conclusions........................................................... 21

Chapter 3 Elephant Poaching Risk Assessed Using Spatial and Non-Spatial

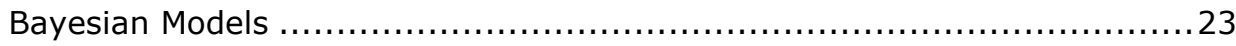

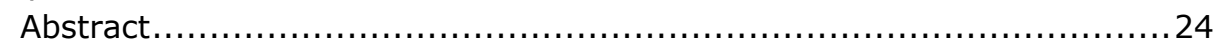

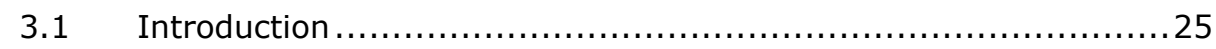

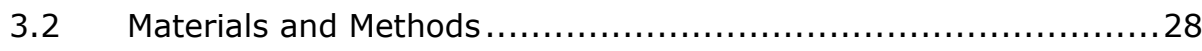

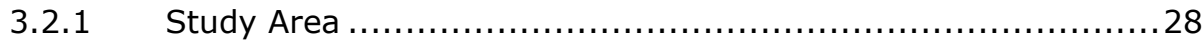

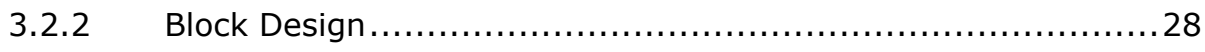

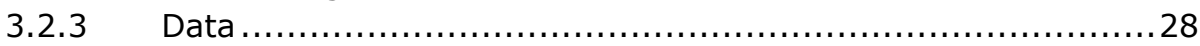

3.2.3.1 Elephant Population and Poaching Incidence Data ............... 28

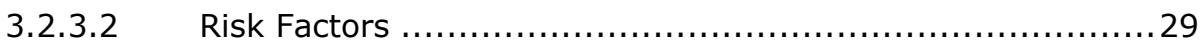


3.2.4 Expert Rating of Poaching Risk Factors ......................... 31

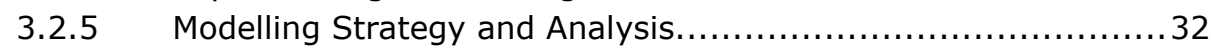

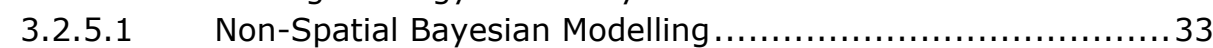

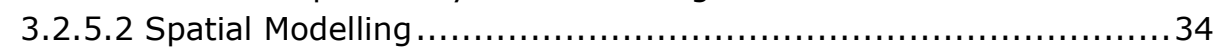

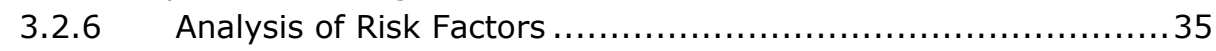

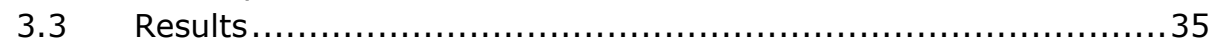

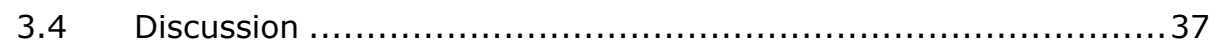

3.5 Conclusions.................................................. 39

Chapter 4 Assessing Trends and Seasonal Changes in Elephant Poaching Risk at the Small Area Level Using Spatio-Temporal Bayesian Modelling...........41

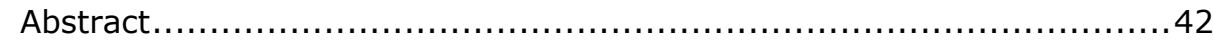

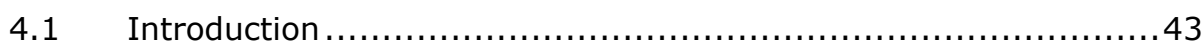

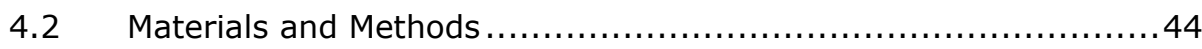

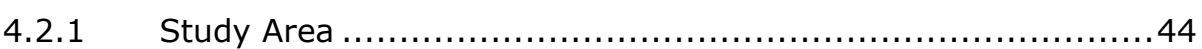

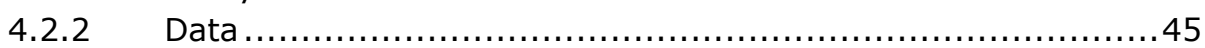

4.2.2.1 Elephant Population and Poaching Incidence Data .............45

4.2.2.2 Environmental Risk Factors................................... 45

4.2.3 Modelling Strategy and Analysis.................................... 46

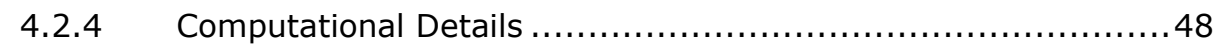

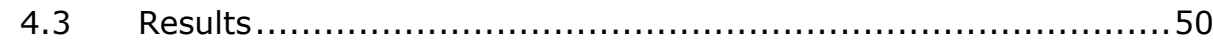

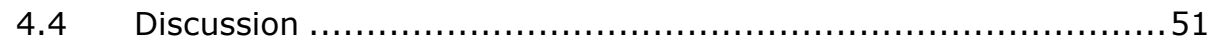

4.5 Conclusions......................................................... 54

Chapter 5 Areas at High Risk of Elephant Poaching Shift from the South-East to the West of Kenya During 2002-2012 .................................. 55

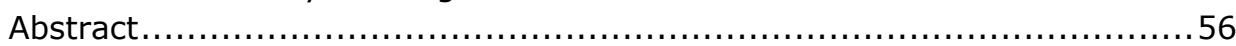

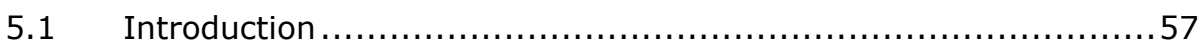

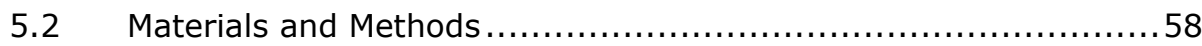

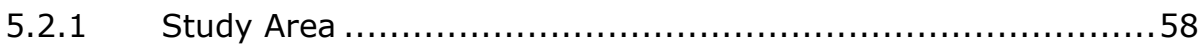

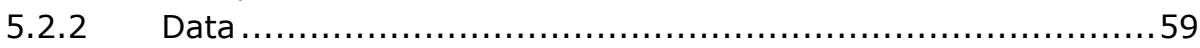

5.2.2.1 Elephant Population and Poaching Incidence Data .............. 59

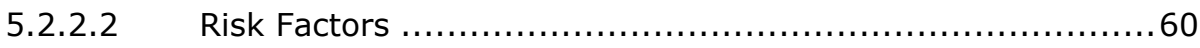

5.2.3 Accounting for the Effects of Multicollinearity Regarding Risk

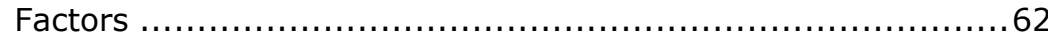

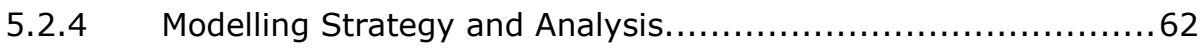

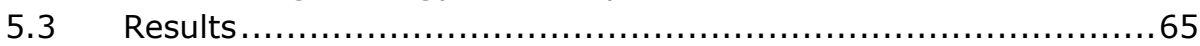

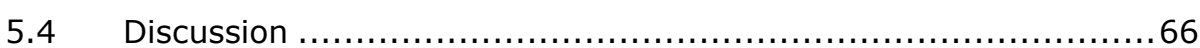

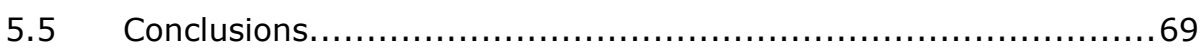

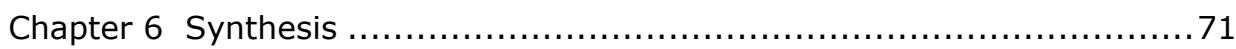

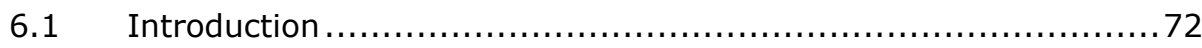

6.2 Detecting Elephant Poaching Hotspots at Local Level in the Tsavo Ecosystem. ............................................ 73

6.3 Spatial and Spatio-temporal Dynamics of Elephant Poaching Risk at Local and National Level ................................. 74 
6.4 Biophysical and Anthropogenic Factors Influencing Elephant Poaching Risk...................................................... 76

6.5 Applications of Spatial and Spatio-Temporal Models in Elephant Poaching Research .................................................. 78

6.6 Relevance to Conservation and Management. ........................79

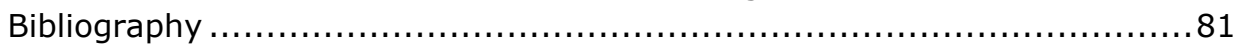

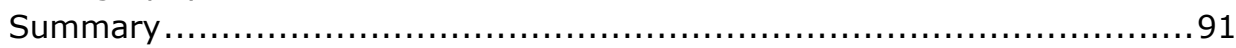

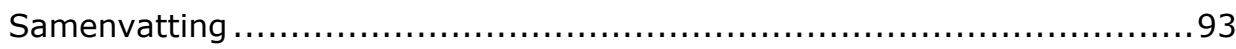

Appendix Table A2: Descriptive statistics for elephant poaching incidents between 2002 and 2012 within the defined blocks in the Greater Tsavo

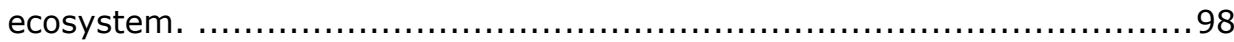
Appendix Table A3: Descriptive statistics for elephant poaching incidents in in the dry seasons between 2002 and 2012 within the defined blocks in the Greater Tsavo ecosystem. ......................................................99 Appendix Table A4: Descriptive statistics for elephant poaching incidents in the wet seasons between 2002 and 2012 within the defined blocks in the Greater Tsavo ecosystem. ................................................... 100

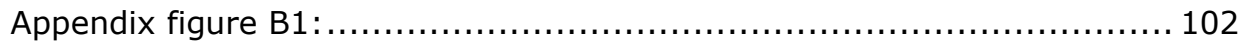

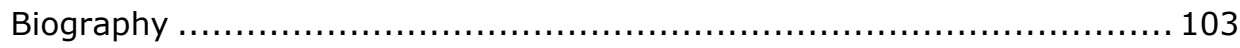

Scientific publications: ........................................................ 103

International conferences: ............................................. 103 


\section{List of Figures}

Figure 1.1: Location of the conservation regions in Kenya; and total elephant poaching incidents per conservation region (2002-2012)......................6 Figure 1.2: Location of the Greater Tsavo ecosystem in Kenya. The points (151) indicate the recorded sites of elephant poaching and the colors show the different ranches and sections of the Greater Tsavo ecosystem (20022012).

Figure 2.1: Distribution of recorded elephant poaching incidents between 2002 and 2012 within the defined blocks in the Greater Tsavo ecosystem. . 13 Figure 2.2: The most likely clusters identified by the two spatial clustering methods:(a) Kulldorff's spatial scan statistic, and (b) the flexible spatial scan statistic with a restricted likelihood ratio..........................................17 Figure 2.3: The most likely clusters identified by two spatiotemporal cluster methods, using monthly spatiotemporal data from 2000 to 2012. (a) Spatiotemporal scanstatistic and (b) spatiotemporal permutation scan statistic. 18

Figure 2.4: Consistent blocks of elephant poaching in the Tsavo ecosystem, Kenya. They were derived from (a) spatial clustering methods, and (b) spatiotemporal clustering methods. Figure 2.5: Consistent blocks of elephant poaching in the Tsavo ecosystem, Kenya. They were derived from (a) spatial clustering methods, and (b) spatiotemporal clustering methods. ............................................. 20 Figure 3.1: Tsavo ecosystem displaying the probability of elephant poaching risk for each block: (a) Bayesian non-spatial model and (b) Bayesian spatial

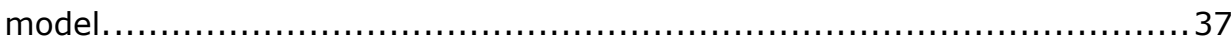
Figure 3.2: Areas of high elephant poaching risk that were unexplained by the measured risk factors, i.e., using the spatial model in which the spatial random variable is acting as a proxy of the unmeasured risk factors that were

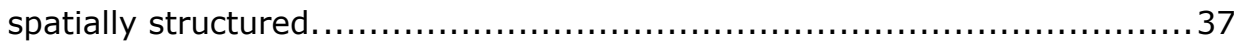
Figure 4.1: Probability that local elephant poaching risks were greater than the mean temporal trend: (a) Model 1.1: spatio-temporal Bayesian model without accounting for the potential risk factors and (b) Model 1.2: spatiotemporal Bayesian model which includes potential risk factors.

Figure 4.2: Seasonal changes in high risk areas for elephant poaching in Tsavo ecosystem (2002-2012) using the spatio-temporal Bayesian model: (a) Model 2.1: wet season and (b) Model 2.2: dry season.

Figure 5.1: Yearly distribution of recorded elephant poaching incidents

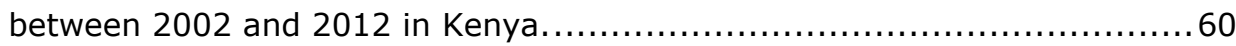

Figure 5.2: Time series maps depict the shifts in high-risk elephant poaching areas from the south-east to the west of Kenya (2002 to 2012)..............65 Figure 5.3: Spatio-temporal high-risk areas in Kenya with a persistently high risk of elephant poaching over the study period $(2002-2012) . \ldots \ldots \ldots \ldots \ldots . . .65$ 
Figure 6.1: Consistent elephant poaching hotspots in the Tsavo ecosystem, Kenya.................................................................... 74

Figure 6.2: The probability of elephant poaching risk for each block in the Tsavo ecosystem, Kenya: (a) Bayesian spatial model and (b) Bayesian spatito-temporal model. .75

Figure 6.3: Shifts in high-risk elephant poaching areas from (a) the southeast of Kenya with high recorded elephant poaching incidents in the year 2002 to (b) the west of Kenya where minimal poaching incidents were

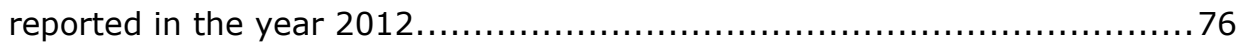

\section{List of tables}

Table 3-1: The potential risk factors and their associated mean and standard deviation. 31

Table 3-2: Information elicited from 30 experts on the risk factor's impact on elephant poaching in the Tsavo ecosystem, showing the mean response from the experts and the corresponding precision (the inverse of variance) 32 Table 3-3: Posterior summaries for $\beta$ coefficients of the explanatory variables in Bayesian non-spatial and spatial models. ................................... 36 Table 4-1 Model structure for the two different model sets used in this

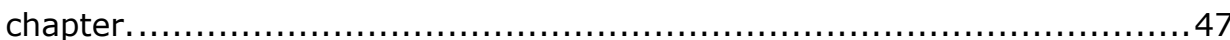

Table 4-2: The results of model fitting for Model 1.1 and $1.2 \ldots \ldots \ldots \ldots \ldots \ldots 1$ Table 5-1: The potential risk factors with their associated mean and the mean response elicited from the experts on the risk factor's impact on elephant poaching. 62

Table 5-2: Posterior summaries for $B$ coefficients of the explanatory variables

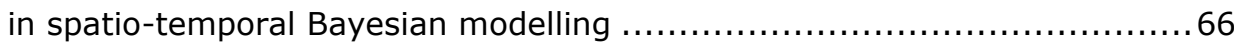
Table 6-1: Posterior summaries for $B$ coefficients of the consistent explanatory variables at local and national level using spatio-temporal Bayesian modelling 78 
Chapter 1

General Introduction 


\subsection{Background}

The African elephant (Loxodonta africana) plays a vital role: ecologically as keystone species, culturally as an iconic representation of the African continent, and economically as a driver of tourism (Chase et al., 2016). However, elephants are considered vulnerable and are under threat in most parts of Africa from poaching, human-elephant conflict, habitat fragmentation and loss, and isolation of populations (UNEP et al., 2013). This is related to weak governance as well as poverty in the elephant range countries (Blanc et al., 2013, Kyando et al., 2017). Poaching or hunting for economic, social, and cultural reasons currently forms the main cause of the reduction in elephant populations in Africa (Bouché et al., 2011, Chase et al., 2016, Maisels et al., 2013, Zafra-Calvo et al., 2018).

Poaching forms an immediate threat to the survival of African elephants and is responsible for the decline in African elephants at alarming rates throughout numerous African range countries (Kyando et al., 2017). For example, one hundred thousand elephants are estimated to have been killed across the African continent during the period 2008-2012 (Wittemyer et al., 2014). Existing poaching levels in Africa remain unacceptably high and if the present killing rate of 7.4 percent continues (which is higher than the natural population growth rate of up to 5 percent (Kyando et al., 2017)), this could soon lead to the decline and even local extinction of some elephant (Nyirenda et al., 2015). The loss or decline in numbers of elephants can influence the integrity of the ecosystems and their services as well as affect human livelihoods through reduced tourism income potential (Zafra-Calvo et al., 2018).

Elephants are an umbrella species, and their conservation depends on huge areas of the ecosystems being protected, which will assist the objective of wider biodiversity conservation (Omondi and Ngene, 2012b). Moreover, elephants are also a flagship species, extremely charismatic animals that can assist as a rallying point for conservation, appealing to the imagination of people from all over the world and generating significant returns from wildlife-based tourism (Omondi and Ngene, 2012b). Last but not least, elephants are a keystone species playing a substantial role in ecological dynamics. Therefore, their survival is important to the conservation of other elements of biodiversity (Omondi and Ngene, 2012b).

In the first decade of the twenty-first century, there was an upsurge in the price of ivory, coinciding with a rise in ivory demand (Litoroh et al., 2012). Many believe that the down-listing of four Southern African elephant populations from Appendix I to Appendix II by CITES, along with two legal 'one-off' sales of ivory, have enhanced poaching and illegal trade (Maingi et al., 2012). 
According to the IUCN's African Elephant Status Report presented in September 2016 at the 17th meeting of the Conference of the Parties to CITES, in Johannesburg, South Africa, Africa's overall elephant population has seen its most serious decline in 25 years, largely due to poaching over the past ten years. That elephant poaching occurs at an alarming rate is a result of the high demand for illegal ivory in Asia (Kyando et al., 2017). Trade in ivory depends on a subtle balance of supply and demand (Chaiklin, 2010). Factors driving this crime include fast growth in the demand for ivory in Asian countries and the Middle East for fashion and medicinal purposes, as well as widespread poverty, unemployment, and corruption in supply countries (Kideghesho, 2016).

Most large deliveries of ivory are reaching the Asian markets through the eastern Africa sub-region. Since 2009, trade routes switched from Central Africa and West seaports to East Africa, with Kenya and Tanzania becoming the primary departure points for illegal ivory trade leaving the continent through Indian Ocean ports (Mombasa, Dar es Salaam and Zanzibar)(Vira et al., 2014). Kenya and Tanzania are now involved in the ivory trade on a large scale both as source and as the departure point (Kyando et al., 2017, Vira et al., 2014). This reflects the shifts in poaching patterns from West and Central Africa to Eastern and Southern Africa (Blanc et al., 2013, Kyando et al., 2017).

\subsection{Elephant Poaching and Research Problem}

\subsubsection{Elephant Poaching in Kenya}

Elephants were effectively eradicated from large areas of Africa due to ivory trade in the 18th and, in particular, the late 19th century (Spinage, 1973). The population of the African elephant decreased severely throughout the continent, from an estimate of 1.3 million in 1979 to about 600,000 in the late 1980s (Onyango and Lesowapir, 2016).

The international ivory trade, which started increasing at the end of the 1960s, expanded due to large illegal hunting during the 1970s and 1980s, leading to a rapid decline in elephant populations across West, Central, East and parts of Southern Africa (Douglas-Hamilton, 1989). Kenya, like most African countries, formed no exception regarding the elephant carnage (Onyango and Lesowapir, 2016). Between 1973 and 1990, elephant numbers in Kenya decreased from about 167,000 to as few as 20,000 (Litoroh et al., 2012). In 1990, with the formation of a more effective management authority, i.e. the Kenya Wildlife Service (KWS), and through the termination of legal international ivory trade (through elevation of the African elephant to Appendix I of CITES), the elephant population re-established itself. However, illegal poaching and black market trading remain challenges this species still faces (Hassan and Baqer, 2016). For example, the year 2006 again saw a 
dramatic rise in illegal poaching. Large upsurges have also been documented since 2007 (Hassan and Baqer, 2016). Although elephant poaching has been forbidden globally for more than 40 years now, in Kenya the illegal killing of elephants has not decreased. This is due to poverty, to the high return associated with elephant tusks and to the ease of shipping to the ready black market (Hassan and Baqer, 2016).

\subsubsection{Limitation in the Research and Knowledge Gap Regarding the Analysis of Elephant Poaching}

Insufficient human and financial resources, combined with the large areal extent to be monitored, pose major challenges for anti-poaching activities in Kenya (Maingi et al., 2012, Rashidi et al., 2015). Because of high conservation costs, Kenya cannot offer adequate protection of wildlife from poaching within national parks and reserves. The KWS is understaffed with less than one ranger per $100 \mathrm{~km} 2$ of wildlife reserve (Maingi et al., 2012). Also, an absolute measure of the poaching based on direct observation is impossible because of the covert nature of poaching (Burn et al., 2011, Sharma et al., 2014). Moreover, detailed data are scarce, and many poaching reports are collected incidentally, and may possibly be indirect (Madhusudan and Karanth, 2002, Sánchez-Mercado et al., 2008). Nevertheless, in order to protect elephants against current poaching threats, conservation managers require timely information on spatial and temporal variations in high-risk poaching areas for prioritizing intelligence and enforcement efforts (Critchlow et al., 2015).

This study will fill the existing gap in knowledge needed to ensure efficient law enforcement and management of elephants, considering restraints regarding data availability and finance. This research assists in the targeting of specific locations where poaching may be concentrated as well as in the setting of conservation priorities and the concentration of management resources. Therefore, this research is valuable not only for the identification of risk areas, through further understanding of annual and seasonal trends, but also to recognize the reasons why conflicts are clustered in a certain area, as well as the factors, biophysical and human, that promote poaching risk. In addition, it is important to evaluate whether some of the new methods developed and discussed in this research may be more effective for analyzing poaching because they overcome the scarce data problem (Gelman and Price, 1999), which appears when low incident counts and high sampling variation cause unstable estimations (Bernardinelli et al., 1995, Congdon, 2000).

\subsubsection{Innovative Application of Cluster Analysis and Bayesian Modelling Regarding Elephant Poaching Data}


In this study, cluster analysis has been applied to poaching data to detect spatial and spatiotemporal patterns in elephant poaching and to discern areas or periods of high occurrence (hotspots) of a specific feature from other areas or periods with a more random occurrence. Bayesian modelling was used to assess the spatial and spatio-temporal variation in elephant poaching trends. The aim was to identify probability risk for the areas within the study area that are at greater risk of elephant poaching and to ascertain associations between occurrence and potential risk factors. Such information is useful in guiding the deployment of policing resources in the protected areas and its surroundings, and to help improve or alter the management actions. The findings could be incorporated in future national and regional management programs in order to reduce human-induced elephant deaths.

\subsection{Research Objectives}

The general objective of this research is to assess spatial and spatiotemporal trends, as well as seasonal and annual changes in elephant poaching risk at local and national level utilizing cluster and Bayesian modelling. Therefore, the specific objectives can be described as follows:

- To identify elephant poaching hotspots by analyzing the differences in clusters of poached elephants in the Tsavo ecosystem (Kenya) that emerge from different cluster detection methods.

- To investigate elephant poaching risk by comparing spatial and nonspatial Bayesian models in small areas (blocks) in the Tsavo ecosystem, Kenya.

- To assess inter-annual trends and seasonal changes in elephant poaching risk for Kenya's Greater Tsavo ecosystem over an eleven-year period, from 2002 to 2012, using spatio-temporal Bayesian modelling.

- To investigate, on a regional level, how elephant poaching risk in Kenya may change at different locations or times or for any interaction between space and time.

- To identify the key factors influencing high-risk elephant poaching areas.

\subsection{Study Area}

The study was conducted at national as well as local level. At national level we focussed on Kenya (Figure 1.1). The republic of Kenya covers an area of about $582,646 \mathrm{~km}^{2}$ on the equator in East Africa. It lies between $5^{\circ} 30^{\prime} \mathrm{N}$ and $4^{\circ} 30^{\prime} \mathrm{S}$ latitude and $34^{\circ} \mathrm{E}$ and $42^{\circ} \mathrm{E}$ longitude (Ouko, 2013). Kenya has thirteen National Parks and twenty-five reserves that occupy ten percent of the country (Burnett and Rowntree 1990). There are a wide range of natural regions in the country, varying from hot, arid lowlands to cool, humid highlands, with numerous soils types (Batjes, 2004). The altitude steadily rises from $0 \mathrm{~m}$ above mean sea level nearby the Indian Ocean to between 
$2000-3400 \mathrm{~m}$ in the highlands (Ouko, 2013). The climate of Kenya varies by location. The long rainy season takes place from March through May in many regions of Kenya and the short rainy season occurs between October to November (Batjes, 2004). The dry seasons encompass January to February and June to September in most years (Batjes, 2004). Mean annual rainfall varies between $150-500 \mathrm{~mm}$ in the arid east and northeast of the Kenya, to $500-1000 \mathrm{~mm}$ in the semi-arid regions, and 1000 to $2500 \mathrm{~mm}$ in the more humid areas in the central highlands and near Lake Victoria (Ouko, 2013). The mean annual air temperature is acutely correlated with elevation. It declines from about $27^{\circ} \mathrm{C}$ near the sea, to $17^{\circ} \mathrm{C}$ in Nairobi in the central highlands, to below $10^{\circ} \mathrm{C}$ above $3000 \mathrm{~m}$ (Ouko, 2013).

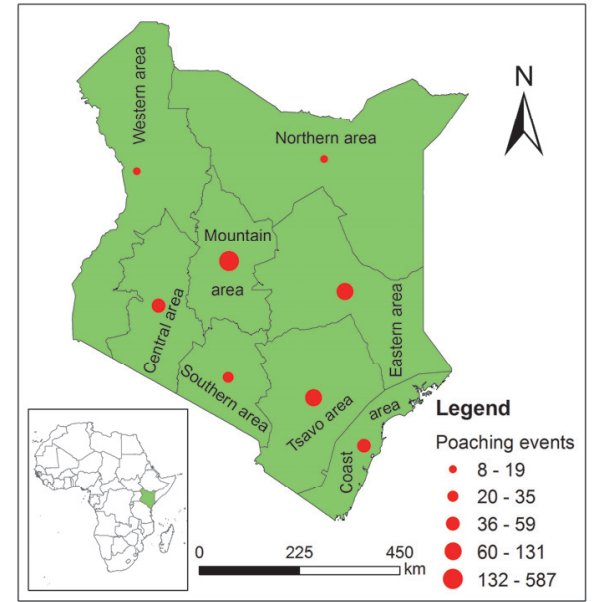

Figure $\mathbf{0 . 1}$ Location of the conservation regions in Kenya; and total elephant poaching incidents per conservation region (2002-2012)

At local level we focus on the Tsavo ecosystem. The Greater Tsavo ecosystem covers $38,128 \mathrm{~km}^{2}$ in south-east Kenya (Figure 1.2). Our study area was composed of the Tsavo East National Parks North (north of the Galana River) and South (south of the Galana River), as well as the Tsavo West National Park, and also a number of private ranches (Figure 1.2). The rivers and streams of the Tsavo ecosystem include the Tsavo, the Tiva, the Galana, the Athirivers, and the Voi (Maingi et al., 2012). Commiphora savanna forms the prevailing vegetation community in the study area (Cobb, 1976). The area's climate shows clear seasonality and also displays a large geographic variation. The long wet season takes place between March and May. Rainfall amounts during the wet season are largest between the Taita Hills and the Kilimanjaro area. The short rainy season occurs in November and December, when rainfall is concentrated mostly in the eastern and northern parts of the area (Ngene et al., 2013, Smith and Kasiki, 2000). The Tsavo ecosystem is home to the largest population of Kenya's elephants, but also experiences the largest number of elephant poaching incidents in Kenya (Maingi et al., 2012, 
Rashidi et al., 2015). It is also one of four sites for "Monitoring of Illegal Killing of Elephants" (MIKE program) in Kenya (Shaffer and Bishop, 2016).

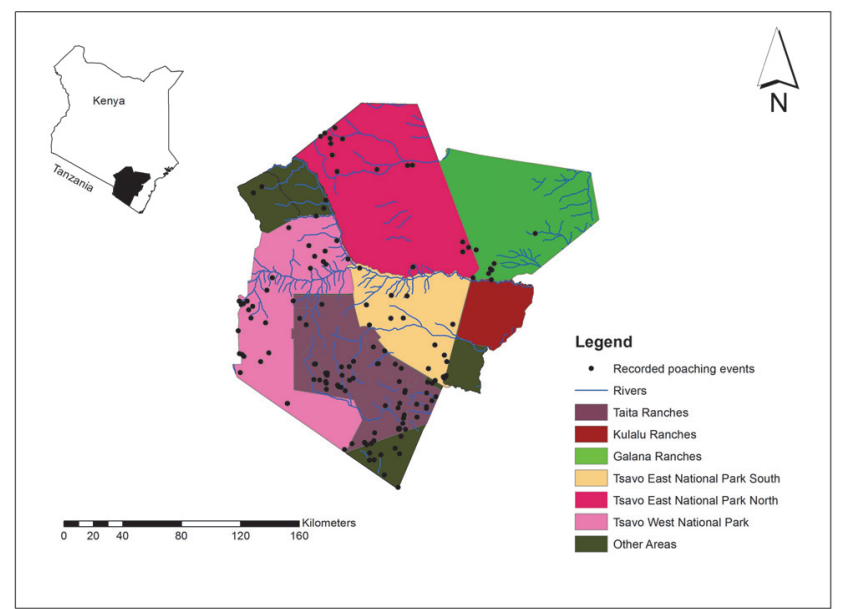

Figure $\mathbf{0 . 2}$ Location of the Greater Tsavo ecosystem in Kenya. The points (151) indicate the recorded sites of elephant poaching and the colors show the different ranches and sections of the Greater Tsavo ecosystem (2002-2012).

\subsection{Thesis outline}

Structurally this thesis comprises six chapters, namely the introduction, four core chapters, and a synthesis. The core chapters include four stand-alone papers that have been published (three) or submitted (one) to peer reviewed international journals. The chapters are in the following order:

Chapter 1: In this chapter, the background to this research is discussed briefly, the research problems and objectives are described and the thesis outline presented.

Chapter 2: In this chapter, elephant poaching hotspots are identified by analyzing the differences in clusters of poached elephants in the Tsavo ecosystem (Kenya) that emerged from different cluster detection methods. Two spatial- and two spatio-temporal clustering methods are applied to the data. The predictive accuracy of the spatial methods in defining hotspots is assessed using the prediction accuracy index (PAI), which is then modified (MPAI) for measuring the predictive accuracy of the spatiotemporal methods. Finally, blocks consistently identified as poaching hotspots are introduced.

Chapter 3: In this chapter poaching risk for African elephant (Loxodonta africana) is investigated by comparing spatial and non-spatial Bayesian models. Spatial and non-spatial Bayesian models are fed with expert knowledge obtained through survey responses from 30 experts. The predictive accuracy of both models is assessed using the Deviance 
Information Criterion (DIC). Key factors influencing elephant poaching risk are determined by Bayesian spatial and non-spatial models. Risk probability values per spatial unit are determined.

Chapter 4: In this chapter inter-annual trends and seasonal changes in elephant poaching risk are assessed for Kenya's Greater Tsavo ecosystem for the eleven-year period from 2002 to 2012, using spatio-temporal Bayesian modelling. The hypothesis concerning whether risk factors enhance the prediction of the model are tested. At a local level specific areas with a persistently high risk of elephant poaching in the years studied (2002 - 2012) are highlighted. Also, locations with the highest elephant poaching risk during the wet and dry seasons are assessed.

Chapter 5: In this chapter Bayesian spatio-temporal methods with the ability to incorporate prior knowledge (expert knowledge) are used to investigate how elephant poaching risk in Kenya may change at different locations or times or with any interaction between space and time. These models are also used to identify the key factors influencing high risk elephant poaching areas at a national level. Annual shifts in high risk elephant poaching areas in Kenya (2002 to 2012) are also identified. At a national level, spatio-temporal high risk areas with a persistently high risk of elephant poaching over the studied years (2002 - 2012) are identified.

Chapter 6: In this chapter, the research findings are logically amalgamated. An overview of the research findings from the previous chapters is provided. It elaborates on the implications of these results regarding prevention or reduction of poaching activity in areas with relatively strongly increasing poaching trends. Ultimately, suggestions are made for further study. 


\section{Chapter 2}

\section{Spatial and Spatiotemporal Clustering Methods for Detecting Elephant Poaching Hotspots*}

* This chapter is based on: Rashidi, P., Wang, T.J., Skidmore, A.K., Vrieling, A., Darvishzadeh, R., Toxopeus, A.G., Ngene, S.M. and Omondi, P. (2015) Spatial and Spatiotemporal Clustering Methods for Detecting Elephant Poaching Hotspots. In: Ecological Modelling, 297, 180-186. 


\section{Abstract}

Spatial and spatiotemporal cluster methods are used for a wide range of applications including the study of criminal activities, but have never been compared for studying a specific form of crime, i.e. wildlife poaching. We aimed to identify elephant poaching hotspots by analyzing the differences in clusters of poached elephants in the Tsavo ecosystem (Kenya) that emerged from different cluster detection methods. Reports of elephant poaching in the Tsavo ecosystem were obtained for 2002-2012 from the Kenya Wildlife Service. The study area was divided into 34 blocks for analysis. Two spatialand two spatiotemporal clustering methods were applied to the data. The predictive accuracy of the spatial methods in defining hotspots was assessed using the prediction accuracy index (PAI), which was then modified (MPAI) for measuring the predictive accuracy of the spatiotemporal methods. The results from the spatial methods indicated eight consistent poaching blocks, with Kulldorff's spatial scan statistic having a slightly higher PAI value than the flexible scan statistic (2.39 vs 2.12$)$. The spatiotemporal clustering methods revealed four consistent poaching blocks. The MPAI value was higher for the spatiotemporal scan statistic than the spatiotemporal permutation scan statistic ( 1.46 vs 0.97$)$. The results demonstrated that although the hotspot predictions varied for the different methods, three blocks were consistently identified as poaching hotspots. Our findings may assist wildlife departments such as the Kenyan Wildlife Service to allocate their financial and human resources as effectively as possible in combating poaching. Further research is needed to examine the environmental and human factors contributing to the patterns that have been observed in elephant poaching. 


\subsection{Introduction}

Cluster analysis aids in identifying the presence of spatial and temporal patterns (Quick and Law, 2013). It can discern areas or periods of high occurrence (hotspots) of a specific feature from other areas or periods with a more random occurrence. Many methods for testing the presence of clusters in spatial point features have been defined and they can be broadly divided into global and local clustering methods (Chiu et al., 2008). In global clustering methods, the average tendency (a typical value for a probability distribution, e.g. mean or median) in a dataset is measured to test the null hypothesis of spatial randomness over the whole study area. However, the specific location or significance of individual clusters is not specified by global methods (Burra et al., 2002, Chakravorty, 1995, Quick and Law, 2013). In contrast, local clustering methods identify the location of individual clusters by processing subsets of global data; local clustering methods recognize neighboring regions that show exceedingly high or low occurrences relative to the null hypothesis of spatial randomness (Anselin, 1995, Anselin et al., 2000, Kulldorff et al., 2003, Quick and Law, 2013). Local clustering can be classified in three groups: temporal clustering, spatial clustering, or spatiotemporal clustering (Tango, 2010). Temporal clustering investigates whether cases show a tendency to be placed close to each other in time (Tango, 2010). Spatial clustering investigates if the occurrence of a specific feature is particularly high in some geographical areas, irrespective of when it occurred during the study period. Spatiotemporal clustering investigates whether events that are close in space are also close in time (Tango, 2010).

Cluster analysis used in epidemiology (Hanson and Wieczorek, 2002; Kulldorff, 1997; Torabi and Rosychuk, 2011) and has been applied to crime data to assist decision-making on where and when to address potential crime clusters in future, e.g. for drug offences (Quick and Law, 2013) or city violence and property crimes (Uittenbogaard and Ceccato, 2012). However, few studies exist that aimed at detecting spatial and spatiotemporal patterns in the specific criminal act of wildlife poaching. One example is Haines et al. (2012) who studied white-tailed deer poaching activity in Fayette County, Iowa, USA, in terms of temporal, spatial, and environmental patterns. They used logistic regression models and produced poaching activity hotspots map.

Although elephant populations are declining across their habitat range in Africa and poaching is a significant source of mortality, little attention has been paid to predicting poaching hotspots. Analysis of data related to poaching is important for wildlife conservation. Based on elephant mortality data collected between 1989 and 2005 Kyale et al. (2011a) identified spatial patterns of elephant mortality, which is largely due to poaching, in Tsavo East National Park in Kenya. They used kernel density analyses and found that the patterns were clustered, with poaching being more intensive in the northern 
and central areas of the park. Maingi et al. (2012) studied spatial patterns of elephant poaching separately for wet and dry season for the period between January 1990 and December 2009 in south-eastern Kenya. They used kernel density analyses and concluded that poaching was more common in the dry season when the elephants aggregate along permanent rivers. However, their analysis merely separated the two seasons and assessed hotspots for each, but did not address both space and time in a single model. In fact, poaching hotspots have never been mapped using spatiotemporal methods and the differences in hotspots that emerge from various clustering methods have not been evaluated.

We therefore set out to identify elephant poaching hotspots by analyzing the differences in emerging clusters of poached elephants in the Tsavo ecosystem. We used different cluster detection methods on data covering a continuous period of ten years. We selected four common clustering methods (two spatial, two spatiotemporal) for this purpose. Our study aimed to answer the following five questions: (1) Where are the consistent elephant poaching hotspots as determined by various spatial and spatiotemporal clustering methods? (2) What are the differences between the emerging clusters obtained by the different spatial clustering methods? (3) Do spatial clustering methods differ in their ability to predict where hotspots may occur? (4) What are the differences between the emerging clusters obtained by different spatiotemporal clustering methods? (5) Do the spatiotemporal clustering methods differ in their ability to predict where and when hotspots may occur?

\subsection{Materials and Methods}

\subsubsection{Study Area}

The Tsavo ecosystem covers an area of about $38,128 \mathrm{~km}^{2}$ in south-east Kenya (Figure 1.2). The ecosystem lies between $2-4^{\circ} \mathrm{S}$, and $37.5-39.5^{\circ} \mathrm{E}$ (Ngene, 2013). It has a population of about 11,000 elephants (Kyale et al, 2014), and the highest reported poaching of elephants, in Kenya (Maingi et al., 2012). The anti-poaching activities in the Tsavo ecosystem are challenged by inadequate resources (human and financial), and the extensive area covered (Maingi et al., 2012). Various rivers traverse the ecosystem, including the Galana, Voi, Tiva, Tsavo and Athirivers (Maingi et al., 2012). Our study area comprised the Tsavo East national park north, Tsavo East national park south, and Tsavo West national parks, with the remainder covered by private ranches (Figure 1.2). The climate of the area is semi-arid, with the long rainy season occurring between March and May, and the short rainy season in November and December. Mean annual rainfall varies locally between 250 and $500 \mathrm{~mm}$ (Maingi et al., 2012). Vegetation in the Tsavo ecosystem is dominated by Commiphora savanna (Maingi et al., 2012). 


\subsubsection{Elephant Data}

The poaching and population data on elephants used for this study were obtained from the Kenya Wildlife Service (KWS). The poaching data were collected from aerial patrols and daily ground patrols carried out by KWS through monitoring illegal killing of elephants (MIKE) program. Regular patrols and extensive coverage of monitored sites is essential to collect comprehensive data for the MIKE program. Rangers are expected to complete patrol forms and carcass forms, and to use GPS units to record locations. The dataset listed 151 poaching locations in the study area between June 2002 and August 2012. The data included geographic coordinates, names of the locations where elephant carcasses were found, and the estimated date of death. Elephant population data were collected by aerial surveys carried out in the Tsavo ecosystem from 7-12 February 2011 (Ngene, 2013). We assumed that the spatial population at risk data from 2011 can be used for all years, since there were no significant changes in elephant population and distribution from 2002 till 2012 (Ngene, 2013). The data included the date, geographic coordinates and names of the locations where elephants were seen.

\subsubsection{Block Design}

In order to compare the results of the different cluster analysis methods on the same basis, the study area was divided into 37 blocks, which were initially designed for the aerial counting comparison of the elephant population in the Tsavo-Mkomazi ecosystem. The blocks were described by Ngene (2013). They were defined mostly by easily detectable features such as hills, road, rivers, and protected area boundaries. The average block size was $1,098 \mathrm{~km}^{2}$ (Ngene, 2013). Block numbers 33-35 were excluded because they are located in Tanzania and no poaching data was available. We used the 34 blocks in Tsavo ecosystem to compare our findings (Figure 2.1).

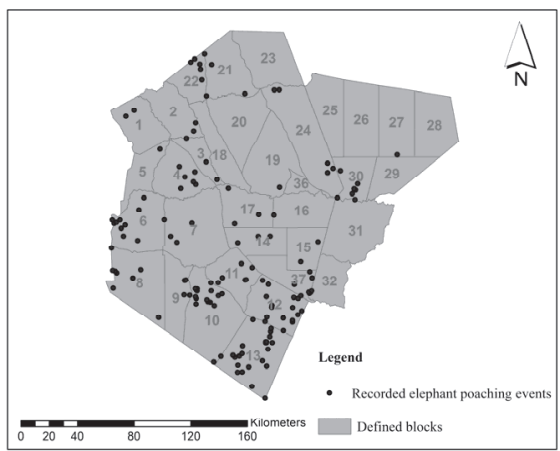

Figure 0.1 Distribution of recorded elephant poaching incidents between 2002 and 2012 within the defined blocks in the Greater Tsavo ecosystem. 


\subsubsection{Spatial Clustering Methods}

\subsubsection{Kulldorff's Spatial Scan Statistic}

The spatial scan statistic was originally proposed by Kulldorff to examine occurrences of breast cancer (Kulldorff, 1997; Tango and Takahashi, 2005). It has been broadly applied in spatial cluster analysis (Wu et al., 2011). Kulldorff's spatial scan method imposes a circular scan window of a given radius centered on a target location centroid(Hanson and Wieczorek, 2002). The radius increases in size to an upper limit specified by the user(Xu, 2008). For each circle, a likelihood ratio statistic is computed based on the number of observed and expected cases within the window compared with outside the window (Hanson and Wieczorek, 2002, Torabi and Rosychuk, 2011). The window with the highest value for the likelihood ratio and the greatest relative risk (RR) is identified as the most probable cluster. Kulldorff's spatial scan method utilizes the maximum likelihood ratio as the test statistic to overcome the problem of multiple testing(Mennis and Guo, 2009). RR represents how much more common high incidence rates are in this particular cluster compared to the average outside this cluster. Thus, Kulldorff's spatial scan method reports the most likely cluster with a set of secondary clusters(Mennis and Guo, 2009). It initially calculates the likelihood ratio for each window and finds the maximum(Mennis and Guo, 2009).

To determine the statistically significant level, a large number of random replications of the dataset are generated under the null hypothesis using a Monte Carlo simulation and the test statistic value is calculated for each replication (Mennis and Guo, 2009, Xu, 2008). At that point, the true test statistic value is compared to the test values for all replications to detect the significant level for the most likely cluster and the secondary clusters (Mennis and Guo, 2009). In this study, we used spatial cluster analysis for higher incidence in the SaTScan software (version 9) (Kulldorff, 2011), in which the block centroids were included in the radius of the circle since aggregate data were used in this research. The maximum spatial cluster size was set to a circle with a 70-km radius, because an analysis of poaching locations using ArcGIS's incremental spatial autocorrelation tool demonstrated that maximum clustering occurred at a distance of $70 \mathrm{~km}$.

\subsubsection{Flexible Spatial Scan Statistic}

The flexible spatial scan statistic was developed by Tango and Takahashi (2005) and it permits irregularly shaped clusters to be identified (Quick and Law, 2013, Torabi and Rosychuk, 2011). The flexible spatial scan statistic is similar to Kulldorff's spatial scan statistic, but it is able to detect clusters with any shape, although the detected cluster is limited to a relatively small neighborhood in each region (Torabi and Rosychuk, 2011). The flexible scan statistic imposes an irregularly shaped window on each region by connecting 
its adjacent regions and Monte Carlo hypothesis testing is used to find the distribution of the test statistic under the null hypothesis of spatial randomness (Tango and Takahashi, 2005). In this study, we used the flexible spatial scan statistic implemented with a restricted likelihood ratio in order to considerably reduce the computational time required (Tango and Takahashi, 2012). This method scans only the regions with an elevated risk. The method was implemented with the FleXScan software and the maximum spatial cluster size was set to a default setting of 15 blocks(Takahashi et al., 2005). Similar to the circular spatial scan statistic, the window with the highest likelihood ratio values and the greatest relative risk are identified as potential clusters.

\subsubsection{Spatiotemporal Clustering Methods}

\subsubsection{Spatiotemporal Scan Statistic}

The spatial scan statistic can be extended to the spatiotemporal scan statistic by considering both spatial and temporal aspects of the recorded elephant poaching incidents. This is done by modifying the scanning window so that, instead of circles across space, cylinders are tested. The base of the cylinder represents the space and the height represents time (Kulldorff, 2011). Since we had elephant poaching data for a ten-year period, a retrospective spacetime cluster analysis of incidents was selected using SaTScan software (version 9). Cases files, population files, and coordinate files (i.e. the centroids of the blocks) were generated for analysis(Wang et al., 2013). Spatiotemporal clusters were identified by fitting a discrete Poisson model and using a maximum cluster size of $50 \%$ of the study period in the temporal window and a circle of 70-km radius spatially (see 2.4.1). The primary cluster and secondary clusters were detected through the log likelihood ratio (LLR) test. The greatest relative risk was calculated as the estimated risk within the cluster divided by the estimated risk outside the cluster (Kulldorff, 2011). We tested the null-hypothesis that there is no cluster of occurrence inside the window against the alternative hypothesis that there is an elevated risk inside the window in comparison with outside $(\mathrm{Xu}, 2008)$. The $p$-values for identified clusters were computed by utilizing Monte Carlo simulations to create various random replications of the dataset under the proper null hypothesis (Liu et al., 2013). To ensure sufficient statistical power, and taking computation times in to account, we created 999 random simulations to obtain $p$-values (Liu et al., 2013). The null hypothesis of a spatiotemporally random distribution was rejected if the $p$-values was $<0.05$ (Wang et al., 2013).

\subsubsection{Spatiotemporal Permutation Scan Statistic}

The spatiotemporal permutation scan statistic uses a cylindrical window while scanning. A circular or ellipsoid radius of the cylinder indicates the number of incidents covered by the cluster, and the height of the cylinder corresponds to the time covered. The spatiotemporal permutation scan statistic requires 
only case data (with information about the location and date) and does not need population-at-risk data (Kulldorff et al., 2005). The expected number of elephant poaching incidents was calculated by assuming complete spatial randomness, which is the same if the observed events with a persistent average were roughly independent Poisson random parameters ( $\mathrm{Si}$ et al., 2009). A likelihood ratio, based on this approximation, was estimated to determine whether the cylinder contained a cluster or not. One cylinder with the maximum likelihood ratio test statistic is then considered to be the key candidate for the most likely cluster (Kulldorff et al., 2005). The statistical significance of detected clusters was evaluated using a Monte Carlo simulation (Dwass, 1957). The rank of the maximum likelihoods from the real dataset were compared to those of the random datasets to compute the $p$ values (Dwass, 1957, Kulldorff, 2006). The space-time permutation scan statistic was used to detect clusters mathematically. The center of the window was positioned at the centroid of each block (the latitude/longitude information of geometric center was obtained using ArcGIS geocoding function), and the radius of the circular window varied continuously from zero to a maximum radius of $70 \mathrm{~km}$ (see 2.4.1). For each spatial base, the height of the cylinder was modified from the shortest time aggregation length of 1 month to a maximum of $50 \%$ of the whole study period. The number of Monte Carlo replications was set at 999 and the statistical significance at 0.05 .

\subsubsection{The Prediction Accuracy Index}

The Prediction Accuracy Index (PAI) was used to measure the predictive accuracy of the spatial clustering methods(Chainey et al., 2008). This index provides a single measure of how reliable such a method is for predicting where hotspots may occur. A higher value of PAI reflects a greater accuracy. The index is calculated by:

PAI $=\frac{\left(\frac{n}{N}\right) \times 100}{\left(\frac{n}{A}\right) \times 100}$

where $n$ is the number of poached elephants in areas where poaching is predicted to occur (hotspots), $N$ is the total number of elephants poached in the study area in the 10-year study period, $a$ is the area where poaching is predicted to occur (e.g. area of hotspots in $\mathrm{km}^{2}$ ) and $A$ is the whole study area in $\mathrm{km}^{2}$. A higher PAI value indicates higher prediction accuracy.

Since the PAI is suitable for spatial clustering methods but does not consider the temporal aspects of incidents, in this study, we modified the PAI (MPAI) by adding a time factor to evaluate the spatiotemporal methods. Equation 2 shows how this new index was calculated. 
MPAI $=\frac{\left(\frac{n t}{N T}\right) \times 100}{\left(\frac{q}{A}\right) \times 100}$

where $n_{t}$ is the number of elephants poached in areas where poaching is predicted to occur (hotspots) and in the time range (t) of occurrence, $N_{T}$ is the number of elephants poached in the whole study area during the total study period, $a$ is the area where poaching is predicted to occur (e.g. area of hotspots in $\mathrm{km}^{2}$ ) and $A$ is the whole study area in $\mathrm{km}^{2}$.

\subsection{Results}

Kulldorff's spatial scan statistic detected two significant clusters $(p<0.05)$ $(P<0.05)$ ranging in size from $1-7$ blocks (Figure 2.2). The most likely cluster consisted of seven blocks, defined by the highest relative risk $(R R=21.75)$ and log likelihood ratio $(L L R=146.89)$. The secondary clusters included one block, with a smaller RR (11.85) and LLR (9.23) compared with the most likely clusters (Figure 2.2).

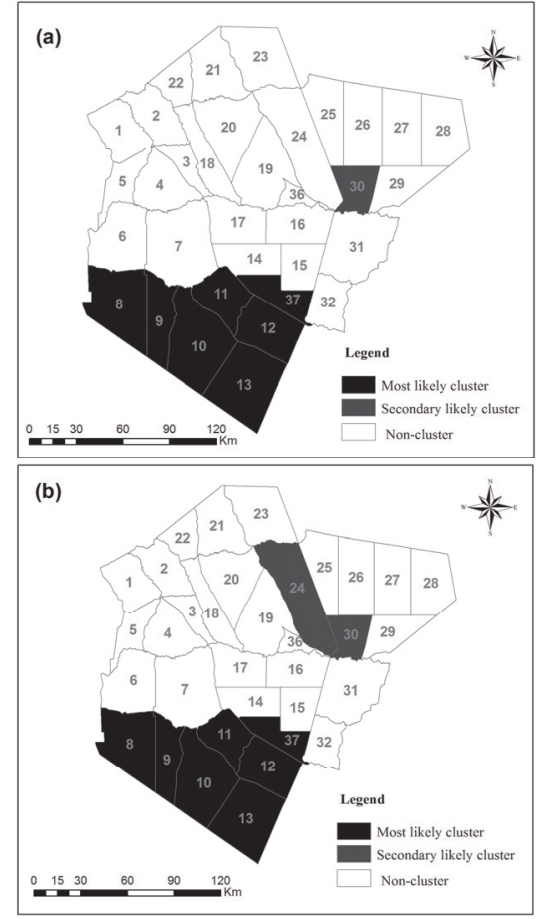

Figure 0.2 The most likely clusters identified by the two spatial clustering methods:(a) Kulldorff's spatial scan statistic, and (b) the flexible spatial scan statistic with a restricted likelihood ratio.

The flexible spatial scan statistic with a restricted likelihood ratio resulted in two significant clusters $(p<0.05)$ (Figure 2.2$)$. The most likely cluster consisted of seven blocks with the greatest RR (10.01) and LLR (146.89). The secondary clusters consisted of two blocks with smaller RR (5.76) and LLR (11.44) compared to the most likely cluster. 
The results for the spatiotemporal scan statistic cluster are shown in Figure 2.3. The spatiotemporal cluster analysis of cases of elephant poaching in 2002-2012 in the Tsavo ecosystem showed that elephant poaching was not distributed randomly in space and time. Using the maximum spatial cluster size of a circle with $70-\mathrm{km}$ radius, and the maximum temporal cluster size of $50 \%$ of the study period, one most likely cluster and two secondary clusters were identified (Figure 2.3). The most likely cluster consisted of seven blocks with the greatest RR (77.10) and LLR (235.33). It was detected for the period December 2009 to August 2012. The two secondary clusters also consisted of seven blocks; the RR of these clusters (69.62 and 32.51 respectively) within a non-random distribution pattern was also significant $(p<0.05)$ (Figure 2.3).

The retrospective spatiotemporal permutation scan analysis of elephant poaching data during 2002-2012 detected two significant clusters $(p<0.05)$ (Figure 2.3). The most likely cluster consisted of seven blocks with the greatest likelihood ratio test statistic $(L L R=8.46)$. It was detected between August 2002 and August 2006. The secondary clusters consisted of three blocks with a smaller test statistic compared to the most likely cluster (LLR= 6.61).
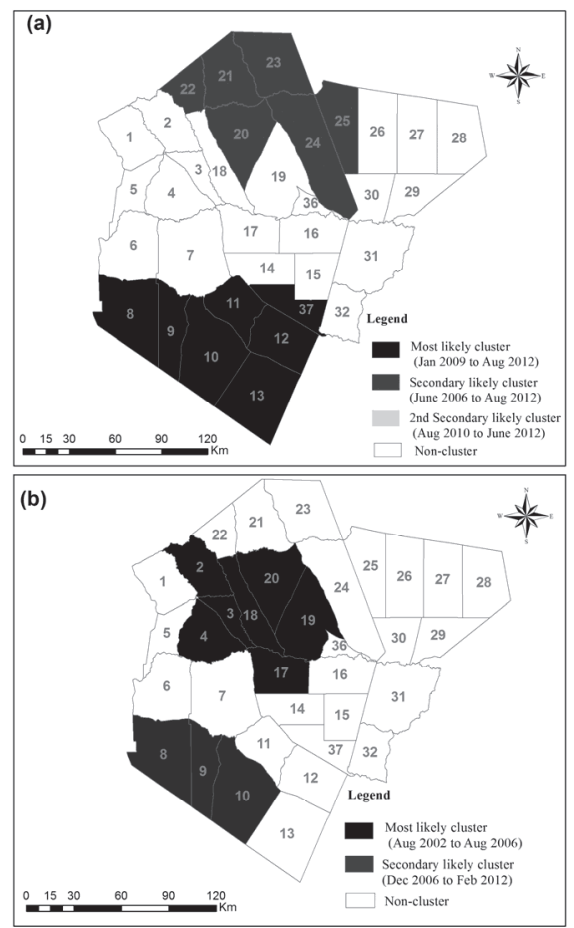

Figure $\mathbf{0 . 3}$ The most likely clusters identified by two spatiotemporal cluster methods, using monthly spatiotemporal data from 2000 to 2012. (a) Spatiotemporal scanstatistic and spatiotemporal permutation scan statistic. 
As can been seen from Figure 2.4 a, eight blocks were detected as having high poaching, irrespective of the spatial clustering method used. When the spatiotemporal analyses were included (Figure 2.4 b), four blocks were detected as having high poaching, irrespective of the method used. Three of these blocks overlapped in space and time $(8,9$, and 10), but one overlapped in space, but not time (block 20). Figure 2.4 shows the locations of these consistent blocks.
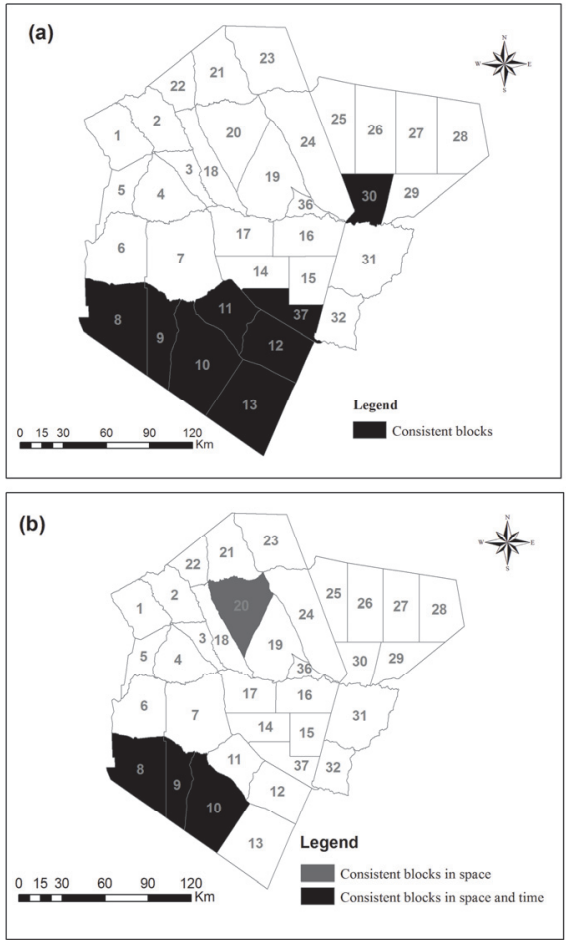

Figure 0.4 Consistent blocks of elephant poaching in the Tsavo ecosystem, Kenya. They were derived from (a) spatial clustering methods, and (b) spatiotemporal clustering methods.

The PAI results for the two spatial clustering methods indicated that the cluster analysis methods vary in their ability to predict patterns of poaching events. Our results showed that Kulldorff's spatial scan statistic had a slightly higher PAI value than the flexible scan statistic (2.39 vs 2.12 ).

An evaluation of the modified PAI results for the two spatiotemporal clustering methods showed that the spatiotemporal scan statistic predicts when and where hotspots occur with greater accuracy than the spatiotemporal permutation scan statistic (1.46 vs 0.97$)$. 


\subsection{Discussion}

A number of consistent elephant poaching hotspots in the Tsavo ecosystem emerged from the different cluster detection methods. Among the 34 blocks in the study area, three blocks were selected consistently, irrespective of the clustering method used, indicating a consistently high risk of poaching in these areas (Figure 2.5). The consistently detected hotspots are located in Taita ranches and Tsavo West National Park and most were located along the border of Tanzania.

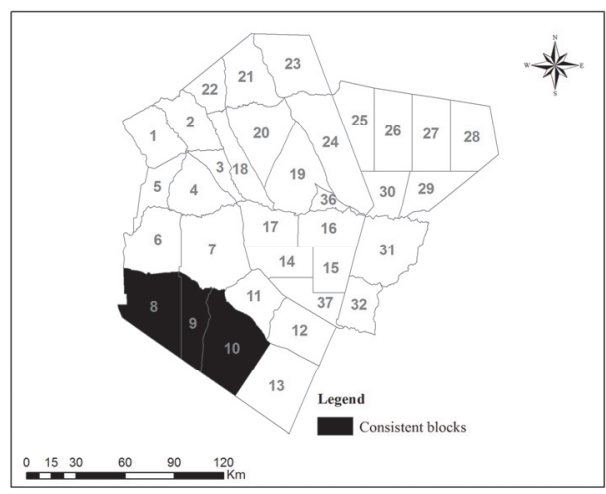

Figure 0.5 Consistent blocks of elephant poaching in the Tsavo ecosystem, Kenya. They were derived from (a) spatial clustering methods, and (b) spatiotemporal clustering methods.

Our results indicated that similarities occurred between clusters detected by different cluster detection methods, but also differences emerged. This is partly due to variations in the sizes of search window and because the input data used are different. Our (Kulldorff's spatial scan statistic method) results identified a smaller number of combined blocks as a potential cluster compared to flexible scan statistic method. This may be due to the noncircular shape of the regions in the Tsavo ecosystem (Torabi and Rosychuk, 2011). Despite the small deviation, the results of the spatial scan statistics and flexible spatial scan statistics were largely consistent (Figure 2.4 a). This suggests that both spatial methods could be used interchangeably for application in the field of the poaching.

The PAI was used to assess the predictive accuracy of the spatial clustering methods. The results using PAI indicated that Kulldorff's spatial scan statistic had a slightly higher PAI value than the flexible scan statistic (2.39 vs 2.12 ). This finding implies that the shape of the search window has a small effect on the prediction accuracy. Based on the PAI value, Kulldorff's spatial scan statistics showed reasonably good prediction accuracy in detecting circular clusters. The flexible scan statistic also showed a reasonably good PAI value plus the ability to detect non-circular clusters (Figure 2.2). 
Clusters that emerged from the spatiotemporal clustering methods demonstrated an interesting phenomenon. For instance the most likely cluster in the spatiotemporal permutation scan statistic was selected as the area of the secondary cluster by the spatiotemporal scan statistic (Figure 2.3). This different result may be partly explained by the influence of the input data, which are different for both methods. The spatiotemporal permutation scan statistic requires only case data, with information about the location and time for each case, but it does not need population-at-risk data, whereas the spatiotemporal scan statistics does require population-at-risk data. When comparing the two spatiotemporal methods, a few consistent poaching clusters were detected (Figure 2.4b), which indicates the importance of considering the assumptions made in the scan statistic models in relation to the data being used(Alton et al., 2013). For example, when using the spatio-temporal scan statistics, the expected number of cases in each area is proportional to the population of the cases in that area, whereas for the spatiotemporal permutation scan statistic, the expected values are calculated only on the basis of cases. The permutation scan statistic is advantageous if population data are missing, but it may not be appropriate for analyzing poaching activities due to their covert nature and the fact that some cases of elephant poaching may not be reported (Burn et al., 2011).

By modifying the prediction accuracy index (MPAI), we demonstrated that it is possible to evaluate the predictive accuracy of spatiotemporal clustering methods over time. Our results indicate that the spatiotemporal scan statistic had a higher MPAI value when detecting cluster areas than the spatiotemporal permutation scan statistic (1.46 vs 0.97$)$. This lower accuracy may be explained by the spatiotemporal permutation scan statistic being independent of the population-at-risk and a cluster being detected if an area has a higher proportion of cases during a specific time period compared to the remaining geographical areas(Alzahrani et al., 2013).

\subsection{Conclusions}

Clustering methods are useful for understanding the pattern of criminal activities; in this paper we compared four clustering methods for the purpose of examining one such activity, i.e. elephant poaching, using 10 years of patrol data. Elephant poaching clusters in the Tsavo ecosystem from two spatial methods (flexible scan statistic and Kulldorff's scan statistics) almost coincided and had a similar predictive accuracy. The two spatiotemporal methods showed larger differences; the spatiotemporal scan statistic outperformed the spatiotemporal permutation scan statistic in accurately predicting elephant poaching hotspots in the Tsavo ecosystem, based on a modified Predication Accuracy Index (MPAI). This difference can largely be explained by the fact that the permutation scan statistic does not use population-at-risk input data, which we had available in the form of an aerial 
elephant survey. Our results and methodological comparison may assist the Kenya Wildlife Service in allocating financial and human resources effectively to tackle (elephant and other species) poaching. 


\section{Chapter 3}

\section{Elephant Poaching Risk Assessed Using Spatial and Non-Spatial Bayesian Models ${ }^{2}$}

2 This chapter is based on: Rashidi, P., Wang, T.J., Skidmore, A.K., Mehdipoor. H.,
Darvishzadeh, R., Ngene, S.M., Vrieling, A., Toxopeus, A.G. (2016) Elephant Poaching
Risk Assessed Using Spatial and Non-Spatial Bayesian Models. Ecological Modelling, 338, 60-68. 


\section{Abstract}

Bayesian statistical methods are being used increasingly in crime research because they overcome data quality problems that arise due to the covert nature of crime, but the use of such methods is still in its infancy in the field of wildlife poaching - a specific form of crime. We analyzed poaching risk for African elephant (Loxodonta africana) by comparing spatial and non-spatial Bayesian models. Reports on elephant poaching in the Tsavo ecosystem were obtained for 2002-2012 from the Kenya Wildlife Service. The ecosystem was divided into 34 spatial units for which poaching data were aggregated and served as the base units for analysis. Spatial and non-spatial Bayesian models were fed with expert knowledge obtained through survey responses from 30 experts. The predictive accuracy of both models was assessed using the Deviance Information Criterion (DIC). Our results indicated that spatial Bayesian modelling improved the model fit for mapping elephant poaching risk compared to using non-spatial Bayesian models (DIC value of 193.05 vs 199.03). The results further showed that the seasonal timing of elephant poaching (i.e., in dry and wet seasons), density of waterholes, livestock density and elephant population density were factors significantly influencing the spatial patterns of elephant poaching risk in the Tsavo ecosystem for both models. Although there were similarities in the high risk areas for elephant poaching recognized in both models, risk probability values per spatial unit could differ. Furthermore, spatial Bayesian modelling also identified areas of high poaching risk that were not predicted by the nonspatial model. These findings provide vital information for identifying priority areas for combating elephant poaching and for informing conservation management decisions. The model we present here can be applied to poaching data for other threatened species. 


\subsection{Introduction}

Widespread illegal hunting and the bush meat trade occur more frequently and with greater impact on wildlife populations in the Southern and Eastern savannas of Africa than previously thought (Lindsey et al., 2012). For example, in 2011 alone, about 40,000 elephants were poached for their ivory in Africa - equivalent to a species loss of about 3\% (Wittemyer et al., 2014). A better understanding of where and when poaching is likely to occur would enable more effective law enforcement and possibly decrease the decline of wildlife due to poaching (Critchlow et al., 2015). Given the covert nature of poaching (Burn et al., 2011) that makes it difficult to record detailed spatial and temporal information on all poaching events, methods are needed that can deal with data scarcity (Gelman and Price, 1999). Not accounting for such scarcity can lead to unstable estimations of poaching patterns (Bernardinelli et al., 1995, Congdon, 2000).

With the ability to incorporate expert knowledge to help inform estimates for poorly sampled areas, Bayesian methods are becoming an increasingly common tool for ecological and disease mapping (Gelman and Price, 1999). In Bayesian statistical methods, crime data is regarded as a fixed quantity, whereas model parameters are considered to be random quantities when the measurement uncertainty is determined. Bayes' theorem combines information contained in the data (recorded crime) with prior knowledge to obtain posterior probabilities of crime risk, including risks for those areas that have a crime incidence count of zero (Law and Chan, 2012). The advent of recently developed Bayesian statistical approaches enables associations between crime occurrence and potential risk factors to be analyzed (Law and Chan, 2012, Law and Haining, 2004, Law et al., 2006, Law and Quick, 2013). Although in some situations non-spatial regression models can be carefully implemented to examine such associations (MacNab, 2004), these methods are limited in their ability to handle spatial data in which unmeasured confounders and spatial autocorrelation are evident (Einhorn et al., 1977, MacNab, 2004).

Crime research is increasingly using spatial methods because geocoded crime data and crime-related spatial data are becoming more available, and spatial methods for analyzing crime data at the local level are being developed (Law and Chan, 2012). Spatial analysis at the local level typically takes the form of exploratory spatial analysis such as cluster detection (e.g., hot spot identification) (Rashidi et al., 2015), or confirmatory spatial regression (e.g., risk factor identification) (Law and Quick, 2013).

The spatial association between crime occurrence and potential risk factors has traditionally been modeled using a frequentist (classical) statistical approach in the form of logistic regression (Haines et al., 2012, Nielsen et al., 2004). However, such an approach does not satisfactorily account for local 
risk factors (i.e., existing in one unit but not in neighboring ones) that remain unknown and are not captured in the model (Law and Chan, 2012). As a result, spatial autocorrelation remains a problem in traditional approaches even if the covariates are adjusted for it (Law and Chan, 2012). Moreover, developing accurate models requires large datasets; this can be a problem in crime research where observational data are scarce, costly to obtain, or subject to design and quality concerns.

Bayesian statistics have been used to fit spatial models in several crime studies (Law and Chan, 2012, Law and Haining, 2004, Law et al., 2006, Law and Quick, 2013, Haining and Law, 2007, Porter and Brown, 2007). However, to our knowledge, few studies have utilized spatial Bayesian methods to explore relationships between wildlife poaching (a specific form of crime) and potential risk factors. One example is Burn et al. (2011), who studied global trends and factors associated with the illegal killing of elephants in Africa and Asia between 2002 and 2009. They used a Bayesian hierarchical modelling approach to estimate the trend and the effects of site- and country-level factors associated with the poaching. At a country level, key determinants for elephant poaching were poor governance and low levels of human development; whereas at a site level they were low human population density and forest cover. Although Burn et al. [12] explored spatial Bayesian modelling in their analysis, they did not incorporate any informative prior knowledge (expert knowledge) in the model.

Expert knowledge can provide information about model parameters and help characterize uncertainty in models, and it can be useful when data are limited or are not available (Kuhnert, 2011). For example, Murray et al. (2009) used expert judgments to fill information gaps related with species occupancy in unreachable sites. Expert knowledge has also been used to assess the impacts of grazing levels on bird density in woodland habitats (Martin et al., 2005). Furthermore, expert knowledge was used to create Bayesian networks for criminal profiling from limited data (Baumgartner et al., 2008).

Bayesian methods can incorporate expert knowledge through priors (prior knowledge), using probability distributions representing what is known about the effect of the factor on what is being modeled (Gelman et al., 2014, Kuhnert et al., 2010, Stigler, 1986). The priors reflect the knowledge available on model parameters before observing the current data (Schoot et al., 2014, Stigler, 1986). Non-informative priors can be specified if one does not want to impose any prior knowledge on a model. The use of noninformative priors is referred to as objective Bayesian statistics since only the data determine the posterior results (Clarke, 1996, Press, 2009, Schoot et al., 2014). In contrast, informative priors convey information on prior preference for certain parameter values. Methods using informative priors are referred to as subjective Bayesian statistics (Akaike, 1977, Clarke, 1996, De Finetti et al., 1990, Press, 2009, Schoot et al., 2014). Subjective priors are 
beneficial because findings from previous research and expert knowledge can be incorporated into the analyses (Akaike, 1977, Clarke, 1996, Press, 2009, Schoot et al., 2014). For example, after several studies on the relationship between elephant poaching and risk factors, we may be able to provide a fairly accurate prior distribution of the parameters that measure this relationship. Prior information can also be obtained from expert knowledge gained from extensive experience. Different points of view might represent different priors for parameters, however, it has been shown that Bayesian expert systems are robust with respect to the absolute difference in priors (McCarthy, 2007). For example, Crome et al. (1996) used Bayesian methods to study effects of logging on mammals and birds. They were mainly interested in investigating real differences of opinion, which were elicited from experts. Differences of opinion were represented in the different priors for the impact of logging on mammals and birds. They revealed that these differences of opinion could reach consensus for various species (McCarthy, 2007).

In a previous study, we analyzed elephant poaching hotspots from poaching incidence data using clustering techniques (Rashidi et al., 2015). However, we did not incorporate any knowledge about risk factors nor did we account for the possibility of missing poaching data in the records. In the present study, we propose to use expert knowledge as prior information on risk factors.

A key feature of the spatial Bayesian modelling approach is the specification of the spatial random effect term to the Bayesian non-spatial model; this term can account for unidentified or unexplained sources of spatial autocorrelation. The spatial random effect term includes a spatially unstructured random variable and a spatially structured variable. Spatially unstructured random variables ignore the geographical location of the analysis units, whereas spatially structured random variables assume that geographically proximate spatial units tend to have similar risks (Law and Chan, 2012). Another advantage of the Bayesian spatial model is its capability to account for missing data, where, due to data limitations, the analyst is concerned about the effects of important covariates that are missing (Law and Haining, 2004, Law and Quick, 2013).

Our study aimed to address four questions: (1) Is the Bayesian spatial model more effective for mapping elephant poaching risk than the non-spatial model? (2) What are the key factors influencing elephant poaching risk as determined by Bayesian spatial and non-spatial models? (3) Where are the high risk areas for elephant poaching in the Tsavo ecosystem based on both models? (4) Where are areas of high risk unexplained by the covariates? 


\subsection{Materials and Methods}

\subsubsection{Study Area}

The Tsavo ecosystem consists of an area of about $38,128 \mathrm{~km}^{2}$ in south-east Kenya (Figure 1.2). It lies between $2-4^{\circ} \mathrm{S}$, and $37.5-39.5^{\circ} \mathrm{E}$. The Tsavo ecosystem has the highest population of elephants in Kenya, and also the highest number of reported elephant poaching incidents (Rashidi et al., 2015, Maingi et al., 2012). The anti-poaching activities in the Tsavo ecosystem face challenges of insufficient human and financial resources, and the extensive area to be covered (Rashidi et al., 2015, Maingi et al., 2012). Several rivers cross the ecosystem, including the Tsavo, Tiva, Galana, Athirivers, and Voi (Maingi et al., 2012). The study area includes the Tsavo West National Park, Tsavo East National Park North (north of Galana River) and, Tsavo East National Park South (south of Galana River), with the remainder of the area covered by private ranches (Figure 1.2). Vegetation in the Tsavo ecosystem is dominated by Commiphora shrub savannas (Cobb, 1976) and the climate is semi-arid with a mean annual rainfall varying between 250 and $500 \mathrm{~mm}$, characterized by large spatial and interannual variability. The short rainy season occurs between November and December, when rainfall is concentrated most in the northern and eastern parts, and a long rainy season occurs between March and May (the highest rainfall is between Taita Hills and the Kilimanjaro area) (Leuthold and Leuthold, 1978, Tyrrell and Coe, 1974).

\subsubsection{Block Design}

To study the probability of elephant poaching between neighboring areas, the study area was divided into 37 blocks, which were initially designed for the aerial counting of the elephant population in the Tsavo-Mkomazi ecosystem (Ngene et al., 2013). They were defined mostly by easily detectable features such as rivers, hills, roads, and protected area boundaries. The average block size was $1,098 \mathrm{~km}^{2}$. The smallest block measured $248 \mathrm{~km}^{2}$ and the largest block was 2,008 km² (Ngene et al., 2013). Block numbers 33-35 were excluded because they are located in Tanzania (Rashidi et al., 2015). We used the 34 blocks in the Tsavo ecosystem to differentiate area-level risk probabilities (Figure 2.1).

\subsubsection{Data}

\subsubsection{Elephant Population and Poaching Incidence Data}

The Kenya Wildlife Service (KWS) provided the population and poaching data on elephants for this study. Elephant population data were collected by aerial surveys carried out in the Tsavo ecosystem from 7-12 February 2011 (Ngene et al., 2013). Since there were no significant changes in elephant population and distribution from 2002 till 2012 (Ngene et al., 2013), we assumed that 
the spatial distribution of the elephant population in 2011 could be used for all years. The dataset included the geographic coordinates and names of the locations where elephants were seen, the number of elephants observed at that location, and the dates of observation (Ngene et al., 2013). The poaching incidence data were collected from aerial patrols and daily ground patrols carried out by KWS through the Monitoring the Illegal Killing of Elephants (MIKE) program. Regular patrols and extensive coverage of monitored sites is essential to collect comprehensive data for the MIKE program. Rangers used their bush and tracking skills as well as contacts in the local communities to recognize poachers and poacher trails, as well as visual observations in the field (e.g. presence of vultures) to identify carcass locations. Rangers are expected to complete patrol forms and carcass forms, and to use global positioning system (GPS) units to record locations (CITES, 2010). The dataset listed 151 poaching locations in the study area between June 2002 and August 2012 and included the estimated date of death, geographic coordinates, and names of the locations where elephant carcasses were found.

\subsubsection{Risk Factors}

We selected potential risk factors for poaching based on discussions with experts and previous research (Kyale et al., 2011b, Maingi et al., 2012). These factors included: (1) distance to roads, (2) distance to settlements, (3) distance to rivers and streams, (4) density of waterholes, (5) elevation, (6) slope, (7) mean normalized difference vegetation index (NDVI), (8) standard deviation of NDVI, (9) elephant population density, (10) livestock density, (11) distance to international border, and (12) seasonal timing of elephant poaching (i.e., poaching probabilities in the dry and wet seasons). 'Distance to roads' may be important because this would provide easy access and escape opportunities for the poachers (Haines et al., 2012). We modeled 'distance to settlements' as a potential risk factor because the distance-decay concept implies that poaching will tend to cluster where opportunities and motivated offenders are plentiful (Maingi et al., 2012). 'Distance to rivers and streams' may be a potential risk factor because these linear landscape features are places where elephants aggregate, thus hunting pressure may be higher near rivers and streams. Likewise, we can expect poaching to be related to the 'density of waterholes', because these are areas with many elephants. 'Elevation' may add to the risk because of the abundance of browse species favored by elephants at different elevations. 'Slope' could pose a risk because rough terrain can provide cover for poachers. We modeled the mean NDVI and standard deviation of NDVI as potential risk factors because vegetation condition could provide cover for poaching activities. 'Elephant population density' was included as a potential risk factor because we would expect poaching to be concentrated where elephants are most plentiful (Maingi et al., 2012). 'Livestock density' is an important risk 
factor because it can provide cover for poachers in the form of ranchers and ranches. 'Distance to international border' could be a risk factor because it may allow for easy transportation of the ivory directly to the ivory traders. Finally, we focused on the 'seasonal timing of elephant poaching', which might influence the extent of poaching because in different seasons poaching is likely to occur at different locations due to elephants' requirements such as food, water, or even land cover.

ArcGIS' Spatial Analyst was used to generate the nearest distance $(m)$ from the center of each block to roads, settlements, rivers and streams, and to the border with Tanzania (ESRI, 2011). Elevation and slope of the study area were extracted from a 90-m digital elevation model (DEM) derived from the Shuttle Radar Topographic Mission (SRTM). Time series of the NDVI from SPOT-VEGETATION were obtained through the Flemish Institute for Technological Research as 10-day composites. Mean NDVI corresponds to the NDVI average obtained from a time series of 10-day NDVI composites from November 2002 to November 2012 and was used to summarize annual NDVI values for the period studied. We calculated their average over the 10 years. Standard deviation of NDVI corresponds to the mean annual standard deviation of NDVI, obtained from a time series of 10-day NDVI composites from November 2002 to November 2012. The annual standard deviation provides a measure of the within-year NDVI variation as it is affected by seasonality. The mean and standard deviation of NDVI are a proxy for vegetation condition in the Tsavo ecosystem for the period 2002-2012. Based on an aerial count, data on livestock density were compiled by the World Resources Institute and the International Livestock Research Institute. For each block, we calculated mean values for elevation, slope, mean NDVI, standard deviation of NDVI, and livestock density (Table 3.1). Seasonal timing of elephant poaching (i.e., dry and wet seasons) was used to take seasonality into account. To quantify the seasonal timing of elephant poaching, of the 151 events recorded between June 2002 and August 2012, we first indicated how many were recorded during the dry season (January, February, June, July, August, September, October) and the wet season (March, April, May, November and December) in each block. Then, the probabilities of elephant poaching were calculated for the dry and wet seasons in each block. The dates of poaching events were obtained from the estimated date of death recorded with each observation. 
Table 0-1 The potential risk factors and their associated mean and standard deviation.

\begin{tabular}{lll}
\hline Risk factors & Mean & SD \\
\hline Distance to roads (m) & 6791 & 6044 \\
Density of waterholes ( number per km²) & 0.042 & 0.056 \\
Distance to rivers and streams (m) & 7742 & 6960 \\
Distance to settlements (m) & 19,870 & 12,400 \\
Elevation (m) & 489 & 256 \\
Slope (degrees) & 0.988 & 0.884 \\
Mean NDVI (no dimension) & 0.348 & 0.072 \\
Standard deviation of NDVI & 0.012 & 0.021 \\
Elephant population density (number per km²) & 0.341 & 0.316 \\
Distance to international border (m) & 77,730 & 35,090 \\
Probability of elephant poaching in wet season (\%) & 0.150 & 0.229 \\
Probability of elephant poaching in dry season (\%) & 0.614 & 0.406 \\
Livestock density (number per square kilometer) & 31.590 & 37.804 \\
\hline
\end{tabular}

\subsubsection{Expert Rating of Poaching Risk Factors}

Thirty experts from the Kenya Wildlife Service were interviewed based on their knowledge about elephants, their habitat, and poaching. They were asked to score how they thought selected factors would contribute to elephant poaching in the Tsavo ecosystem (Table 3.2) in order to populate a Bayesian expert system with a priori probabilities (Skidmore, 1989). The terminology was explained to the rangers. The survey required the expert to give each factor a score between 0 and 1 , depending on how much they thought the factor contributed. There has been considerable debate in the statistical literature regarding elicitation methods and how they can be used to form prior distributions and inform analyses (Kuhnert et al., 2005, Martin et al., 2005). In our study, since there were no major differences in the expert ratings of poaching risk factors, the equal weighted linear opinion pool (i.e., group average) was used to determine the mean response elicited from the experts. This method is simple and delivers accurate judgments compared with more complex methods (Armstrong, 2001). By taking this opinion pool, we avoided difficulties concerned with rating the comparative 'accuracy' of each expert's opinion on the relationship between poaching and various factors (Einhorn et al., 1977, Martin et al., 2005). 
Table 0-2 Information elicited from 30 experts on the risk factor's impact on elephant poaching in the Tsavo ecosystem, showing the mean response from the experts and the corresponding precision (the inverse of variance).

\begin{tabular}{lll}
\hline Risk Factors & Mean Response & Precision \\
\hline Distance to roads & 0.56 & 12.17 \\
Density of waterholes & 0.73 & 18.55 \\
Distance to rivers and streams & 0.54 & 8.85 \\
Distance to settlements & 0.77 & 34.60 \\
Elevation & 0.32 & 16.90 \\
Slope & 0.30 & 17.88 \\
Mean NDVI & 0.97 & 0.65 \\
Standard deviation of NDVI & 0.97 & 0.65 \\
Elephant population density & 0.52 & 7.51 \\
Distance to international border & 0.65 & 9.68 \\
Probability of elephant poaching in wet season & 0.65 & 11.07 \\
Probability of elephant poaching in dry season & 0.65 & 11.07 \\
Livestock density & 0.74 & 17.79 \\
\hline
\end{tabular}

\subsubsection{Modelling Strategy and Analysis}

To analyze elephant poaching risks, we fitted Bayesian non-spatial and spatial models using the statistical software WinBUGS (McCarthy, 2007). WinBUGS is a Bayesian modelling tool which requires the specification of priors on the parameters; these priors were determined through expert knowledge. The prior information specified for each factor is a normal distribution with a mean representing the expert opinion the expert opinion for the model parameter and a precision which is based on the overall expert response for each factor (Kuhnert et al., 2010). Spatial interactions between neighboring areas can be defined using an Intrinsic Conditional AutoRegressive Gaussian distribution (ICAR) (Law et al., 2006). The ICAR distribution is a special case of the general conditional autoregressive (or CAR) distribution, which is used as a prior distribution for spatially structured random effects (Law and Haining, 2004). Under the ICAR specification, the mean of spatial structure for one block depends on the spatial structure of its neighboring blocks (Law et al., 2014). The prior information specified for the spatially unstructured random effect is a normal distribution. Both the precision parameters of spatially unstructured random effect and spatially structured random effect follow a gamma distribution $(a, b)$, where $a$ and $b$ are equal to 0.5 and 0.0005 , respectively. This gamma distribution is a prior that would provide a reasonable range for relative risks (Elliot et al., 2000). A sensitivity analysis was performed using a different gamma distribution of parameters 0.001 and 0.001 for testing the sensitivity of results to the choice of prior distributions. 
WinBUGS uses Markov chain Monte Carlo (MCMC) algorithms to estimate parameters (McCarthy, 2007). This software takes samples from the posterior distribution by using MCMC methods, a series of random numbers in which the value of each is conditional on the previous number (Kéry, 2010), and finally converging to the required posterior (Law et al., 2006). The idea of this iterative procedure is that with sufficiently many simulated observations, it is feasible to acquire an accurate picture of the distribution (Kim, 2011).

\subsubsection{Non-Spatial Bayesian Modelling}

The first method of analysis in this study is a non-spatial Bayesian model. The Tsavo ecosystem was divided into 34 blocks labeled $i=1, \ldots, n$, where $n$ $=34$, the total numbers of areas. $C_{i}$ represents mutually independent and Poisson-distributed poaching counts. We assumed that $C_{i} \sim P\left(\lambda_{i}\right)$, where the parameter $\lambda_{i}$ of the Poisson distribution $(P)$ is the expected value of $C_{i}$, exp $\left[C_{i}\right]$.

$\operatorname{Exp}\left(C_{i}\right)=\lambda_{i}=E_{i} r_{i}$

where $E_{i}$ and $r$ are the area-specific expected count and unknown risk, respectively, of elephant poaching events.

We log-transformed Eq. (1) as follows:

$$
\begin{aligned}
\log \left[\lambda_{i}\right] & =\log \left[E_{i}\right]+\log \left[r_{i}\right] \\
& =\log \left[E_{i}\right]+B O+B_{1} X_{1 i}+B_{2 X 2 i}+\ldots . .+B_{k} X_{k i}
\end{aligned}
$$

Equation (3) is a Poisson regression model, where $\log \left[E_{i}\right]$ is an offset term with a regression coefficient of one, $X_{1, i}, X_{2, i}, \ldots$, and $X_{K, i}$ are observations defined for the explanatory variables of $X_{1}, X_{2}, \ldots$, and $X_{K}$ for block $i, K$ is the total number of explanatory variables, and $\beta$ represents covariate coefficients (Law and Quick, 2013, Law and Chan, 2012). This model, however, has problems estimating the area-specific elephant poaching risk $\left(r_{i}\right)$ and testing for the significance of explanatory variables. The maximum likelihood of $r_{i}$ (which is calculated by $C_{i} / E_{i}$ ) cannot be calculated if data for $C_{i}$ are missing or equal to zero. Furthermore, the Poisson model assumption presented in Eq. (4) is not valid when over-dispersion is present (Thogmartin et al., 2004). Over-dispersion occurs when some areas have large counts and other areas have small or no counts (Law and Quick, 2013, Law and Chan, 2012). Accounting for over-dispersion is necessary because its effect on a nonspatial model (see Eq. (3)) is that standard errors of parameter estimates will be underestimated, thus inducing type one errors in the hypothesis testing (Law et al., 2006).

$\operatorname{Exp}\left[C_{i}\right]=\operatorname{var}\left[C_{i}\right]=\lambda_{i}$ 
Likewise, this relationship may display spatial autocorrelation, representing observations that are not independent, which then need to be accounted for in the spatial structure of the non-spatial model (Law and Quick, 2013).

\subsubsection{Spatial Modelling}

Two Gaussian random effects terms, $U_{i}$ (spatially unstructured) and $S_{i}$ (spatially structured), were added to the non-spatial model Eq. (3) to form the spatial model Eq. (5). These terms accommodate any over-dispersion that may be unaccounted for in the non-spatial model Eq. (3) (Maingi et al., 2012, Law and Quick, 2013). Priors for $U_{i}$ and $S_{i}$ were determined by an independent normal distribution and the ICAR distribution (Besag et al., 1991), respectively.

$\log \left[\lambda_{i}\right]=\log \left[E_{i}\right]+B_{0}+B_{1} X_{1 i}+B_{2} X_{2 i}+\ldots . .+B_{k x} k_{i}+U_{i}+S_{i}$

The models represented by Eqs. (3) and (5) were fitted to the data using an MCMC simulation approach in the WinBUGS software. For each model, MCMC chains comprising 100,000 iterations with a burn-in of 1,000 were found to be sufficient to achieve convergence. The Brook-Gelman-Rubin Diagnostic and Monte Carlo standard error ( $<5 \%$ of the sample posterior standard deviation) helped to ensure sufficient burn-in and iterations. Fitting of this model has been reported in detail in the literature (Haining et al., 2009, Law et al., 2006). Based on Eq. (5), the Bayesian spatial random effect model, the relative risk function, $r_{i}$, can be written as

$r_{i}=\left[\exp B_{0}\right] \exp \left[B_{1} X_{1 i}\right] \exp \left[B_{2} X_{2 i}\right] \ldots . . \exp \left[B_{k x} k_{i}\right] \exp \left[U_{i}\right] \exp \left[S_{i}\right]$

The DIC was used to evaluate model fit and measure the relative performance of models (McCarthy, 2007). The DIC is a Bayesian equivalent of the Akaike Information Criterion (AIC). The DIC compares model fit without predetermining the number of model parameters, whereas AIC is a penalized likelihood ratio model-choice criterion, where the penalty is the number of parameters in the model (Law and Chan, 2012, Law and Quick, 2013). Smaller values for the DIC indicate a better model fit; the difference should be at least 5 for concluding the model fit is better because Monte Carlo sampling errors inherent in the calculation of DIC need to be accounted for (Law et al., 2014). The DIC is defined by Eq. (7), where $D^{-}$is the deviance when using the mean of the posterior distributions for the parameters, $P D$ is the number of effective parameters in the model, $\theta^{-}$is the posterior mean of the parameters, and $D\left(\theta^{-}\right)$is the deviance of the posterior means. It is obtained by using the posterior means of the relevant parameters (Law and Quick, 2013, Spiegelhalter et al., 2002).

$\mathrm{DIC}=D^{-}+p_{D}=D\left(\theta^{-}\right)+2 P D$ 


\subsubsection{Analysis of Risk Factors}

The most significant explanatory factors related to elephant poaching were identified using the Bayesian spatial and non-spatial models (see Eqs. (3) and (5)). First, a set of explanatory variables used to fit Eq. (3) was identified from Table 3.1 after accounting for the effects of multicollinearity. Equation (3) was then fitted with the set of 'non-highly correlated' explanatory variables identified, and those variables that were found significant were used to fit Eq. (5). Explanatory variables that remained significant from the fitting of Eq. (5) were identified as significant risk factors (Law and Quick, 2013).

In the presence of potential multicollinearity between the selected explanatory variables of Table 3.1, the estimated regression coefficients would tend to have larger sampling variability (Law and Chan, 2012, Law and Quick, 2013). The problem of multicollinearity in the statistical inference of a multiple regression equation can be tackled by calculating a variance inflation factor (VIF) for a set of variables and excluding the highly correlated variables from the set through a stepwise procedure (Dormann et al., 2013, Naimi, 2013). VIFCOR was used to exclude highly collinear variables in Table 3.1 through a stepwise procedure. VIFCOR is a method based on the calculated VIF statistics. VIFCOR works by looking for the pair of variables that has the maximum linear correlation, and removes the variable which has the larger VIF, replicating the procedure until there is no variable pair with a high coefficient of correlation (Naimi, 2013). Here, we first selected variable pairs that had a linear correlation coefficient greater than a threshold of 0.5 . For the variable pair with the highest correlation, one of the variables was excluded, i.e. the one with the highest VIF. The procedure was repeated until no variable pair with a correlation coefficient above 0.5 remained (Naimi, 2013). The variables left were then used to fit Eqs. (3) and (5) separately. By comparing the DIC values (the smaller the DIC, the better the model fit) from these two equations, we identified which model performed better. If any of the explanatory variables were deemed insignificant by our modelling framework, the improved model was re-fitted using only those explanatory variables that were significant to form the final model (Law and Quick, 2013).

\subsection{Results}

Among the selected variables (Table 3.1), distance to road, waterhole density, elephant population density, distance to rivers and streams, seasonal timing of elephant poaching (i.e., probabilities in dry and wet seasons), distance to international border, standard deviation (STD) of NDVI, and livestock density remained after accounting for multicollinearity (Table A.1 ). The non-spatial analysis (Eq. (3) revealed that distance to road, distance to rivers and streams, standard deviation of NDVI, and distance to international border were insignificant at the $95 \%$ credible interval among 
those variables that remained after accounting for multicollinearity (Table 3.1). Therefore we ignored them in further analysis. The inclusion of zero values within the $95 \%$ Bayesian credible intervals implies the insignificance of the estimates (Jianmei, 2014).

Table 0-3 Posterior summaries for $B$ coefficients of the explanatory variables in Bayesian non-spatial and spatial models.

\begin{tabular}{lll}
\hline Explanatory variables & $\begin{array}{l}\text { Non-spatial model } \\
\text { mean } B \quad(\text { credible } \\
\text { interval: } 2.5 \%, 97.5 \%)\end{array}$ & $\begin{array}{l}\text { Spatial model } \\
\text { mean } \\
\text { interval: 2.5\%, 97.5\%) }\end{array}$ \\
\hline $\begin{array}{l}\text { Probability of elephant } \\
\text { poaching in wet season }\end{array}$ & $1.05(0.78,1.36)$ & $0.83(0.42,1.22)$ \\
$\begin{array}{l}\text { Probability of elephant } \\
\text { poaching in dry season } \\
\text { Livestock density }\end{array}$ & $0.92(0.55,1.31)$ & $1.01(0.57,1.48)$ \\
Waterhole density & $0.20(0.02,0.37)$ & $0.56(0.22,0.94)$ \\
$\begin{array}{l}\text { Elephant population density } \\
\text { Distance to nearest road }\end{array}$ & $0.30(0.07,0.52)$ & $0.64(0.28,1.03)$ \\
$\begin{array}{l}\text { Distance to rivers and } \\
\text { streams }\end{array}$ & $0.10(-0.01,0.22)$ & NA \\
$\begin{array}{l}\text { Standard deviation (STD) of } \\
\text { NDVI }\end{array}$ & $0.08(-0.13,0.30)$ & NA \\
$\begin{array}{l}\text { Distance to international } \\
\text { border }\end{array}$ & $0.03(-0.27,0.21)$ & NA \\
DIC & 199.03 & 193.05 \\
\hline
\end{tabular}

NA not applicable, DIC Deviance Information Criterion.

We then ran Bayesian spatial analyses (Eq. (5)) with those variables that were found significant in the Bayesian non-spatial model (Table 3.3). The result obtained from Eq. (5) revealed that the seasonal timing of elephant poaching, density of waterhole, livestock density, and the elephant population density were significant factors that influence the spatial patterns of elephant poaching risk in the Tsavo ecosystem (Table 3.3). The Bayesian spatial model had a better model fit than the non-spatial model with a DIC of 193.055 versus 199.03 (Table 3.3).

Figure 3.1 presents the elephant poaching risk probabilities for each block using the non-spatial model (a) and the spatial model (b). The blocks with the highest poaching risk are those that have probabilities greater than 0.9 and the lowest risk blocks are those with probabilities $<0.1$. While similar spatial patterns of high poaching risk were found in both models, eight blocks displayed different probability classes (blocks 11, 12, 13, 17, 23, 24, 26, and 36). 

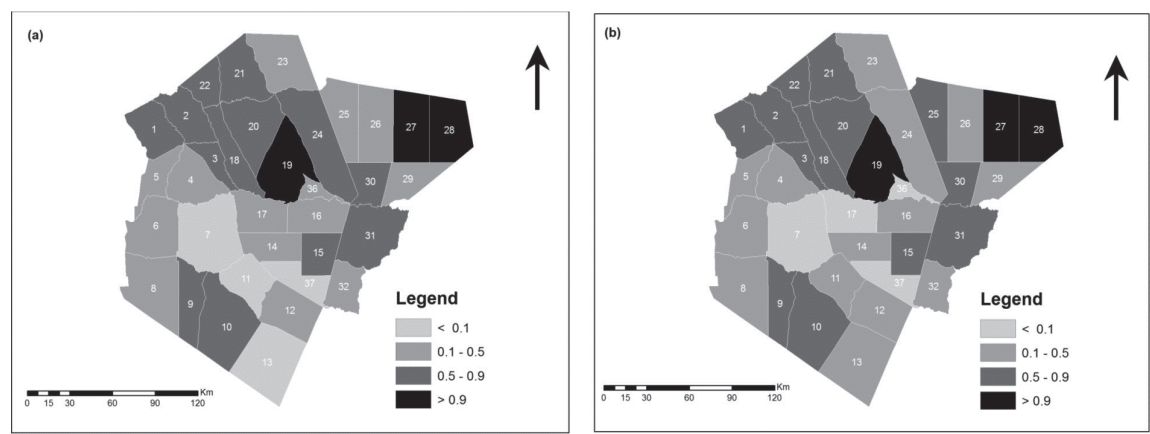

Figure 0.1 Tsavo ecosystem displaying the probability of elephant poaching risk for each block: (a) Bayesian non-spatial model and (b) Bayesian spatial model.

The map of spatially structured random effects displayed in Figure 3.2 indicates the locations of clusters for a high risk of elephant poaching that could not be explained by the factors in the model. When $\exp (S)$ (Eq. (6)) is $<0.5$, it represents a decrease in elephant poaching risk by the unexplained spatial structure in those areas. When $\exp (S)$ is $>0.5$, it represents an increase in risk by the unexplained spatial structure. These areas have a high risk of elephant poaching that is unexplained by the measured variables and their confounding effects.

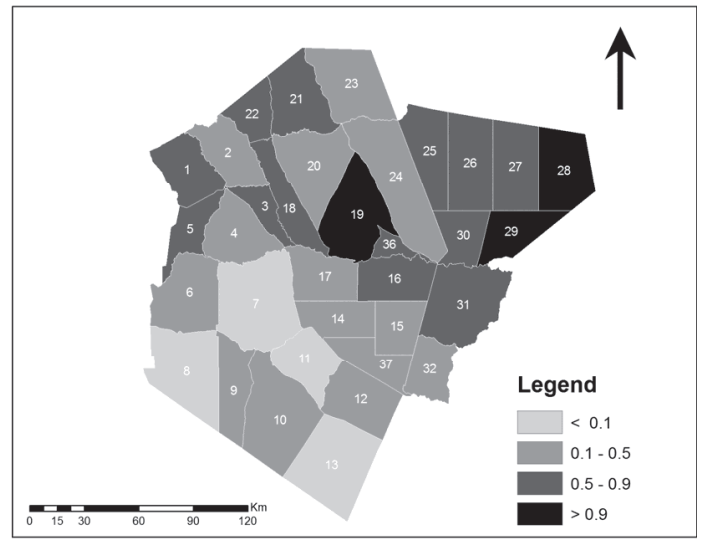

Figure 0.2 Areas of high elephant poaching risk that were unexplained by the measured risk factors, i.e., using the spatial model in which the spatial random variable is acting as a proxy of the unmeasured risk factors that were spatially structured.

\subsection{Discussion}

Under the common conditions where unmeasured confounders and spatial autocorrelation were evident, Bayesian spatial modelling gave a better model fit for analyzing elephant poaching data than Bayesian non-spatial modelling. One reason for this could be the inherent clustering of poaching activities in 
geographical spaces (Kyale et al., 2011b, Maingi et al., 2012, Rashidi et al., 2015). Poaching tends to be concentrated around some common areas which hold a good potential for poaching activities. Most of the poaching clusters are neighborhoods with similar environment characteristics. As a result, the risks of elephant poaching for areas with zero counts was estimated by borrowing information from areas through the spatial random effect term and with a neighboring structure defined in the Bayesian spatial model (Law and Chan, 2012, Law and Quick, 2013).

When there is spatial structure in the dependent variable (elephant poaching) that could not be described by the selected factors, the non-spatial model ignores the unexplained structure and overestimates the effects of the covariates. In contrast, in the spatial model, the spatial random variable acts as a surrogate of the missing covariates (unmeasured risk factors) that are spatially structured (Law and Chan, 2012, Law and Quick, 2013). As a result, compared with Bayesian non-spatial modelling, the spatial modelling demonstrated an improved model fit through a lower DIC and excluded four significant independent variables that had been identified in the non-spatial model (Table 3.3).

The results using Bayesian non-spatial modelling indicated that a seasonal timing of elephant poaching (i.e., in the dry and wet seasons), density of waterholes, livestock density, and the elephant population density were the key determinants of elephant poaching. Waterhole density may be explained by elephants' preference for water, i.e., where elephants aggregate makes them more vulnerable to poaching. The elephant population is a significant factor because this likely provides the poachers with the highest harvest related to their effort. This finding supports this idea that poaching risks are higher in areas with a high elephant population (Kyale et al., 2011b, Maingi et al., 2012). The influence of livestock on elephant poaching can be explained by the fact that poachers may use livestock as a cover for elephant poaching, either directly or with the assistance of livestock herders. The seasonal timing of elephant poaching was also determined to be a significant explanatory variable of elephant poaching. This partly explains why poaching is more likely to occur in different locations in the dry season than the wet season. The suitability of the natural environment for poaching varies in different locations for different seasons and can be linked to elephants' requirements such as food, water, or even land cover for hiding (Osborne, 2000).

The probability relative risk map allows high and low risk areas to be identified (Figure 3.1). This map provides information about the elephant poaching risks in each block and in its neighbors. The different results from the non-spatial and final spatial model can largely be explained by the covariates - the spatially structured or unstructured random effects terms. Areas with a relative risk of poaching $>0.50$ should be further investigated 
as elephant poaching hotspots. Methods for detecting elephant poaching hotspots have been described previously, specifically in Rashidi et al. (2015), who detected hotspots using exploratory spatial analysis. They identified hotspots using different spatial and spatiotemporal clustering models; however, the results from this current study not only cover all their detected hotspots, but could also be used to estimate the probability of an area being a hot or cold spot. Moreover, some new areas were detected as hot spots (Figure 3.1). One reason for these discrepancies could be because in cluster techniques, as described by Rashidi et al. (2015), the number of poaching incidents detects clusters using the maximum likelihood method. They identified areas of significant clusters, but the technique cannot map the probability of clustering across areas (e.g. in areas not classified as 'clustered').

The map of spatially structured random effects (Figure 3.2) reveals the locations of clusters of high risk for elephants that could not be explained by the covariates of factors in the model. This indicated that one or more risk factors (covariates) with spatial structure, which are typically unobserved variables, might be missing in the model (Law and Chan, 2012). These missing risk factors should have little or no connection with the associated factors used in our study (Law and Quick, 2013). Our analyses have not included these factors, which would need to be integrated in a different way. For example, a moonlight factor, which it is not possible to integrate in the model like other variables, or similarly, those variables that were excluded from our analysis under the terms of access to data. For instance, we excluded distance to park offices, park gates, patrol bases and outposts since we could not get data on these factors because of security issues. Moreover, our final model contains all of the factors that are significant after accounting for multicollinearity. One good reason for using the spatial model is that when risk factors that have spatial structure are missing or unidentifiable, the spatially structured random effects term acts as a surrogate for these covariates (Law et al., 2006). This reduces the effects of overestimating the significance of the risk factors in the model or of retaining risk factors in the model that are not actually significant.

\subsection{Conclusions}

This study compared a spatial and non-spatial Bayesian model to investigate elephant poaching risk in small areal units (blocks) in the Tsavo ecosystem, Kenya. The models were fitted using a Bayesian simulation approach, which provided a flexible framework for specifying expert knowledge and fitting complex spatial models that would have been difficult to fit with frequentist approaches. 
Our results indicated that the seasonal timing of elephant poaching (i.e., dry and wet seasons), density of waterholes, livestock density, and the elephant population density were significantly and consistently identified as key factors that influence the spatial patterns of elephant poaching risk in the Tsavo ecosystem, Kenya. A non-spatial Bayesian model initially ran with nine significant explanatory variables; however, when we added spatially structured and unstructured random effects terms to this equation, only five variables remained significant. As demonstrated by a smaller DIC value, the spatial Bayesian model fitted the data better than the non-spatial model.

Our results have several practical implications. The KWS can use them to allocate financial and human resources effectively to patrol against poaching activity more efficiently in areas with high risks. Furthermore, our results provide vital information for conservation decision-making and management so that more attention can be given to certain areas, for example those with a relative risk of elephant poaching $>0.5$. Our findings may be useful in identifying priority areas for elephant poaching prevention. In a wider sense, the model we present here can be applied to poaching data for other threatened species. 


\section{Chapter 4}

\section{Assessing Trends and Seasonal Changes in Elephant Poaching Risk at the Small Area Level Using Spatio-Temporal Bayesian Modelling}

\footnotetext{
3 This chapter is based on Rashidi, P., Skidmore, A., Wang, T., Darvishzadeh, R., Ngene, S., Vrieling, A., 2017. Assessing Trends and Seasonal Changes in Elephant Poaching Risk at the Small Area Level Using Spatio-Temporal Bayesian Modelling. International Journal of Geographical Information Science, 1-15.
} 


\section{Abstract}

Knowledge about trends and seasonal changes of wildlife poaching risk at fine spatial scale can provide essential background intelligence for law enforcement and prevention. We assessed interannual trends and seasonal changes in elephant poaching risk for Kenya's Greater Tsavo ecosystem for an eleven-year period, from 2002 to 2012, using spatio-temporal Bayesian modelling. Data on elephant poaching in the Tsavo ecosystem were obtained from the Kenya Wildlife Service's database on elephant mortality. The Greater Tsavo ecosystem was divided into 34 areas (blocks) for which poaching data were aggregated. We used the Markov chain Monte Carlo simulation approach to fit the spatio-temporal Bayesian models, and then assessed the predictive accuracy of the model fit using the Deviance Information Criterion (DIC). While these model types have been used in earlier poaching studies, the present paper is new because 1) we combine spatial with temporal analysis to investigate the interaction between space and time when defining highest risk poaching areas for elephant; 2) we evaluate if the inclusion of environmental risk factors into the spatio-temporal Bayesian model can improve the accuracy of poaching prediction; and 3) we separately model the dry and the wet seasons to understand seasondependent poaching patterns. Techniques developed here permit trends for different periods to be automatically generated for poaching across individual blocks. The results indicate that although Tsavo's overall poaching trend showed an increase over time, spatio-temporal trends of poaching risk were significantly different between areas of the Greater Tsavo ecosystem. In particular, three out of the 34 blocks had a very high risk of elephant poaching throughout the study period regardless of whether the models included environmental risk factors or not. The results further showed that livestock density, distance to roads and the international border, seasonal timing of elephant poaching, and the density of waterholes were useful predictors, which significantly influenced the spatial variation in trends regarding elephant poaching risk over time in Kenya's Greater Tsavo ecosystem. Adding these variables to the model enhanced the model's predictive power (DIC value of 14725 vs 14870). Furthermore, differences between the dry and the wet season in the highest poaching risk areas were highlighted. The findings improve our understanding of elephant poaching in the Greater Tsavo ecosystem and highlight specific areas where action to reduce elephant poaching is required. 


\subsection{Introduction}

In the past decade, there has been an increase in African elephant (Loxodonta africana) poaching, especially for ivory (Douglas-Hamilton, 2009, Nyirenda et al., 2015, Wittemyer et al., 2014). Estimates suggest that between 2011 and 2013, more than 100,000 African elephants were poached (Wasser et al., 2015, White, 2013), corresponding to $21 \%$ of the total population. Kenya, like many other African countries is suffering from a continuous year-to-year increase in the proportion of illegally killed elephants since 2003 (Douglas-Hamilton, 2009, Maingi et al., 2012).

Insufficient human and financial resources, combined with the large areal extent to be monitored, pose major challenges for anti-poaching activities in Kenya (Maingi et al., 2012, Rashidi et al., 2015). Because of high conservation costs, Kenya cannot offer adequate protection of wildlife from poaching within national parks and reserves (Maingi et al., 2012). The Kenya Wildlife Service (KWS) is understaffed with less than one ranger per $100 \mathrm{~km}^{2}$ of wildlife reserve (Maingi et al., 2012). Therefore, assessment of trends and seasonal changes in wildlife crime on a small spatial scale allows for targeting specific locations where crime may be concentrated and assists in the setting of conservation priorities and the concentration of management resources (Maingi et al., 2012).

Poaching is a dominant wildlife crime, but it is unevenly distributed over space and time (Burn et al., 2011). Poaching data have a covert nature, which makes it difficult to estimate poaching trends (Burn et al., 2011) in small spatial units. We therefore need models that can take scarcity of poaching data or incomplete data into account (Gelman and Price, 1999). Spatio-temporal Bayesian models are particularly useful when working with fine scale data (DiMaggio, 2015) as they can consider poaching risk in areas with zero counts by borrowing information from neighboring areas (Sun et al., 2000). This helps to overcome problems of unstable poaching estimates related to a lack of data (Gelman and Price, 1999) as a result of low incident counts in small areas and large variations in sampling (Bernardinelli et al., 1995, Congdon, 2000).

The assessment of trends in wildlife poaching using Bayesian models has been limited to large-scale studies at countrywide levels (Burn et al., 2011). Critchlow et al. (2015) used ranger-collected data from 1999 to 2012 to identify spatio-temporal trends in general illegal activities in a Ugandan national park. The illegal activities included infringing upon nature reserves for plant harvesting, cultivation, animal grazing or poaching. Although the above studies used Bayesian models to monitor the spatio-temporal variation in trends within a unified framework, they did not incorporate expert knowledge for the selection of ecological covariates or for prior probabilities. Prior probabilities are represented by probability distributions indicating 
known effects of the ecological covariates on illegal activities. Moreover, they also did not investigate seasonal changes in areas highly at risk of illegal activity. Rashidi et al. (2015) addressed the problem of limited data in small geographic units (blocks) using expert knowledge and Bayesian modelling, but focused on spatial variations. Here we incorporate a temporal element into the analysis. Space-time analyses have extra benefits to purely spatial analyses, since they permit the simultaneous study of mean trends and unusual local trends (Richardson et al., 2006). This is important because patterns of illegal activities can vary over time and space (Critchlow et al., 2015).

In this paper, we assess interannual trends and seasonal changes in elephant poaching risk for Kenya's Greater Tsavo ecosystem for an eleven-year period, from 2002 to 2012, using spatio-temporal Bayesian modelling. This study has three specific objectives, i.e. 1) to identify the presence of space-time interactions, by ascertaining if temporal trends in poaching risk differ between areas of the Greater Tsavo ecosystem; 2) to investigate if the accuracy of poaching prediction can be improved by adding environmental risk factors to the spatio-temporal Bayesian model; and 3) to assess whether locations of the highest elephant poaching risk differ between wet and dry seasons.

\subsection{Materials and Methods}

\subsubsection{Study Area}

The Greater Tsavo ecosystem covers $38,128 \mathrm{~km}^{2}$ in south-east Kenya (Figure 1.2). Our study area was composed of the Tsavo East National Parks North (north of the Galana River) and South (south of the Galana River), as well as the Tsavo West National Park, with the remaining areas being covered by private ranches (Figure 1.2). The rivers and streams of the Tsavo ecosystem include the Tsavo, Tiva, Galana, Athirivers, and Voi (Maingi et al., 2012). Commiphora savanna is the prevailing vegetation community in the study area (Cobb, 1976). The area's climate shows clear seasonality and also displays a large geographic variation. The long wet season takes place between March and May. Rainfall amount during the wet season is largest between the Taita Hills and the Kilimanjaro area. The short rainy season occurs in November and December, when rainfall is concentrated mostly in the eastern and northern parts of the area (Ngene et al., 2013, Smith and Kasiki, 2000). The Tsavo ecosystem is home to the largest population of Kenya's elephants, but also experiences the largest number of elephant poaching incidents in Kenya (Maingi et al., 2012, Rashidi et al., 2015). It is also one of four sites for "Monitoring of Illegal Killing of Elephants" (MIKE program) in Kenya (Shaffer and Bishop, 2016). 
To quantify local differences in elephant poaching trends, the Greater Tsavo ecosystem was subdivided into 37 blocks, which were initially designed for the aerial counting of the elephant population in the Tsavo-Mkomazi ecosystem (Ngene et al., 2013). Block boundaries were defined by the Kenya Wildlife Service (KWS) according to easily detectable features such as roads, hills, rivers, and protected area boundaries. Block sizes ranged from $248 \mathrm{~km}^{2}$ to $2,008 \mathrm{~km}^{2}$, with and average size of $1,098 \mathrm{~km}^{2}$ (Ngene et al., 2013). Block numbers 33-35 were omitted since they were located in Tanzania and poaching data there were not accessible (Rashidi et al., 2015). We used the 34 blocks in the Kenyan part of the ecosystem as the geographic units in our analysis. All data, for both the elephant population and elephant poaching incidents, were linked to these geographic units (Figure 2.1).

\subsubsection{Data}

\subsubsection{Elephant Population and Poaching Incidence Data}

Data on elephant populations and poaching were obtained from the KWS. Aerial surveys were undertaken by the KWS in the Tsavo ecosystem from 712 February 2011 to record elephant populations (Ngene et al., 2013). We assumed that the spatial distribution of the elephant population in 2011 could be used for all blocks and years because there were no significant changes in the population from 2002 till 2012 ( $N g e n e$ et al., 2013). The dataset comprised the number of elephants observed per location, the geographic coordinates and names of these locations, and the observation dates (Ngene et al., 2013). Aerial patrols and daily ground patrols were executed by the KWS through the MIKE program to record elephant poaching incidents. Consistent patrolling and a wide coverage of the monitored sites belong to the core methods employed by the MIKE program (Burn et al., 2011) Rangers used their bush and tracking skills, as well as contacts with the local communities, to recognize poachers and poacher trails (Rashidi et al. 2016). They also used visual cues in the field (e.g., the presence of vultures) to identify carcass locations (Rashidi et al. 2016) and global positioning system (GPS) units for recording locations (CITES, 2010). Patrol forms and carcass forms were completed by the rangers. The full dataset consisted of 151 poaching locations in the study area for the years 2002 to 2012. The data contained the estimated date of death, location names of where elephant carcasses were found, and coordinates of the locations where elephant carcasses were found. The Spatial Join geoprocessing tool in ArcMap 10 was used to link the data on the 151 poaching locations to the 34 blocks (Table $A 2, A 3$ and $A 4)$.

\subsubsection{Environmental Risk Factors}

The selection of environmental risk factors was based on previous studies (Kyale et al., 2011b, Maingi et al., 2012, Rashidi et al., 2016). We obtained spatial and spatio-temporal information on these risk factors as per Rashidi et 
al. (2016). The factors included: (1) elephant population density, (2) livestock density, (3) mean normalized difference vegetation index (NDVI), (4) standard deviation of NDVI, (5) elevation, (6) slope, (7) density of waterholes, (8) distance to rivers and streams, (9) distance to roads, (10) distance to international border, (11) distance to settlements, and (12) seasonal timing of elephant poaching (i.e., poaching probabilities in the dry and wet seasons).

We used the variance inflation factor (VIF) to evaluate and account for the effects of multicollinearity between variables (Dormann et al. 2013). This is a method based on the calculated VIF statistics, which iteratively selects variables based on the maximum linear correlation found between pairs of variables and excludes the variable that has the larger VIF. This procedure is repeated until there is no variable pair with a high coefficient of correlation left (Naimi, 2013). Here, we first selected variable pairs that had a linear correlation coefficient greater than the threshold set to 0.5 . For the variable pair with the highest correlation, one of the variables was excluded, i.e. the one with the highest VIF. The procedure was repeated until no variable pair with a correlation coefficient above 0.5 remained. Of the selected variables, elephant population density, livestock density, standard deviation (STD) of NDVI, distance to rivers and streams, waterhole density, distance to road, distance to international border, and seasonal timing of elephant poaching (i.e., probabilities in dry and wet seasons) remained after accounting for multicollinearity (Table A5).

\subsubsection{Modelling Strategy and Analysis}

We fitted two different sets of spatio-temporal Bayesian models (Table 4.1). The first set was used to assess local trends of elephant poaching from 2002 to 2012 in the Greater Tsavo ecosystem, and includes two models. Model 1.1 did not account for the potential risk factors that vary geographically across the blocks, while Model 1.2 added risk variables to the model to test whether the 'risk' covariates enhanced the prediction of poaching (Table 4.1). Expert knowledge, based on survey responses from 30 experts, was input to Model 1.2 (Rashidi et al., 2016). We used this expert knowledge for the selection of environmental risk factors and also incorporated expert knowledge through priors (prior knowledge), based on probability distributions representing what is known about the effect of the environmental risk factor on elephant poaching risk. The second spatio-temporal Bayesian model set was used to investigate seasonal changes in elephant poaching risk. The second set also includes two models, one fitted for the wet and one for the dry season (Table 4.1). Data were divided into seasonal categories (wet and dry) based on rainfall distribution in the study area. Model 2.1 was used to determine risk areas for elephant poaching during the wet season, and Model 2.2 was used to determine risk areas for elephant poaching in the dry season (Table 4.1). 
Table 0-1 Model structure for the two different model sets used in this chapter.

\begin{tabular}{|c|c|c|}
\hline Model & Types & Data \\
\hline \multicolumn{3}{|l|}{ Set1 } \\
\hline 1.1 & $\log \left(e_{i j}\right)+a+u_{i}+s_{i}+\left(y+\delta_{i}\right) t_{j}$ & $\begin{array}{l}\text { Data include wet and dry } \\
\text { season data }\end{array}$ \\
\hline 1.2 & $\begin{array}{l}\log \left(e_{i j}\right)+a+u_{i}+s_{i}+\left(y+\delta_{i}\right) t_{j+}+ \\
\beta_{1 X_{1 i}}+\ldots . .+\beta_{k x} k_{i}\end{array}$ & $\begin{array}{l}\text { Data include wet and dry } \\
\text { season data }\end{array}$ \\
\hline \multicolumn{3}{|l|}{ Set 2} \\
\hline 2.1 & $\log \left(e_{i j}\right)+a+u_{i}+s_{i}+\left(y+\delta_{i}\right) t_{j}$ & $\begin{array}{l}\text { Data include } \\
\text { season data }\end{array}$ \\
\hline 2.2 & $\log \left(e_{i j}\right)+a+u_{i}+s_{i}+\left(y+\delta_{i}\right) t_{j}$ & $\begin{array}{l}\text { Data include } \\
\text { season data }\end{array}$ \\
\hline
\end{tabular}

For all models, we used Poisson regression with the log link function, as this function accounts for rare incidences ( $\mathrm{Li}$ et al., 2014, McCullagh and Nelder, 1989, Torabi and Rosychuk, 2012). Bayesian approaches combine observed data (i.e., elephant poaching incidents) and prior knowledge (e.g., neighborhood structure, information from adjacent blocks or experts) to estimate posterior distributions of unknown parameters (e.g., local differential trends in elephant poaching) (Luan et al., 2015). The prior data reflect the knowledge available on model parameters before observing the current data (Schoot et al., 2014, Stigler, 1986). The prior distribution is used to model data dependence between neighboring areas (Law and Chan, 2012) since it contains information about how the poaching risks are related to one another.

The poaching cases $\left(Y_{i j}\right)$ for area $i=1, \ldots, \mathrm{I}$, and time period $j=1, \ldots, \mathrm{T}$ can be modeled as a

$Y_{i j} \sim$ Poison $\left(\right.$ lambda $\left._{i j}\right)$.

where the parameter lambdaij of the Poisson distribution $(\mathrm{P})$ is the expected value of $Y_{i j}$, $\exp \left[Y_{i j}\right]$.

$\exp \left[Y_{i j}\right]=l a m b d a_{i j}=\theta_{i j} * e_{i j}$

Using a log link function, unknown risk $\left(\theta_{i j}\right)$ is split into parameters measuring purely spatial variation, purely temporal variation, and spatiotemporal interaction:

$\log \left(\theta_{i j}\right)=a+u_{i}+s_{i}+\left(y+\delta_{i}\right) t_{j}$

$\log \left(\operatorname{lambda}{ }_{i j}\right)=\log \left(e_{i j}\right)+a+u_{i}+s_{i}+\left(y+\delta_{i}\right) t_{j}$

where $e_{i j}$ is the corresponding number of expected elephant poaching cases for area $i=1, \ldots, I$, and time period $j=1, \ldots, T$. The purely spatial variation is represented by an intercept $a$ (average elephant poaching for the study region), $u_{i}$ (unstructured random effects), and $s_{i}$ (spatially structured random effects). These terms accommodate any over-dispersion that may 
arise when modelling count data at the areal level (Luan et al., 2015). Regional temporal variation of elephant poaching for the study region is captured by $y$. We assumed a linear regional trend over all areas in the study region, which depends on the nature of the data set (the observed elephant poaching incidents data) (Torabi and Rosychuk, 2012). $\delta_{i}$ is the interaction between the spatial and temporal effects. To explore the geographic variation of the local trends, we mapped the posterior probability (PP) of a local differential trend $\left(\delta_{\mathrm{i}}\right)$ that was greater than the mean trend (Law et al., 2014, Law et al., 2015). PP can be viewed as the Bayesian equivalent of the p-value (Meng and Dempster, 1987). It represents the degree that each spatial unit is greater than the mean trend, which accounts for the variance of areaspecific trends. High $\mathrm{PP}_{\mathrm{i}}$ values indicate that area-specific trends have a high probability of differing from the mean trend, whereas low PPi values indicate that area-specific trends have a low probability of differing from the mean trend.

To capture the number of elephant poaching incidences expected, we used an indirect standardization method (utilizing the average trend and elephant population) (Law et al., 2015). Indirect standardization utilizes the risk estimates in the reference population (total population in the study region as a whole) to calculate the expected number of incidents in the study population (Yuan, 2013). The expected number of elephants poached was calculated for each block, season and year. For example, in 2011 block \#3 had an elephant population of 27 and 5 poaching incidents. Given that from 2002 to 2012 the overall increase in incidents in the study region was 246, and in 2011 the total elephant population in the study region was 1370, the expected number of incidents for block 3 in 2011 was $9.59(=5+(27 \times$ $246 / 1370)$ ), where $246 / 1370$ is the average trend of elephant poaching in the whole study region.

\subsubsection{Computational Details}

An improper uniform prior $U(-\infty,+\infty)$ was defined for the intercept $a$ (Luan et al., 2015). A normal distribution prior with mean 0 and variance $\sigma_{s}{ }^{2}$ was specified for $u_{i}$ (Law et al., 2015). The prior for the regional time trend $(y)$ was a vague prior normal distribution with mean equal to zero and variance of 1,000 (Law et al., 2014). An Intrinsic Conditional Autoregressive Gaussian distribution (ICAR) was used to specify priors for spatial random effect $s_{i}$ and spatio-temporal interaction $\delta_{i}$ (Law et al., 2014, Law et al., 2015, Li et al., 2014, Luan et al., 2015, Torabi and Rosychuk, 2012). Under the ICAR specification, the means of $s_{i}$ and $\delta_{i}$ for one block depend on the $s_{i}$ and $\delta_{i}$, respectively, of the neighboring blocks' distribution, where adjacency is defined as areas that have common borders (Luan et al., 2015, Torabi and Rosychuk, 2012). The amount of variation of $s_{i}$ and $\delta_{i}$ is controlled by hyperparameters $\sigma_{s}^{2}$ and $\sigma_{\delta}^{2}$, respectively, and is contrariwise related to the 
number of neighbors of the $i^{\text {th }}$ block (Law et al., 2014, Law et al., 2015, Li et al., 2014, Luan et al., 2015, Torabi and Rosychuk, 2012). In Bayesian approaches, priors assigned to hyperparameters (i.e. the parameters of priors) are called hyperpriors (Luan et al., 2015). We conducted analysis using a uniform hyperprior distribution of $(0.5,0.0005)$ for $\sigma_{u}, \sigma_{s}$ and $\sigma_{\delta}$. This gamma distribution is a prior that offers a reasonable range for relative risk (Elliot et al., 2000).

Spatio-temporal modelling was conducted using the statistical software WinBUGS, version 1.4.3 (McCarthy, 2007). Models were specified textually via the BUGS language in WinBUGS, in which the model likelihood and the prior distribution are defined (Figure B1) (McCarthy, 2007). WinBUGS uses 'Markov Chain Monte arlo' (MCMC) algorithms to estimate posterior distributions of the model parameters (McCarthy, 2007). MCMC methods create random samples from the posterior distribution: the value of each step is conditional on the previous step (Kéry, 2010), and after enough iterations, the algorithm converges to the required posterior value (Law et al., 2006). With a sufficient number of simulated observations, this iterative procedure leads to an accurate estimation of the distribution (Kim, 2011). To assess trends and seasonal changes in the elephant poaching risk in the Greater Tsavo ecosystem from 2002 till 2012, we fitted the spatio-temporal Bayesian models using WinBUGS software with two parallel chains thinned by 10 to reduce autocorrelation (Luan et al., 2015). For each model, to obtain 20,000 samples from the posterior distribution, MCMC chains comprising 10,000 iterations with a burn-in of 1,000 were found to be sufficient to achieve convergence. Convergence was assessed by Brook-Gelman-Rubin Diagnostic, history plots, visually examining trace plots, and Monte Carlo standard error ( $<5 \%$ of the sample posterior standard deviation) (Law et al., 2014, Luan et al., 2015).

To assess the model fit, we used the Deviance Information Criterion (DIC) (Spiegelhalter et al., 2002). The DIC can be considered as Bayesian equivalent of the Akaike Information Criterion (AIC), and it utilizes the number of effective parameters (defined as the posterior expectation of the deviance minus the deviance evaluated at the posterior mean of the parameter (King et al., 2009)) instead of the actual number of parameters used by the AIC (Ntzoufras, 2011). The advantage of DIC is that it can be directly computed from an MCMC output, and moreover it can be applied in a larger variety of models (Ntzoufras, 2011). Lower values for the DIC indicate that the model fit is closer to the data. A difference in DIC values between two models should be at least 5 to conclude that one of the models fits the data better, because of Monte Carlo sampling errors inherent in the calculation of the DIC (Law et al., 2014). 


\subsection{Results}

Figure 4.1 shows the probability that local elephant poaching trends were greater than the mean trend (Table 4.2) using two different models (Table 4.1). Variation in area-specific elephant poaching trends was statistically significant at the $95 \%$ credible interval (Table A5). Blocks with the highest probability were areas that have experienced relatively higher risks of elephant poaching over the 11 years and showed a steeper, increasing trend in poaching compared with the mean trend (Figure 4.1). In both models, the largest positive trends (probability that elephant poaching risk is above mean trend > 0.9) were located in specific blocks (blocks 9, 26 and 29) in the Tsavo West National Park, Tita ranch and Galana ranch (Figure 4.1).

Our results indicate that while similar blocks with the highest poaching trend were found by both models (Model 1.1 and Model 1.2), some blocks displayed different probability classes (blocks 1, 2, 5, 6, 10, 14, 17, 19, 20, $22,24,25,27$, and 31) (Figure 4.1). Moreover, Model 1.2, which accounts for potential risk factors, had a smaller value for the DIC (Table 4.2) which indicates a more accurate model fit for Model 1.2 than Model 1.1.
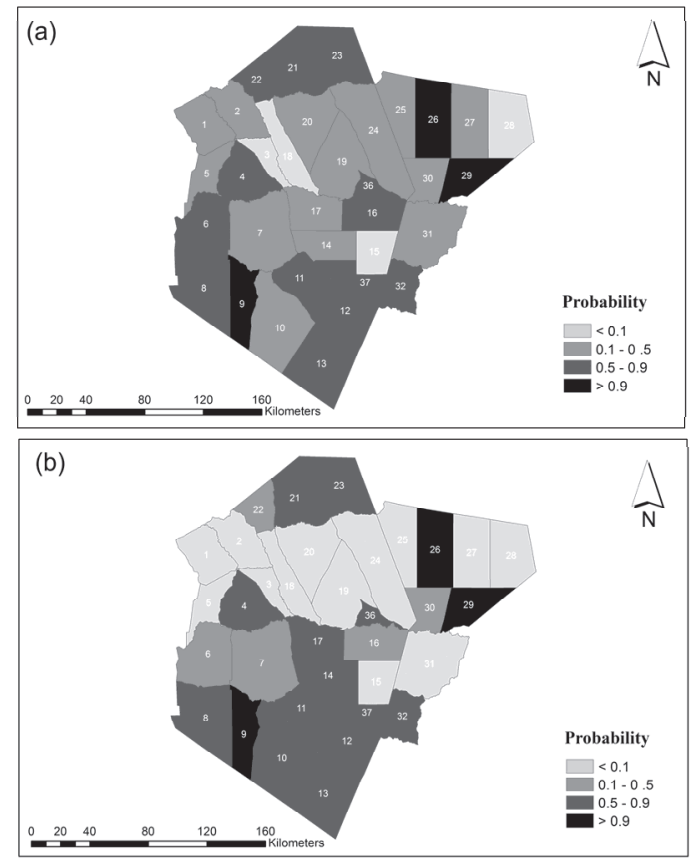

Figure 0.1 Probability that local elephant poaching risks were greater than the mean temporal trend: (a) Model 1.1: spatio-temporal Bayesian model without accounting for the potential risk factors and (b) Model 1.2: spatio-temporal Bayesian model which includes potential risk factors.

Based on our modelling results, we could map elephant poaching incidences (Figure 2.1) and estimate poaching trend over time (Figure 4.1). A large spatial variability can be observed both in observed poaching incidence and estimated risk. 
Table 0-2 The results of model fitting for Model 1.1 and 1.2.

Model 1.1

Model 1.2

$y$ : overall time trend (credible

interval: $2.5 \%, 97.5 \%$ )

DIC: deviance information criteria

$P_{D}$ : effective number of

parameters
$0.27(0.4,0.6)$

14870

$0.76(0.1,1)$

276
14725

250

Further, the results indicate that among the selected factors that remained after accounting for multicollinearity, livestock density, distance to road, seasonal timing of elephant poaching, density of waterholes, and distance to international border were significant at the 95\% credible interval (Table A5). Inclusion of zero values within the $95 \%$ Bayesian credible intervals implies the insignificance of the estimates (Jianmei, 2014). In other words, if the credible interval for estimated parameters covers zero, then that would be considered as lack of evidence for different variances (Kéry, 2010).

Figure 4.2 shows that the highest risk areas for elephant poaching differ between the wet and dry season.

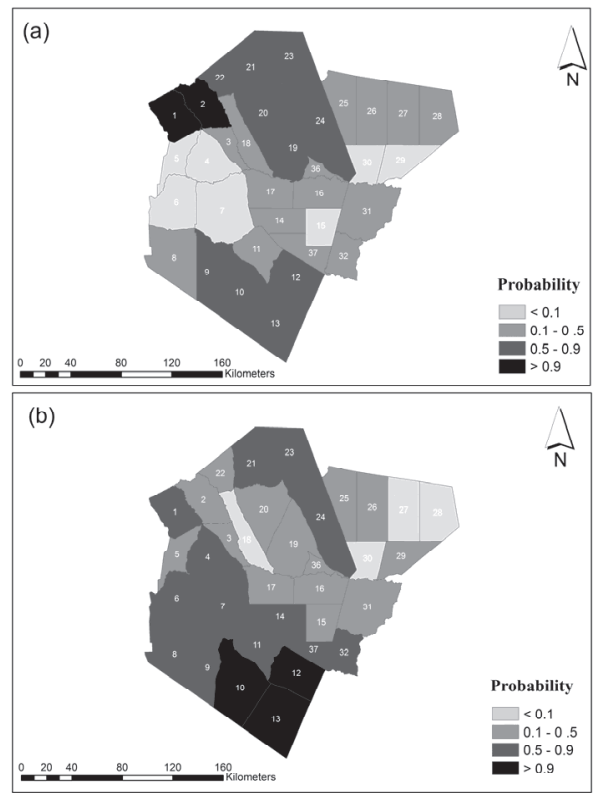

Figure 0.2 Seasonal changes in high risk areas for elephant poaching in Tsavo ecosystem (2002-2012) using the spatio-temporal Bayesian model: (a) Model 2.1: wet season and (b) Model 2.2: dry season.

\subsection{Discussion}


The ability to detect areas with increasing elephant poaching can aid decision making regarding conservation priorities, by prompting the need for further management attention, such as increased ranger/patrol activities in areas with higher poaching risk (Figure 4.1). For example, for the Tsavo, blocks \#26 and \#29 in the Galana ranch and \#9 in the in the Tsavo West National Park and Tita ranch should be prioritized for preventive actions.

These three blocks are all located in areas with human settlements in and around them. Therefore, the result can be partly explained by humanelephant conflict over resources (space, water, and forage) in these areas (Ngene, 2010). Another reason could be possible collaboration of local people with poachers or their indifference towards elephant poaching (Maingi et al., 2012). The findings thus indicate the need for strategies such as local community conservation programs (Maingi et al., 2012) to obtain community support. And priority should be given to security patrols in these areas to mitigate elephant poaching risks.

The highest risk areas for elephant poaching determined by this study differ from those identified in the previous study (Rashidi et al., 2016), which focused only on the spatial variation observed in elephant poaching in the Tsavo ecosystem without investigating the interaction between time and space. Spatio-temporal methods may therefore detect relatively subtle changes in elephant poaching risk in specific blocks over time that would not have been detected by spatial analyses alone (Critchlow et al., 2015). However, there were also blocks (blocks 6, 10, 16, and 21), which did display similar probability classes in both studies.

Furthermore, we found that block \#9 was consistently identified as a hot spot with a high poaching risk, as Rashidi et al. (2015) had also observed, when using spatial as well as spatiotemporal clustering methods (Figure 4.1). However, in the current study, some new areas showing a significantly increasing trend were detected (Figure 4.1) and we further demonstrated the probability that each block would show a differential trend from the mean elephant poaching trend in the Tsavo ecosystem (Figure 4.2). By explicitly stating the probability of observed poaching risk in a particular block, we detected high-risk areas where this risk is unlikely to be due to chance (DiMaggio, 2015). This allowed us to be more specific about high risk area locations rather than having to resort to reporting clusters of areas (as typically recognized by SaTScan). For example, Rashidi et al. (2015) found that blocks \#8, \#9 and \#10 were hotspots, irrespective of the clustering method used. However, they did not detect probabilities regarding elephant poaching risk for these areas. In the current study, we detected that the elephant poaching risk probability differed between these three blocks (Figure 4.1). 
The fact that some areas show significantly different trends in poaching could be due to potential risk factors that vary geographically across the blocks. Therefore, we set Model 1.2 to consider the effect of adding these variables to the Model 1.1 (Table 4.1) and to test whether the covariates enhanced the prediction of the model. We found that density of waterholes, livestock density, seasonal timing of elephant poaching, distance to roads and distance to international border significantly contributed to the estimation of temporal trends in elephant poaching in Kenya's Greater Tsavo ecosystem (Table A5). Rashidi et al. (2016) also found the first three risk factors to be covariates, while the latter two were new in the present study. The fact that some variables like elephant density and distance to rivers have been deemed important by experts but were not significant in our models could be due to theoretical knowledge rather than personal and local experience (Doswald et al., 2007). Such variables may be collinear with other covariates responsible for elephant poaching, and therefore make scoring difficult (Doswald et al., 2007). Although expert opinion is useful for collecting general knowledge on elephant poaching, combined expert and field data enhanced the posterior estimates and further improved elephant poaching models. Our results also indicated that selected variables were useful predictors, because Model 1.2 provided an improved model fit through a lower DIC. This result is in contrast with the results of Critchlow et al. (2015), who found that their selected ecological covariates were not useful predictors for incidences of illegal activities. One reason for this contrast could be the selection of potential risk factors in our study, which were based on expert knowledge. This supports the idea that combining expert opinion with empirical data improves model performance (Murray et al., 2009).

Furthermore, the results obtained from Model 2.1 and 2.2 demonstrated that the highest risk areas for elephant poaching differed between the wet and dry seasons. This finding supports the idea from the previous study (Rashidi et al., 2016) that elephant poaching is more likely to occur in different locations in the dry season than in the wet season. This could be explained by seasonal preferences for specific land cover by elephant (Shaffer and Bishop, 2016) as well as seasonal variations in surface water availability. It may be expected that elephants move to other areas where water and food supplies are plenty, but conservation security there might be lower (Sibanda et al., 2016).

A limitation when studying elephant poaching trends lies in the collection of poaching data, which may be underreported or misreported by rangers (Maingi et al., 2012). It is possible that the elephant poaching data that we used for this study only represent a proportion of the total poaching that occurred between 2002 and 2012. However, we mitigated this problem by utilizing a spatio-temporal Bayesian model, which provides a flexible framework for borrowing information over space and time from adjacent blocks by using spatial and temporal random effects (Li et al., 2014). For 
example, the recorded elephant poaching incidences (Figure 2.1) and estimated poaching trend over time (Figure 4.1 ) are very different in blocks \#26 and \#29 in the Galana ranch. Our study demonstrates that the spatiotemporal Bayesian model is a valuable approach when recorded elephant poaching incidents are scarce or incomplete, as it allowed the discerning of elephant poaching trends in some blocks that could not be ascertained from a visual analysis of the poaching data alone. With improvements to the observation effort and the recording of patrol data and associated contextual information, and with the development of appropriate models, predictions of poaching could be further improved (Keane et al., 2011).

A linear regional trend over an eleven-year period was assumed in this study, which is appropriate for the data on observed elephant poaching incidents. When using poaching data that cover multiple time periods rather than subsequent years, a non-linear trend analysis may further reduce error in the model, thereby providing additional insight into poaching change over time.

\subsection{Conclusions}

We examined spatial variation in trends and seasonal changes in elephant poaching risk from 2002 to 2012 in Kenya's Greater Tsavo ecosystem, using spatio-temporal Bayesian modelling. We also tested the hypothesis concerning whether risk factors enhanced the prediction of the model. This modelling framework has been shown to effectively account for inconsistent results due to limited and/or missing data. Our results indicate that the mean trend in elephant poaching is increasing in the Tsavo ecosystem over time. Assessment of spatio-temporal poaching trends in small areas showed that blocks with the strongest positive trends in elephant poaching are situated in the Tsavo West National Park, Tita ranch and Galana ranch. Our results also indicate that adding risk factors enhances model fit. Furthermore, our results indicate that areas with the highest poaching risk differ between dry and wet seasons.

Obtained results have several practical implications. The KWS can benefit from our results by allocating their financial and human resources more effectively to prevent or reduce poaching activity in areas with relatively strongly increasing poaching trends. Our results also provide vital information for decision-making and management regarding setting conservation priorities. Moreover, the models we present here may also be adjusted and applied to poaching data for other threatened species and in other areas. 
Chapter 5

\section{Areas at High Risk of Elephant Poaching Shift from the South-East to the West of Kenya During 2002-2012 ${ }^{4}$}

\footnotetext{
4 This chapter is based on: Rashidi, P., Wang, T.J., Skidmore, A.K., Darvishzadeh, R., Ngene, S.M (2018) Areas at High Risk of Elephant Poaching Shift from the South-East to the West of Kenya During 2002-2012. In review: AMBIO
} 


\section{Abstract}

Poaching is an increasingly rampant problem in Kenya as it is right across Africa. Poaching risk analysis may have a considerable mitigating effect on the illegal killing of wildlife. Using a Bayesian spatio-temporal model, we investigate how elephant poaching risk in Kenya might change at different locations, over time or through interaction between space and time, and we try to identify key factors influencing high-risk elephant poaching areas at a national level. Data on elephant population, poaching incidence, biophysical and anthropogenic factors for the period 2002 - 2012 were obtained from Kenya Wildlife Service. Kenya was divided into eight conservation regions, for which poaching data were aggregated and which served as the base units for analysis. Our results show that areas at risk of elephant poaching are temporally dynamic, shifting from areas with high recorded elephant poaching incidents to areas where minimal poaching incidents have been reported. We found that there is a shift in poaching from the south-east to the west of Kenya. We also found that the Mountain, Tsavo and Coast regions have been high-risk poaching areas in Kenya for over a decade. Our results also show that seasonal timing of elephant poaching, density of waterholes, and distance to an international border, a road, or a settlement were all consistently identified as key factors influencing the spatial and temporal variation regarding elephant poaching risk in Kenya. Although the Bayesian spatio-temporal model has been used in earlier poaching studies, the present paper is innovative, because high-risk areas for elephant poaching had not previously been investigated at a national level and there was a distinct lack of understanding of factors causing shifts in elephant poaching areas over time. The findings of our study provide new information for recognizing key factors causing elephant poaching, providing management with information to assist in the battle against poaching. 


\subsection{Introduction}

High-risk poaching areas threaten species survival by providing opportunities for poaching activity (Maingi et al., 2012, Rashidi et al., 2016). Given limited resources, many researchers advocate focusing conservation efforts on highrisk poaching areas (Rutledge et al., 2001). Identifying high-risk poaching areas as well as the factors that abet poaching plays an important role in reducing poaching.

Poaching has long been considered the main threat to keystone and umbrella species such as elephants, rhinos and tigers (Sharma et al., 2014). Elephants play a vital role in the ecosystems throughout Africa, and their persistence is also significant to the conservation of other elements of biodiversity (Omondi and Ngene, 2012a). Poaching and illegal ivory trafficking in recent years form the key factors driving the decline of African elephant populations (Burn et al., 2011). Around 22,000 elephants were illegally killed for their ivory in Africa in 2012 (Wittemyer et al., 2014). Most large deliveries of ivory are reaching the Asian markets through the eastern Africa sub-region. Since 2009, trade routes have switched from Central and West Africa to seaports in East Africa, with Kenya and Tanzania forming primary departure points for illegal ivory trade with shipments leaving the continent through Indian Ocean ports (Mombasa, Dar es Salaam and Zanzibar) (Kyando, 2014). As both significant source and departure point of ivory, Kenya and Tanzania are more involved in the ivory trade than any other country in Africa (Kyando, 2014), reflecting the shift in poaching patterns from West and Central Africa to Eastern and Southern Africa (Blanc et al., 2013, Kyando et al., 2017).

Despite the ecological significance of elephants, the effectiveness of antipoaching patrols is limited in most African countries due to inadequate resources as well as the large spatial extent of the areas to be monitored. This limits the effectiveness of patrols by rangers (Maingi et al., 2012). It is, therefore, all the more important that conservation managers receive timely information on spatial and temporal variations in high-risk poaching areas to be able to prioritize intelligence and enforcement efforts, ultimately to reduce poaching (Critchlow et al., 2015).

Obtaining an absolute measure of poaching levels based on direct observation is practically impossible due to the covert nature of poaching (Burn et al., 2011, Sharma et al., 2014). Detailed data are scarce and many poaching reports are collected incidentally, and may be indirectly obtained (Madhusudan and Karanth, 2002, Sánchez-Mercado et al., 2008). Such reports may be challenging to analyze because of the absence of a sampling design and uncertainty concerning locations (Reutter et al., 2003, SánchezMercado et al., 2008). It is therefore important to apply methods that can overcome the scarce data problem (Gelman and Price, 1999), which emerges when unstable estimations occur due to low counts of incidents and high 
sampling variation (Bernardinelli et al., 1995, Congdon, 2000). Moreover, poaching analysts need to consider the interrelatedness of spatial and temporal shifts in poaching patterns before labelling poaching areas as highrisk (Herrmann, 2015).

Poaching is attributed to a variety of biophysical and anthropogenic factors. For example, the seasonal timing of elephant poaching, density of waterholes, distance to roads or an international border, livestock density as well as elephant population density may enhance poacher motivation (Rashidi et al., 2017, Rashidi et al., 2016). Previous studies indicated that these factors significantly influenced elephant poaching risk at the local level (Rashidi et al., 2017, Rashidi et al., 2016). Bayesian spatio-temporal models have been developed to better represent the uncertainties in the data and in the models (Burn et al., 2011), which can account for the interrelatedness of spatial and temporal shifts in poaching analysis. The advent of recently developed Bayesian statistical approaches enables associations between poaching occurrence and potential risk factors to be analyzed (Rashidi et al., 2016). To date a number of studies have used poaching data in Bayesian spatio-temporal models (Burn et al., 2011, Critchlow et al., 2015, Rashidi et al., 2017). However, high-risk areas for elephant poaching have not been investigated at the national level and (annual) time series maps depicting shifts in elephant poaching areas are missing.

The goal of this study is to investigate the spatial and temporal dynamics of elephant poaching risk in Kenya from 2002 to 2012, using a Bayesian spatiotemporal model. Specifically, we attempt to answer the following questions: How do elephant poaching risk areas in Kenya shift in space and over time? Where are the persistently high-risk areas for elephant poaching in Kenya located between 2002 to 2012? What are the key factors determining the emergence of high-risk elephant poaching areas in Kenya?

\subsection{Materials and Methods}

\subsubsection{Study Area}

Kenya covers an area of about $582,646 \mathrm{~km}^{2}$ on the equator in East Africa. It lies between $5^{\circ} 30^{\prime} \mathrm{N}$ and $4^{\circ} 30^{\prime} \mathrm{S}$ latitude and $34^{\circ} \mathrm{E}$ and $42^{\circ} \mathrm{E}$ longitude (Ouko, 2013). Kenya has thirteen National Parks and twenty-five reserves that cover ten percent of the country (Burnett and Rowntree 1990). There is a wide range of natural regions in the country, varying from hot, arid lowlands to cool, humid highlands, with numerous soils types (Batjes, 2004). The altitude steadily rises from $0 \mathrm{~m}$ above sea level nearby the Indian Ocean to between $2000-3400 \mathrm{~m}$ in the highlands (Ouko, 2013). The climate of Kenya varies by location. The long rainy season takes place from March through May in many regions of Kenya and the short rainy season occurs 
between October to November (Batjes, 2004). The dry seasons are from January to February and from June to September most years (Batjes, 2004). Mean annual rainfall varies from $150-500 \mathrm{~mm}$ in the arid east and northeast of Kenya to $500-1000 \mathrm{~mm}$ in the semi-arid regions and $1000-2500 \mathrm{~mm}$ in the more humid areas in the central highlands and near Lake Victoria (Ouko, 2013). The mean annual air temperature is extremely connected to elevation. It declines from about $27^{\circ} \mathrm{C}$ near the sea level, to $17^{\circ} \mathrm{C}$ in Nairobi in the central highlands, to less than $10^{\circ} \mathrm{C}$ above $3000 \mathrm{~m}$ (Ouko, 2013).

Kenya is divided into eight conservation regions by the Kenya Wildlife Service, namely: Tsavo, Mountain, Central Rift, Coast, Southern, Northern, Western, and Eastern regions (Figure 1.1). These conservation regions are administrative and delineated according to their biodiversity uniqueness (Litoroh et al., 2012, Ouko, 2013). Poaching crimes occur in both protected and un-protected conservation areas (Ouko, 2013).

\subsubsection{Data}

\subsubsection{Elephant Population and Poaching Incidence Data}

Elephant population and poaching data were obtained from the Kenya Wildlife Service (KWS). The elephant population dataset includes the geographic coordinates and names of the locations where elephants were seen, the number of elephants observed at that location, and the dates of observation. The elephant population in Kenya has been surveyed through aerial total and sample counts, total ground counts, dung density surveys, and the use of individual elephant registration(Litoroh et al., 2012).

Elephant-mortality data covered the period from 2002 to 2012. The elephantmortality data set comprised dates and names of the locations where the carcasses were found, geographic coordinates of incidents, and cause of the elephant mortality. Of the mortality dataset only elephant mortality incidences due to poaching were included in our analyses (Figure 5.1). All other data, referring to natural deaths, problem animal control, unknown deaths, accidents, and human wildlife conflicts were omitted. KWS had collected the poaching incidence data from daily ground patrols and aerial patrols through the Monitoring the Illegal Killing of Elephants (MIKE) program (Rashidi et al., 2016). 


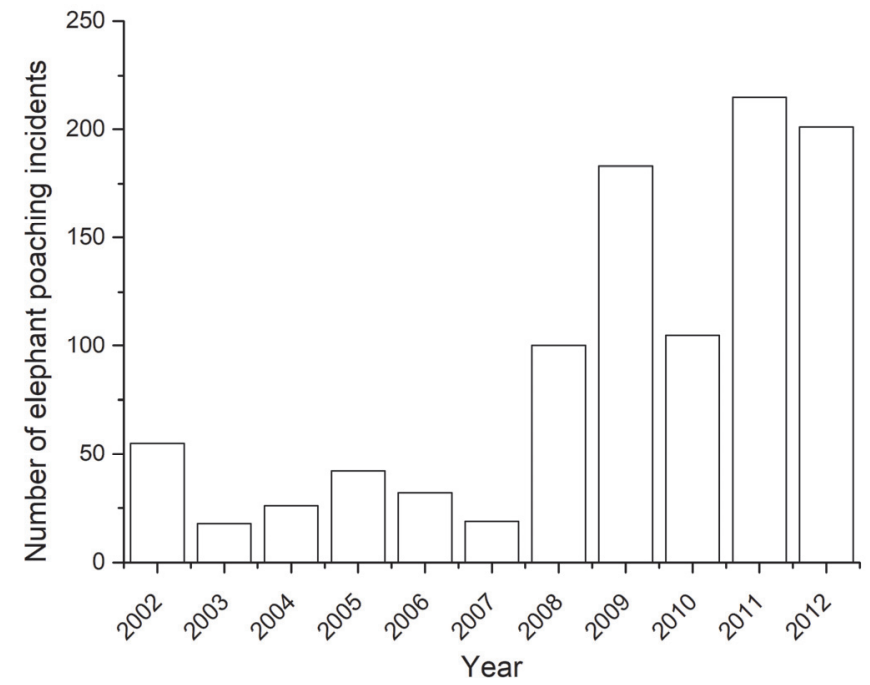

Figure 0.1 Yearly distribution of recorded elephant poaching incidents between 2002 and 2012 in Kenya.

\subsubsection{Risk Factors}

We selected potential risk factors for poaching based on discussions with experts and previous research (Kyale et al., 2011b, Maingi et al., 2012, Ouko, 2013, Rashidi et al., 2016). Thirty experts from the Kenya Wildlife Service were interviewed regarding elephants and poaching. They were asked to score how they believed chosen factors would contribute to elephant poaching risk (Table 5.2). In order to settle a Bayesian expert system with a priori probabilities (Skidmore, 1989), we asked the experts to give a score between 0 and 1 for each factor, depending on how much they believed that the factor may contribute to poaching risk. The equal weighted linear opinion pool (i.e., group average) was used to determine the mean response elicited from the experts, because there were no key differences in the expert ratings of poaching risk factors in this study (Armstrong, 2001) (Table 5.1). This method helps to avoid troubles concerned with rating the comparative 'accuracy' of each expert's opinion on the association between poaching and different factors (Einhorn et al., 1977, Martin et al., 2012, Rashidi et al., 2016).

We expected evidence of elephant poaching to occur closer to roads because roads provide easy access for human exploitation as well as escape opportunities for the poachers (Haines et al., 2012, Sibanda et al., 2016). We modeled the distance to international borders since these may facilitate the transportation of ivory straight to the ivory traders (Rashidi et al., 2016). Areas of high waterhole density and areas in close proximity to rivers and streams are also a potential risk factor, because these linear landscape features are places with relatively high densities of elephants (Maingi et al., 
2012, Rashidi et al., 2016). Likewise, we can expect elephant poaching to be more probable closer to human settlement where occasions and motivated offenders are abundant. The 'near' tool in ArcGIS was used to calculate the nearest distance $(\mathrm{m})$ to settlements, rivers and streams, roads and to the international borders (ESRI, 2011). We included the mean Normalized Difference Vegetation Index (NDVI) and standard deviation of NDVI as indices of land-cover variation, as this may provide a source of food for the elephants as well as camouflage for poachers (Sibanda et al., 2016). Time series of the NDVI from SPOT-VEGETATION were obtained through the Flemish Institute for Technological Research. Following this process, mean NDVI corresponding to the NDVI average was generated from a time series of 10-day NDVI composites for the period from 2002 to 2012. The standard deviation of NDVI corresponds to the mean annual standard deviation of NDVI, obtained from a time series of 10-day NDVI composites for the period from 2002 to 2012. The annual standard deviation is referred to as a measure of the within-year NDVI variation, since it is influenced by seasonality. Seasonal timing of elephant poaching could be a potential predictive variable because in different seasons poaching is expected to happen at dissimilar locations due to elephants' need for water, food or even land cover (Rashidi et al., 2016). To quantify the seasonal timing of elephant poaching in Kenya, we first specified how many poaching incidents were recorded during the wet season (March, April, May, November and December) and the dry season (January, February, June, July, August, September, October) in each region. Then, the probabilities of elephant poaching were computed for the wet and dry seasons in each region (Rashidi et al., 2016). Livestock density could be another potential predictor variable because it could provide cover for poaching activities in the form of ranchers and ranches (Rashidi et al., 2016). Data on livestock density were produced by the World Resources Institute and the International Livestock Research Institute based on an aerial count (Ouko, 2013). We can expect poaching to be related to the elephant population density because poachers prefer areas with high harvesting opportunities in relation to their effort (Burn et al., 2011, Maingi et al., 2012). We modeled elevation as a potential risk factor because of the abundance of browse species preferred by elephants at diverse elevations (Ouko, 2013). Finally, we focused on slope as a potential risk factor because rough terrain can provide cover for poachers (Rashidi et al., 2016). A 90-m digital elevation model (DEM) derived from the Shuttle Radar Topographic Mission (SRTM) was used to extract slope and elevation of the study area. For each region, we generated mean values for mean NDVI, standard deviation of NDVI, elevation, slope, and livestock density (Table 5.1). 
Table 0-1 The potential risk factors with their associated mean and the mean response elicited from the experts on the risk factor's impact on elephant poaching.

\begin{tabular}{|c|c|c|c|}
\hline Explanatory variables & Units & Mean & $\begin{array}{l}\text { Mean } \\
\text { Response }\end{array}$ \\
\hline Distance to settlement & Meter & 14740 & 0.77 \\
\hline $\begin{array}{l}\text { Probability of elephant } \\
\text { poaching in dry season }\end{array}$ & Percentage & 0.668 & 0.65 \\
\hline $\begin{array}{l}\text { Probability of elephant } \\
\text { poaching in wet season }\end{array}$ & Percentage & 0.331 & 0.65 \\
\hline Elevation & Meter & 905 & 0.32 \\
\hline Livestock density & $\begin{array}{l}\text { Number per square } \\
\text { kilometer }\end{array}$ & 0.036 & 0.74 \\
\hline Waterhole density & $\begin{array}{l}\text { Number per square } \\
\text { kilometer }\end{array}$ & 0.003 & 0.73 \\
\hline $\begin{array}{l}\text { Distance to international } \\
\text { border, }\end{array}$ & Meter & 123489 & 0.65 \\
\hline Distance to nearest road & Meter & 6703 & 0.56 \\
\hline Elephant population density & $\begin{array}{l}\text { Number per square } \\
\text { kilometer }\end{array}$ & 0.067 & 0.52 \\
\hline Distance to rivers and streams & Meter & 2676 & 0.54 \\
\hline $\begin{array}{l}\text { Mean normalized difference } \\
\text { vegetation index (NDVI), }\end{array}$ & Dimension less & 0.385 & 0.97 \\
\hline Slope & Degree & 1.479 & 0.30 \\
\hline Standard deviation of NDVI & Dimension less & -0.005 & 0.97 \\
\hline
\end{tabular}

\subsubsection{Accounting for the Effects of Multicollinearity Regarding Risk Factors}

The variance inflation factor (VIF) was used to account for the effects of multicollinearity between risk factors (Table 5.1). The highly correlated risk factors from the set were excluded through a stepwise procedure(Dormann et al., 2013, Naimi, 2013). VIF works by looking for the pair of variables that has the maximum linear correlation, and eliminates the variable which has the higher VIF, duplicating the procedure until there is no variable pair with a high coefficient of correlation (Naimi, 2013).

\subsubsection{Modelling Strategy and Analysis}

Separate Poisson regression models were constructed in a Bayesian framework using the WinBUGS software. We classified our dataset into 11 years based on the yearly reporting of elephant poaching incidents in Kenya. Eleven models were fitted to annually assess the temporal and spatial shifts in elephant poaching risk areas in Kenya during the past 11 years. We did not include risk factors in the annual models. A final model was developed that contained all components of the preceding 11 models to account for the interaction between space and time when defining high-risk poaching areas 
and incorporating the potential effects of risk factors that could have been of influence. It is worthwhile to mention that our final model contains all the potential risk factors that remain significant after accounting for multicollinearity.

Our models assumed that the poaching cases $\left(Y_{i j}\right)$ for area $i=1, \ldots, \mathrm{I}$, and time period $j=1, \ldots, T$ followed a Poisson distribution, which can be modeled as

$Y_{i j} \sim$ Poison (lambdaij).

where the parameter lambdaij of the Poisson distribution $(\mathrm{P})$ is the expected value of $Y_{i j}$, $\exp \left[Y_{i j},\right]$.

$\exp \left[Y_{i j}\right]=l a m b d a_{i j}=\boldsymbol{\theta}_{i j}{ }^{*} e_{i j}$

Using a log link function, unknown risk ( $\left.\theta_{i j}\right)$ is split into parameters measuring purely spatial variation, purely temporal variation, and spatio-temporal interaction:

$\log \left(\theta_{i j}\right)=a+u_{i}+\mathrm{si}+\left(\mathrm{y}+\delta_{\mathrm{i}}\right) \mathrm{t}_{\mathrm{j}}$

$\log (\operatorname{lambda} i j)=\log \left(e_{i j}\right)+a+u_{i}+s_{i}+\left(y+\delta_{i}\right) t_{j}$

where

$e_{i j}=$ is the corresponding number of expected elephant poaching cases for the $i$ th geographic area $(i=1 \ldots 8)$ in the $j$ th year $(j=1, \ldots, 11)$.

$a=$ Intercept (average elephant poaching for the study region)

$S_{i}=$ Spatially structured random effect

$u_{i}=$ Unstructured random effects

$y=$ Regional temporal variation of elephant poaching for the study region

$\delta_{i}=$ Area-specific differential trends

$x=$ Potential risk factors

$B=$ Coefficient of covariate $x$

The indirect standardization method was used to capture expected elephant poaching cases (Law et al., 2015). Intercept $a, s_{i}$ and $u_{i}$ represent purely spatial variation. Any over-dispersion, which arises when modelling count data at the areal level, are accommodated with these terms (Luan et al., 2015). While $y$ represents the overall rate of change in poaching risk, $\delta_{i}$ measures the departure from $y$ for each spatial unit. For example, a negative estimate of $\delta_{i}$ would indicate a slower increase (or even a decrease) in elephant poaching over time for that specific spatial unit. We mapped the posterior mean of area-specific differential trends $\left(\delta_{i}\right)$ to explore areas prone 
to elephant poaching activities in this area. Mapping $\delta_{i}$ allows each spatial unit to have its own risk trend (Li et al., 2014).

It is required to specify a priori distribution for the model parameters in the Bayesian approaches (Bernardinelli et al., 1995). A flat prior distribution was defined for the intercept $a$, whereas a normal prior distribution with a mean representing the expert opinion for the model parameter and a precision that is based on the overall expert response for each factor (Kuhnert et al., 2010, Rashidi et al., 2016) was specified for the coefficients of potential risk factors. Priors for $u_{i}$ and $y$ were determined by a normal distribution prior (with mean 0 and variance $\sigma_{s}^{2}$ ) and a vague prior normal distribution (with mean equal to 0 and variance of 1000), respectively (Law et al., 2014). An Intrinsic Conditional Autoregressive Gaussian distribution (ICAR) prior was defined for spatio-temporal interaction $\delta_{i}$ and spatial random effect $s_{i}$ (Law et al., 2014, Law et al., 2015, Li et al., 2014, Luan et al., 2015, Torabi and Rosychuk, 2012). The ICAR prior on these parameters implies that the means of si and $\delta i$ for one region depend on the si and $\delta i$ of the neighboring regions' distribution, respectively, where the adjacency weights matrix is defined as areas that have common borders (Luan et al., 2015, Torabi and Rosychuk, 2012). For example if two regions share a border, the weight is 1 , and if they do not share a border then the weight is 0 (Restrepo et al., 2014).

Finally, for the hyper-parameters $\sigma_{s}{ }^{2}$ and $\sigma_{\delta}{ }^{2}$, a priori independent distribution gammas were considered with an average and variance equal to 0.5 and 0.0005 , respectively. This gamma distribution is a prior that would offer a logical range for relative risks (Elliot et al., 2000).

Estimates of the parameters and hyper-parameters of interest were acquired from Markov chain Monte Carlo (MCMC) algorithms, with the Win Bugs statistical programs having been implemented. Models were specified textually via the BUGS language in WinBUGS, in which the prior distribution and model likelihood are determined (McCarthy, 2007). For annual models and the final model, MCMC chains comprising 100,00 and 200,00 iterations, respectively, with a burn-in of 1,000 were found to be sufficient to achieve convergence. Monte Carlo standard error and the Brook-Gelman-Rubin Diagnostic ( $<5 \%$ of the sample posterior standard deviation) aided to make certain appropriate burn-in and iterations (Law et al., 2015, Luan et al., 2015, Rashidi et al., 2016).

The deviance information criterion (DIC) was calculated for model selection, where lower DIC indicates a better model fit. To determine if a model fits the data better, the difference in DIC value for the models should be no less than 5 , because of Monte Carlo sampling errors intrinsic in the computation of DIC (Law et al., 2014). 


\subsection{Results}

In total, 11 models were developed to consider how elephant poaching risk areas shifted annually in Kenya over a decade. Our results revealed that the locations of high-risk elephant poaching areas vary annually and are highly dynamic (Figure 5.2). High-risk elephant poaching areas have seen a spatial shift from a contiguous area in the south-east of Kenya in the year 2002 to the west, central rift and south area in the year 2012, where only minimal poaching incidents were actually reported (Figure 5.2).

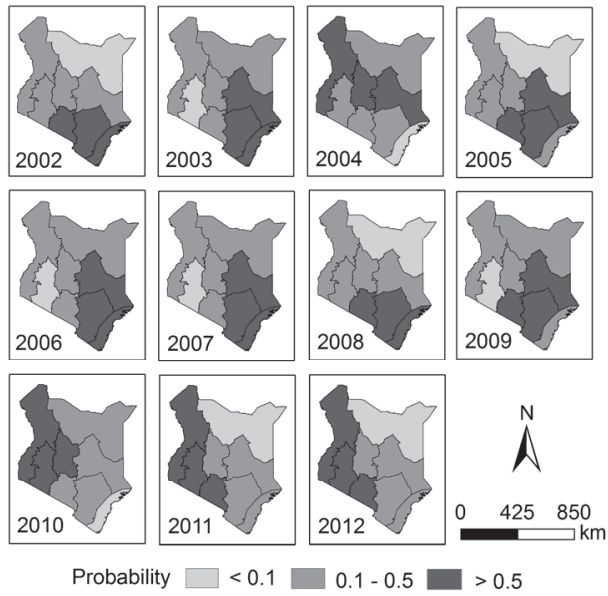

Figure 0.2 Time series maps depict the shifts in high-risk elephant poaching areas from the south-east to the west of Kenya (2002 to 2012).

The final model, which includes data for the eleven-year period from 2002 to 2012, as well as potential risk factors, demonstrates that Mountain, Tsavo and Coast area are poaching risk areas with a persistently high risk of elephant poaching over the study period(2002 - 2012) (Figure 5.3).

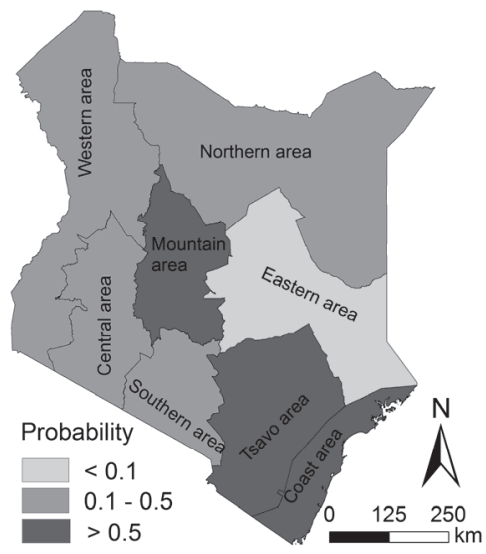

Figure 0.3 Spatio-temporal highrisk areas in Kenya with a persistently high risk of elephant poaching over the study period (2002 - 2012). 
A large spatial variability can be observed both in observed poaching incidence (Figure 5.1) and estimated risk (Figure 5.3) in the Eastern area.

Of the selected risk factors (Table 5.1), distance to an international border, mean normalized difference vegetation index (mNDVI), standard deviation of NDVI, distance to a road, elephant population density, seasonal timing of elephant poaching (i.e., probabilities in the wet season), and waterhole density remained after accounting for multicollinearity.

The results further show that the seasonal timing of elephant poaching, the density of waterholes, and the distance to a road, settlement and international border were the factors significantly influencing the spatiotemporal patterns of elephant poaching risk in Kenya (Table 5.2). The inclusion of zero values within the $95 \%$ Bayesian credible intervals implies an insignificance of the estimates (Jianmei, 2014). Our results indicate that despite expert knowledge, some variables like elephant density, land cover and distance to rivers were not significant.

Table 0-2 Posterior summaries for $B$ coefficients of the explanatory variables in spatiotemporal Bayesian modelling

Explanatory variables mean $B$

(credible interval:

$2.5 \%, 97.5 \%)$

Distance to settlement

$-3.7(-8.7,-0.9)$

Probability of elephant poaching in wet season

$0.65(0.07,1.23)$

Distance to nearest road

$0.98(0.55,1.44)$

Waterhole density

$0.72(0.25,1.19)$

Distance to international border

$0.08(0.05,0.14)$

Elephant population density

$0.54(-0.22,1.28)$

Mean normalized difference vegetation index (NDVI)

$-4.93(-4.73,11.58)$

Standard deviation of NDVI

$0.94(-1.42,3.44)$

It is worth mentioning that DIC values were different for the annual models. Moreover, adding the potential risk factors to the final model didn't enhance the prediction of the model (DIC value of 51773 vs 51775 ).

\subsection{Discussion}

The annual high-risk areas for elephant poaching have not been investigated at national level in previous studies and neither have time series maps depicting shifts in elephant poaching areas been considered. In the current study we found high poaching risk areas in Kenya have varied annually and shifted from the south-east to the west between 2002 and 2012. This could be attributed to elephant movements, enhanced ranger patrols, and/or changes in poacher behavior in certain areas (Sibanda et al., 2016). It is 
obvious that poachers avoid some high-risk areas, which have become known as poaching hotspots, because the increased security in these areas increases a poacher's risk of getting reported or apprehended. For example, elephant poaching risk areas have encountered spatial shifts from the southern area in 2002 to the western area in 2012, where minimal poaching incidents were reported over the 11 years (Figure 1.1 and 5.2). Poachers and buyers clearly shift to new areas like the western area if that means less chance of poacher detection. Spatiotemporal dynamics of high-risk elephant poaching areas (Figure 5.2) may be a useful indicator of changing elephant poaching pressures as well as help to predict areas that could potentially emerge as high-risk elephant poaching areas across the country.

High-risk elephant poaching has seen a spatial shift from areas with high recorded elephant poaching incidents in the year 2002 to the areas where minimal poaching incidents were reported in the year 2012 (Figure 5.2). One reason for this contrast could be that the collection of poaching data has issues related to underreporting or misreporting by rangers (Maingi et al., 2012). Therefore, an increase in the number of reports of elephant poaching incidents in some areas and years cannot automatically be interpreted as an increase in poaching rate in those areas and years, as it could instead be a reflection of better enforcement and more developed data collection systems (Sharma et al., 2014).

Furthermore, we found that the Mountain, Tsavo and Coast areas are poaching risk areas with a persistently high risk of elephant poaching over the studied years (2002 - 2012) (Figure 5.3). Ouko (2013) had also observed this, when using spatiotemporal clustering methods. Moreover, our analysis shows that the Tsavo ecosystem is the main persistently high-risk area in Kenya between 2002 and 2012 (Figure 5.2). However, in the current study, we demonstrated the probability that each region would show a differential trend from the mean elephant poaching trend in Kenya (Figure 5.3). This allowed us to be more specific about high-risk area locations rather than having to resort to reporting clusters of areas. For example, Ouko (2013) found that most of the space-time clusters appeared in the mountain conservation region, Tsavo, and in Coast conservation areas. However, he did not detect probabilities regarding elephant poaching risk for these areas. In the current study, we identified the elephant poaching risk probability for these regions (Figure 5.3).

Non-existence of high-risk poaching areas for elephant in Eastern areas over the studied years in the final model does not necessarily mean that no poaching is taking place in those regions, but could be explained by the fact that there is no interaction between time and space for high-risk elephant poaching areas in Eastern areas (Figure 5.3). 
The fact that some areas show significantly different trends in poaching could be due to potential risk factors that vary geographically across the regions. Therefore, we set up a final model to identify useful predictors that significantly influenced the spatial variation in trends regarding elephant poaching risk over time in Kenya. We found that density of waterholes and the seasonal timing of elephant poaching (the probability of elephant poaching in the wet season) were consistently identified as useful predictors that significantly influenced the spatial variation in trends regarding elephant poaching risk irrespective of scale and the Bayesian methods (spatial or spatiotemporal) used (Rashidi et al., 2017, Rashidi et al., 2016). It is worthwhile to mention that we ignored the probability of elephant poaching in the dry season in our final model because of multicollinearity. We just considered the probability of elephant poaching in the wet season, which was a significant factor. This relationship could be attributed to the fact that during the wet seasons the conservation security may not be very high, because of inaccessibility of some areas after they have been cut off by flooding rivers (Maingi et al., 2012). The influence of density of waterholes on elephant poaching could be explained by the fact that availability of more water resources, limiting elephant less to certain areas, would make them less vulnerable to poaching (Sibanda et al. 2016). Distance to an international border and distance to a road were consistently significant variables contributing to elephant poaching risk. Our results indicate that, regardless of scale (local or national level), these two variables are useful predictors for predicting elephant poaching risk areas when accounting for space and time interaction. Roads would provide easy access and escape opportunities for poachers. The variable 'distance to an international border' confirms the hypothesis from our earlier study (Rashidi et al., 2015) that higher poaching risk exists along international borders, and is possibly associated with reduced anti-poaching activity. For example, this study has identified poaching hot spots along the international border with Somalia, which is consistent with Daskin and Pringle (2018). It is worth noting that distance to human settlement was not a significant factor regarding elephant poaching risk at local level using Bayesian spatial and spatiotemporal modelling in a former study (Rashidi et al., 2017, Rashidi et al., 2016), while, the results in our current study reveal that it is a significant factor contributing to elephant poaching risk. In areas closer to settlements the probability of elephant poaching risk is greater. This could be attributed to the fact that there are human-elephant conflicts over resources (space, water, and forage) and the possibility of participation by local people with the poachers or, at least, their indifference towards elephant poaching (Maingi et al., 2012).

The fact that some variables like elephant density have been deemed important by experts, but were not significant in our models could be due to 
theoretical knowledge rather than personal and local experience (Doswald et al., 2007, Rashidi et al., 2017).

The main limitations of poaching studies include the reliance on elephant poaching data that only represent a proportion of the total poaching in Kenya between 2002 and 2012. Poaching density reports per district and per year often use tables, graphs and maps to indicate rate or percentage of change in poaching, but seldom use spatial statistical methods to analyze poaching trends. This style of poaching trend analysis and reporting has limitations in conveying a comprehensive understanding of small-area changes (Law et al., 2014) in poaching and is ineffective when used to mitigate elephant poaching at local and national level. However, we lessened this problem by utilizing a spatio-temporal Bayesian model, which provides a flexible framework for borrowing information over space and time from adjacent regions by using spatial and temporal random effects (Rashidi et al., 2017). Moreover, the past does seem to be the best predictor of the future regarding poaching activity, therefore further work needs to be carried out to investigate elephant poaching risk in Kenya from 2013 to the present at local and regional scale.

\subsection{Conclusions}

This study investigated the spatial and temporal dynamics of elephant poaching risk areas from 2002 to 2012 in Kenya using a spatio-temporal Bayesian modelling. We also tested whether elephant poaching high-risk areas were influenced by potential risk factors that vary geographically across the regions. Results showed variations in high-risk elephant poaching areas for different regions and different years in Kenya. Furthermore, we found that the Mountain, Tsavo and Coast are areas with a persistently high risk of elephant poaching over the studied years (2002 - 2012). Elephant poaching risk areas at national level in Kenya were mainly determined by the seasonal timing of elephant poaching, density of waterholes, distance to an international border, distance to a road, and the distance to settlements. To aid KWS in their efforts to mitigate elephant poaching, our results offer a promising solution for the allocation of both human and financial resources as effectively as possible, at exact locations and at the right time. This type of modelling can be expanded to incorporate other threatened species over different space - time scales. 
Chapter 6

Synthesis 


\subsection{Introduction}

Elephant poaching is currently the main cause of elephant population decline in Africa (Bouché et al., 2011, Chase et al., 2016, Maisels et al., 2013, ZafraCalvo et al., 2018). The latest African census revealed a $30 \%$ decrease in the elephant population between 2007 and 2014 (Chase et al., 2016, Gholami, 2018). Poaching affects elephant populations in ways that may persist into unfavourably limiting both the rate of population growth and the onset of recovery (Onyango and Lesowapir, 2016). As poachers target older elephants with big tusks, they rob the population of its top reproductive individuals (Onyango and Lesowapir, 2016). As a result, poached elephant populations have a smaller proportion of older individuals, a more female-biased operational sex ratio and a longer calving interval than unpoached populations (Onyango and Lesowapir, 2016).

Kenya, as so many African countries, has not been exempt from elephant poaching. In Kenya, the number of elephants killed by poachers has increased over the past ten years, with more intense poaching occurring in some specific regions. For example, the Tsavo ecosystem has the highest reported incidence of elephant poaching in Kenya (Maingi et al., 2012). In order to effectively protect elephants against poaching threats, timely information on spatial and temporal variations in high-risk poaching areas is required. However, obtaining an absolute measure of poaching levels based on direct observation (carcasses monitoring) is practically impossible due to the covert nature of poaching (Burn et al., 2011). Furthermore, wildlife authorities in Kenya, as in other countries in sub-Saharan Africa, lack adequate manpower with less than one ranger per $100 \mathrm{~km}^{2}$ of wildlife reserve (Maingi et al., 2012), which is very low compared to the international standard of one ranger per $24 \mathrm{~km}^{2}$ for effective policing and patrolling (Kyando, 2014). Therefore, there is a clear need for the development of modelling approaches with the ability to borrow information from those areas that have a long-term observation system, and to incorporate expert knowledge to assist in making informed estimates in poorly sampled areas.

Mapping and assessing poaching risk areas and trends form key components of the anti-poaching initiative, and can make a major contribution to the global fight against poaching, as they allow problems to be recognized, priorities to be established, solutions to be settled, and resources to be targeted (Rashidi et al., 2017). The aim of this thesis has been to assess how elephant poaching risk may change at different locations or times, or for any interaction between space and time, at local and national level. As well, an attempt is made to identify key factors influencing elephant poaching risk.

This thesis encompasses several studies concerned with assessing elephant poaching hotspots as well as spatial and spatio-temporal elephant poaching trends and risks. Although there is some overlap, these studies can be 
classified into four overarching themes: 1) elephant poaching hotspots at local level in the Tsavo ecosystem (chapter 2, $3 \& 4$ ); 2) spatial and spatiotemporal dynamics of elephant poaching risks at local and national level (chapter 3, 4 \& 5); 3) biophysical and anthropogenic factors that are influencing elephant poaching risk at local and national level (chapter 3, 4 \& 5); and 4) applications of spatial and spatio-temporal models in elephant poaching research (chapter 2, 3, 4 \& 5). In the synthesis chapter, the major research findings from the previous chapters are highlighted and brought together to try and understand elephant poaching risk and its relationship with biophysical and anthropogenic factors at different scale levels in Kenya. The practical relevance of these results for management and conservation is discussed.

\subsection{Detecting Elephant Poaching Hotspots at Local Level in the Tsavo Ecosystem. \\ - Where Are Elephant Poaching Hotspots Consistently Located in the Tsavo Ecosystem?}

Poaching hotspots are areas where or periods that the occurrence of poaching is so much more frequent than in other areas or periods that species survival is threatened(Maingi et al., 2012). Given limited resources, many researchers advocate focusing conservation efforts on poaching hotspots (Rutledge et al. 2001). Identifying poaching hotspots plays an important role in reducing poaching. Many methods are used to identify hotspots in a wide range of applications, including the studying of criminal activities, but the use of such methods is still in its infancy in the field of wildlife poaching-a specific form of crime. In this current study, we set out to identify consistent elephant poaching hotspots at local level in the Tsavo ecosystem by using different cluster and Bayesian methods on data that cover a continuous period of eleven years.

The results of our study reveal that although hotspot predictions varied for the different methods, two blocks were consistently identified as encompassing poaching hotspots at local level in the Tsavo ecosystem (Fig. 6.1). These blocks of hotspots are located in the Tsavo west national park, and the Taita ranches and are mainly found along the border with Tanzania, which confirms the hypothesis posed in Chapter 2 (that higher poaching risk exists along international borders) and is possibly associated with reduced anti-poaching activity in that area. Locations along the international border may facilitate the transportation of ivory straight to the ivory traders (Rashidi et al., 2016). Our results and methodological comparison may assist the Kenya Wildlife Service in allocating financial and human resources effectively to reduce elephant poaching. 


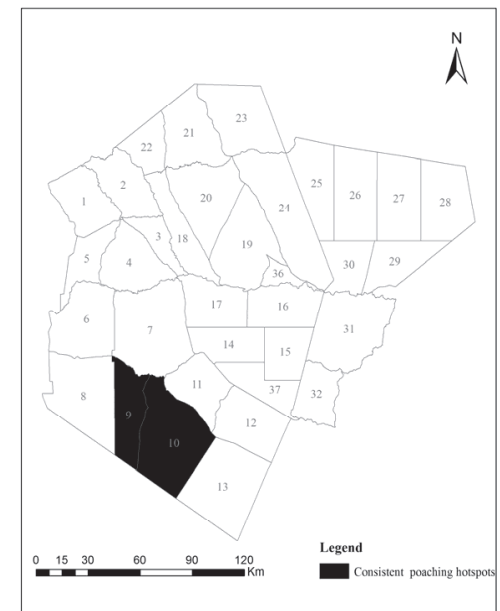

Figure 0.1 Consistent elephant poaching hotspots in the Tsavo ecosystem, Kenya

\subsection{Spatial and Spatio-temporal Dynamics of Elephant Poaching Risk at Local and National Level}

\section{- How do the Elephant Poaching Risk Areas Vary Across Place and Time at Local and National Level?}

Poaching is a dominant wildlife crime, but it is unevenly distributed over space and time (Burn et al., 2011). Within wildlife criminology, both spatial and temporal lenses are useful for studying poaching trends (Burn et al., 2011, Critchlow et al., 2015, Maingi et al., 2012, Rashidi et al., 2017, Rashidi et al., 2016, Rashidi et al., 2015). Quantifying spatial and temporal dynamics of elephant poaching risk at different scale levels provides information needed for setting conservation priorities (Wittemyer et al., 2014), as well as for concentrating management resources where they are most needed ( $\mathrm{Li}$ et al., 2014). However, few studies exist that are aimed at quantifying spatial and spatiotemporal patterns in the specific criminal act of wildlife poaching. In this study, we first used a spatial Bayesian model to investigate spatial variation observed in elephant poaching risk at the local level (blocks in the Tsavo ecosystem) without investigating the interaction between time and space. Next, we integrated spatial and temporal lenses in the Bayesian model to examine variation in elephant poaching risk over space and time at the local (blocks in the Tsavo ecosystem) and national level (conservation regions in entire Kenya).

The results reveal emerging differences between the detected highest risk areas for elephant poaching by the spatial model (which focused only on the spatial variation observed in elephant poaching in the Tsavo ecosystem) and by the spatio-temporal model (which investigating the interaction between 
time and space) (Figure 6.2). This may be partly due to the integration of spatial and temporal random effects into the poaching analysis, possibly detecting relatively subtle changes in elephant poaching risk in specific blocks over time that would not have been detected by spatial analyses alone (Critchlow et al., 2015). However, there were also blocks in the Tsavo ecosystem, which did display similar probability classes in both models (Figure 6.2). Moreover, our analysis at national level shows that high poaching risk areas in Kenya have varied annually from the south-east to the west between 2002 and 2012 (Figure 6.3). This may be attributed to elephant movement, enhanced ranger patrols, and/or changes in poacher behaviour in certain areas (Sibanda et al., 2016). Further results indicate that the Tsavo ecosystem is persistently the main high-risk area at national level in Kenya from 2002 to 2012 . This confirms the hypothesis posed in Chapter 3 that the elephant population size is a significant factor because it is likely to provide the poachers with the highest harvest related to their efforts. This finding supports the idea that poaching risk is higher in areas with a high elephant population (Maingi et al., 2012).

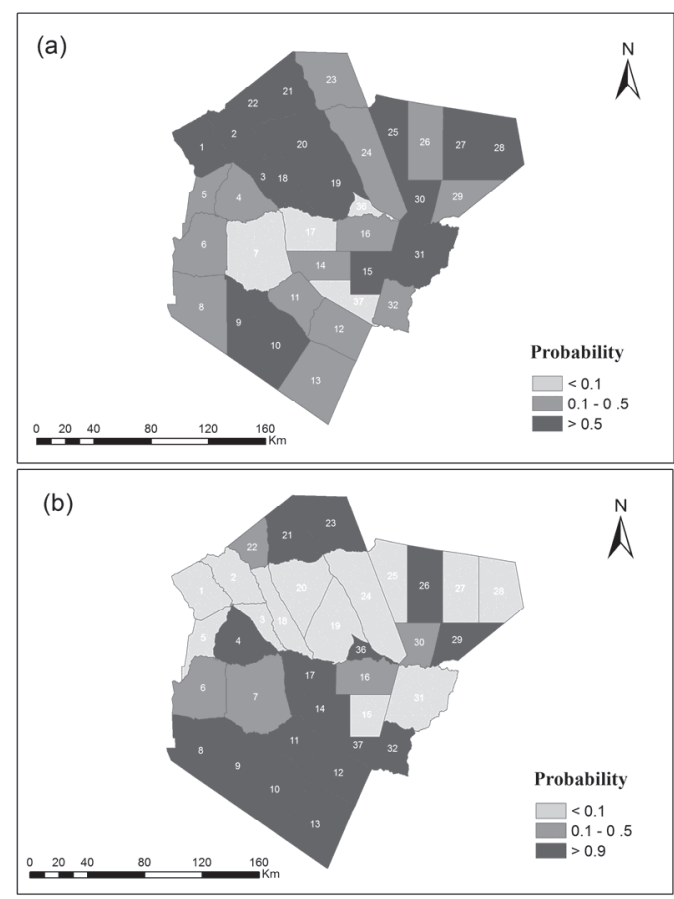

Figure 0.2 The probability of elephant poaching risk for each block in the Tsavo ecosystem, Kenya: (a) Bayesian spatial model and (b) Bayesian spatito-temporal model. 


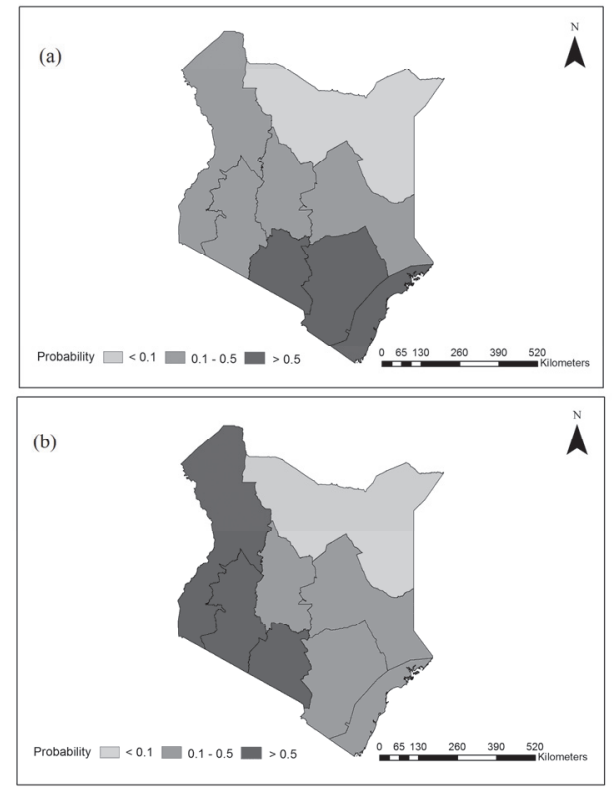

Figure $\mathbf{0 . 3}$ Shifts in high-risk elephant poaching areas from (a) the south-east of Kenya with high recorded elephant poaching incidents in the year 2002 to (b) the west of Kenya where minimal poaching incidents were reported in the year 2012.

\subsection{Biophysical and Anthropogenic Factors Influencing Elephant Poaching Risk}

\section{- What are Persistently the Key Factors Influencing Elephant Poaching Risk at Local and National Level?}

Poaching is attributed to a variety of biophysical and anthropogenic factors (Burn et al., 2011, Critchlow et al., 2015, Kyale et al., 2011b, Maingi et al., 2012). The fact that some areas show significantly different trends in poaching could be due to potential risk factors that vary geographically across the regions (Rashidi et al., 2017, Rashidi et al., 2016). Understanding what key factors determine the spatial and spatio-temporal distribution of elephant poaching is vital to developing effective anti-poaching actions and and to protecting area (Zafra-Calvo et al., 2018). The achievements of antipoaching actions are expected to depend on context-specific circumstances. Consequently, more information about what determines the spatial and spatio-temporal distribution of poaching risk in poaching hotspots is thus immediately needed (Zafra-Calvo et al., 2018). The spatial association between poaching occurrence and potential risk factors has traditionally been modeled using a frequentist (classical) statistical approach in the form of logistic regression (Kyale et al., 2011b, Maingi et al., 2012), but, such an approach does not satisfactorily account for local risk factors (i.e., existing in 
one unit but not in neighboring ones) that remain unknown and are not captured in the model (Law and Chan, 2012). As a result, spatial autocorrelation remains a problem in traditional approaches even if the covariates are adjusted (Law and Chan, 2012). Therefore, in this study we first used Bayesian spatio-temporal modelling at local level (the Tsavo ecosystem) to investigate the key factors determining the emergence of high risk elephant poaching areas at local level. Then we applied the same modelling at national level to assess whether the key factors that are determining the emergence of high-risk elephant poaching areas differ between local and national level.

We selected potential risk factors for poaching based on discussions with experts and previous research. These factors included: (1) distance to roads, (2) distance to settlements, (3) distance to rivers and streams, (4) density of waterholes, (5) elevation, (6) slope, (7) mean normalized difference vegetation index (NDVI), (8) standard deviation of NDVI, (9) elephant population density, (10) livestock density, (11) distance to international border, and (12) seasonal timing of elephant poaching (i.e., poaching probabilities in the dry and wet seasons).

Our results indicate that, of the selected factors that remained after accounting for multicollinearity, the seasonal timing of elephant poaching, density of waterholes, distance to road and distance to an international border were persistent key factors influencing elephant poaching risk at both local and national level in Kenya (Table 6.1). Distance to an international border seems to have the greatest influence on elephant poaching at local level while distance to a road is most influential at national level, with a variation greater than other risk factors (Table 6.1). The seasonal timing of elephant poaching might influence the extent of poaching because poaching is likely to occur at different locations in different seasons due to elephant's requirements such as food, water, and even land cover. Likewise, the influence of density of waterholes on elephant poaching could be explained by the fact that the availability of more water resources, limiting elephant less to certain areas, would make them less vulnerable to poaching (Sibanda et al., 2016). Distance to roads may be important because it could provide easy access and escape opportunities for the poachers (Haines et al., 2012). Distance to an international border also forms a permanent risk factor presumably because it allows for easy transportation of the ivory directly to the ivory traders.

In our study, we found that some variables, such as elephant population density, formed significant predictors in the spatial model at local level, but were not significant in the spatio-temporal model at local or national level. This could be due to the dynamics of elephant populations across different areas, but there were no significant changes in the population during our study period from 2002 till 2012. 
Table 0-1 Posterior summaries for $\beta$ coefficients of the consistent explanatory variables at local and national level using spatio-temporal Bayesian modelling

\begin{tabular}{lll}
\hline Explanatory variables & $\begin{array}{l}\text { mean } B \\
\text { (Local level) } \\
\text { (credible interval: } \\
2.5 \%, 97.5 \%)\end{array}$ & $\begin{array}{l}\text { mean } B \\
\text { (National level) } \\
\text { (credible interval: } \\
2.5 \%, 97.5 \%)\end{array}$ \\
\hline $\begin{array}{l}\text { Probability of elephant poaching } \\
\text { in wet season }\end{array}$ & $0.62(0.022,1.237)$ & $0.65(0.07,1.23)$ \\
Waterhole density & $0.77(0.054,1.288)$ & $0.72(0.25,1.19)$ \\
Distance to road & $0.55(0.004,1.144)$ & $0.98(0.55,1.44)$ \\
Distance to international border & $1.49(0.421,2.711)$ & $0.08(0.05,0.14)$ \\
\hline
\end{tabular}

\subsection{Applications of Spatial and Spatio-Temporal Models in Elephant Poaching Research}

Poaching is a dominant wildlife crime, but it is unevenly distributed over space and time (Burn et al., 2011). Given the covert nature of poaching (Burn et al., 2011) it is difficult to analyze spatial and temporal trends in wildlife poaching at a fine scale, and methods that can deal with data scarcity are required (Gelman and Price, 1999).

Poaching research is incrementally using spatial and spatio-temporal models because geocoded poaching data and temporal data are becoming more readily available. Spatial as well as spatio-temporal methods for analyzing poaching data at different scale levels are being developed (Rashidi et al., 2017, Rashidi et al., 2016). Researchers have taken a variety of spatial and spatio-temporal approaches to investigate and understand poaching risk and contributing risk factors (Burn et al., 2011, Critchlow et al., 2015, Kyale et al., 2011b, Maingi et al., 2012, Rashidi et al., 2017, Rashidi et al., 2016, Rashidi et al., 2015, Wittemyer et al., 2014). Some have used the kernel density and frequentist (classical) statistical approach in the form of logistic regression to map poaching hotspots and investigate contributing risk factors (Kyale et al., 2011b, Maingi et al., 2012). However, such an approach does not satisfactorily account for unexplained variance in the models, missing data and all key risk factors (i.e., factors existing in one unit but not in neighbouring ones) that remain unknown and are not captured in the model (Law and Chan, 2012). As a result, spatial autocorrelation remains a problem in traditional approaches even if the covariates are adjusted for (Law and Chan, 2012). Moreover, developing accurate models requires large datasets; this can be a problem in poaching research where observational data are scarce, costly to obtain, or subject to design and quality concerns (Rashidi et al., 2016).

In this study, various spatial and spatio-temporal models with the ability to estimate poaching risk in areas with zero counts by borrowing information from neighbouring areas and experts (Sun et al., 2000) were used. This helps 
to overcome the scarce data problem (Gelman and Price, 1999), which occurs with unreliable estimations due to low incident counts in small areas and high variation in sampling (Bernardinelli et al., 1995; Congdon, 2000).

Specifically, in Chapter 2, we run the Kulldorff's spatial scan statistic, flexible spatial scan statistic, spatio-temporal scan statistic and spatio-temporal permutation scan statistic for exploring elephant poaching hotspots at local level in the Tsavo ecosystem. Our results indicate that areas of significant clusters can be identified by these methods, but that the technique cannot map the probability of clustering across areas.

Recently, methods have been developed that can account for spatial and spatio-temporal variation in elephant poaching by estimating the probability of detecting an incident independently from the processes that drive the distribution of the incidents (Critchlow et al., 2015). These methods are also capable of accounting for missing data, where, due to data limitations, the analyst is concerned about the effects of important covariates that are missing. These methods have rarely been applied to poaching research (Burn et al., 2011, Critchlow et al., 2015) and informative prior knowledge (expert knowledge) has not been incorporated in the modelling. Expert knowledge can provide information about model parameters and help characterize uncertainty in models, and it can be useful when data are limited or unavailable (Kuhnert, 2011). To our knowledge, our study is the first study in which expert knowledge has been integrated (using Bayesian modelling) to investigate elephant poaching risk and contributing risk factors.

This thesis focuses on spatial and spatio-temporal poaching incident analysis. However, the models we used do not appear to be an effective means of detecting the poachers themselves. Therefore, approaches used in this thesis should be expanded into a model that also models poacher's spatial and spatial-temporal preferences for certain sites across all poaching landscapes.

Moreover, future research is needed to investigate how elephant population dynamics change at the various scales as a result of poaching.

On the whole, despite the study's limitations, our results provide a detailed understanding of the scope of the elephant poaching problem in Kenya, and our results are of relevance to conservation and management actions, not only with immediate consequences but also as a foundation for further study.

\subsection{Relevance to Conservation and Management.}

Insufficient human and financial resources, combined with the large areal extent to be monitored, pose major challenges for anti-poaching activities in Kenya (Maingi et al., 2012, Rashidi et al., 2015). Patrolling is an imperfect process because wildlife authorities lack the manpower to have rangers effectively patrol massive areas regularly (Gholami, 2018). They cannot 
patrol everywhere all the time, and therefore there is considerable uncertainty surrounding the poaching carcasses datasets (Gholami, 2018), which most likely only represent a proportion of the total poaching that has occurred. It is thus necessary to consider models that estimate missing data and hidden variables even for areas with zero incidents.

In the thesis, we employed spatial and spatio-temporal models with the ability to borrow information from those areas that have a better observation system in place to detect elephant poaching hotspots and spatial and spatiotemporal trends of elephant poaching risk from 2002 to 2012 at local and national level in Kenya. Applying this kind of modelling, which provides a flexible framework for borrowing information over space and time from adjacent areas by using spatial and temporal random effects, provides an effective way to form estimates for poorly sampled areas. The findings presented in this thesis assist in the setting of conservation priorities and the concentration of management resources. This is especially important for wildlife authorities in Kenya that cannot offer adequate protection of wildlife from poaching within national parks and reserves because of high conservation costs and due to being understaffed with less than one ranger per $100 \mathrm{~km} 2$ of wildlife reserve (Maingi et al., 2012).

We also quantify the key factors determining the emergence of high-risk elephant poaching areas at different scale levels. Understanding the spatial distribution of elephant carcasses in relation to biophysical and anthropogenic factors is critical to developing targeted management strategies for mitigating poaching.

We have provided the above-mentioned contributions in support of reducing elephant poaching in Kenya. However, KWS should continue to carry out frequent surveillance and intensify patrolling within and around the detected elephant poaching hotspots especially targeting the areas which exist along international borders and areas with human settlements in and around them.

Elephant poaching can be influenced by landscape fragmentation thus increasing the human-wildlife boundary and the incidence of human-wildlife conflicts (Fischer and Lindenmayer, 2007). Therefore, to further clarify the interaction between landscape fragmentation and elephant poaching risk, future research should seek to develop a prediction model for modelling future trends of elephant poaching based on different population and habitat fragmentation scenarios. This is an interesting topic because in a fragmenting landscape, wildlife numbers and diversity decline, while simultaneously human-wildlife conflicts increase as a result of a longer interface between farms and wild lands (Pittiglio, 2012). Last but not least, methods presented in this study may also be adjusted and applied to poaching data for other threatened species and in other areas to devise targeted conservation and management strategies in a bid to reverse current poaching trends. 


\section{Bibliography}

AKAIKE, H. 1977. An objective use of Bayesian models. Annals of the Institute of Statistical Mathematics, 29, 9-20.

ALTON, G. D., PEARL, D. L., BATEMAN, K. G., MCNAB, B. \& BERKE, O. 2013. Comparison of covariate adjustment methods using space-time scan statistics for food animal syndromic surveillance. BMC veterinary research, 9, 231.

ALZAHRANI, A. G., AL MAZROA, M. A., ALRABEAH, A. M., IBRAHIM, A. M., MOKDAD, A. H. \& MEMISH, Z. A. 2013. Geographical distribution and spatio-temporal patterns of dengue cases in Jeddah Governorate from 2006-2008. Transactions of The Royal Society of Tropical Medicine and Hygiene, 107, 23-29.

ANSELIN, L. 1995. Local indicators of spatial association-LISA. Geographical analysis, 27, 93-115.

ANSELIN, L., COHEN, J., COOK, D., GORR, W. \& TITA, G. 2000. Spatial analyses of crime. Criminal justice, 4, 213-262.

ARMSTRONG, J. S. 2001. Combining forecasts. Principles of forecasting. Springer.

BATJES, N. 2004. Soil carbon stocks and projected changes according to land use and management: a case study for Kenya. Soil Use and Management, 20, 350-356.

BAUMGARTNER, K., FERRARI, S. \& PALERMO, G. 2008. Constructing Bayesian networks for criminal profiling from limited data. Knowledge-Based Systems, 21, 563-572.

BERNARDINELLI, L., CLAYTON, D., PASCUTTO, C., MONTOMOLI, C., GHISLANDI, M. \& SONGINI, M. 1995. Bayesian analysis of spacetime variation in disease risk. Statistics in medicine, 14, 2433-2443.

BESAG, J., YORK, J. \& MOLLIÉ, A. 1991. Bayesian image restoration, with two applications in spatial statistics. Annals of the institute of statistical mathematics, 43, 1-20.

BLANC, J., BURNHAM, K., DUBLIN, H., MILLIKEN, T., MWANGI, P., SANGALAKULA, L., SKINNER, D. \& UNDERWOOD, F. 2013. Status of African elephant populations and levels of illegal killing and the illegal trade in ivory: A report to the African Elephant Summit. CITES Secretariat, IUCNx/SSC African Elephant Specialist Group, and TRAFFIC International.

BOUCHÉ, P., DOUGLAS-HAMILTON, I., WITTEMYER, G., NIANOGO, A. J., DOUCET, J.-L., LEJEUNE, P. \& VERMEULEN, C. 2011. Will elephants soon disappear from West African savannahs? PLoS One, 6, e20619.

BURN, R. W., UNDERWOOD, F. M. \& BLANC, J. 2011. Global trends and factors associated with the illegal killing of elephants: a hierarchical Bayesian analysis of carcass encounter data. PLoS One, 6, e24165. 
BURRA, T., JERRETT, M., BURNETT, R. T. \& ANDERSON, M. 2002. Conceptual and practical issues in the detection of local disease clusters: a study of mortality in Hamilton, Ontario. The Canadian Geographer/Le Géographe Canadien, 46, 160-171.

CHAIKLIN, M. 2010. Ivory in world history-early modern trade in context. History Compass, 8, 530-542.

CHAINEY, S., TOMPSON, L. \& UHLIG, S. 2008. The utility of hotspot mapping for predicting spatial patterns of crime. Security Journal, 21, 4-28.

CHAKRAVORTY, S. 1995. Identifying crime clusters: The spatial principles. Middle States Geographer, 28, 53-58.

CHASE, M. J., SCHLOSSBERG, S., GRIFFIN, C. R., BOUCHÉ, P. J., DJENE, S. W., ELKAN, P. W., FERREIRA, S., GROSSMAN, F., KOHI, E. M. \& LANDEN, K. 2016. Continent-wide survey reveals massive decline in African savannah elephants. PeerJ, 4, e2354.

CHIU, Y.-W., WANG, M.-Q., CHUANG, H.-Y., HSU, C. E. \& NKHOMA, E. T. 2008. A new application of spatiotemporal analysis for detecting demographic variations in AIDS mortality: an example from Florida. The Kaohsiung Journal of Medical Sciences, 24, 568-576.

CITES, I. 2010. Monitoring of illegal hunting in elephant range states. Fifteenth conference of the parties to the convention on international trade in endangered species of wild fauna and flora. Doha (Qatar).

CLARKE, B. 1996. Implications of reference priors for prior information and for sample size. Journal of the American Statistical Association, 91, 173-184.

COBB, S. 1976. The distribution and abundance of the large herbivore community of Tsavo National Park, Kenya. University of Nairobi.

CONGDON, P. 2000. Monitoring suicide mortality: a Bayesian approach. European Journal of Population/Revue européenne de Démographie, 16, 251-284.

CRITCHLOW, R., PLUMPTRE, A., DRICIRU, M., RWETSIBA, A., STOKES, E., TUMWESIGYE, C., WANYAMA, F. \& BEALE, C. 2015. Spatiotemporal trends of illegal activities from ranger-collected data in a Ugandan national park. Conservation Biology, 29, 1458-1470.

CROME, F., THOMAS, M. \& MOORE, L. 1996. A novel Bayesian approach to assessing impacts of rain forest logging. Ecological Applications, 1104-1123.

DASKIN, J. H. \& PRINGLE, R. M. 2018. Warfare and wildlife declines in Africa's protected areas. Nature.

DE FINETTI, B., MACHI, A. \& SMITH, A. 1990. Theory of probability: a critical introductory treatment, Wiley New York.

DIMAGGIO, C. 2015. Small-area spatiotemporal analysis of pedestrian and bicyclist injuries in new york city. Epidemiology, 26, 247-254.

DORMANN, C. F., ELITH, J., BACHER, S., BUCHMANN, C., CARL, G., CARRÉ, G., MARQUÉZ, J. R. G., GRUBER, B., LAFOURCADE, B. \& LEITÃO, P. J. 
2013. Collinearity: a review of methods to deal with it and a simulation study evaluating their performance. Ecography, 36, 27-46. DOSWALD, N., ZIMMERMANN, F. \& BREITENMOSER, U. 2007. Testing expert groups for a habitat suitability model for the Iynx Lynx Iynx in the Swiss Alps. Wildlife Biology, 13, 430-446.

DOUGLAS-HAMILTON, I. Overview of status and trends of the African elephant. The ivory trade and the future of the African elephant: Prepared for the Seventh CITES Conference of the Parties, Lausanne, 1989. 1-36.

DOUGLAS-HAMILTON, I. 2009. The current elephant poaching trend. Pachyderm, 45, 154-157.

DWASS, M. 1957. Modified randomization tests for nonparametric hypotheses. The Annals of Mathematical Statistics, 28, 181-187.

EINHORN, H. J., HOGARTH, R. M. \& KLEMPNER, E. 1977. Quality of group judgment. Psychological Bulletin, 84, 158.

ELLIOT, P., WAKEFIELD, J. C., BEST, N. G. \& BRIGGS, D. 2000. Spatial epidemiology: methods and applications, Oxford University Press.

ESRI, R. 2011. ArcGIS desktop: release 10. Environmental Systems Research Institute, $C A$.

FISCHER, J. \& LINDENMAYER, D. B. 2007. Landscape modification and habitat fragmentation: a synthesis. Global ecology and biogeography, $16,265-280$.

GELMAN, A., CARLIN, J. B., STERN, H. S. \& RUBIN, D. B. 2014. Bayesian data analysis, Taylor \& Francis.

GELMAN, A. \& PRICE, P. N. 1999. All maps of parameter estimates are misleading. Statistics in medicine, 18, 3221-3234.

GHOLAMI, S. 2018. Spatio-temporal Model for Wildlife Poaching Prediction Evaluated through a Controlled Field Test in Uganda.

HAINES, A. M., ELLEDGE, D., WILSING, L. K., GRABE, M., BARSKE, M. D., BURKE, N. \& WEBB, S. L. 2012. Spatially explicit analysis of poaching activity as a conservation management tool. Wildlife Society Bulletin, 36, 685-692.

HAINING, R. \& LAW, J. 2007. Combining police perceptions with police records of serious crime areas: a modelling approach. Journal of the Royal Statistical Society: Series A (Statistics in Society), 170, 10191034.

HAINING, R., LAW, J. \& GRIFFITH, D. 2009. Modelling small area counts in the presence of overdispersion and spatial autocorrelation. Computational Statistics \& Data Analysis, 53, 2923-2937.

HANSON, C. E. \& WIECZOREK, W. F. 2002. Alcohol mortality: a comparison of spatial clustering methods. Social Science \& Medicine, 55, 791802.

HASSAN, A. A. \& BAQER, A.-R. 2016. Protecting Elephants from Poaching: Case Study of the Application of GIS for Elephants Conservation in 
Amboseli National Park in Kenya. World Academy of Science, Engineering and Technology, International Journal of Environmental, Chemical, Ecological, Geological and Geophysical Engineering, 9, 1424-1430.

HERRMANN, C. R. 2015. The dynamics of robbery and violence hot spots. Crime Science, 4, 1-14.

JIANMEI, Z. 2014. Rural income diversification patterns and their determinants in China. Agricultural Economics (Zemedeyská Ekonomika), 60, 219-231.

KEANE, A., JONES, J. P. \& MILNER-GULLAND, E. 2011. Encounter data in resource management and ecology: pitfalls and possibilities. Journal of Applied Ecology, 48, 1164-1173.

KÉRY, M. 2010. Introduction to WinBUGS for ecologists. Academic, Burlington.

KIDEGHESHO, J. R. 2016. The Elephant poaching crisis in Tanzania: a need to reverse the trend and the way forward. SAGE Publications Sage CA: Los Angeles, CA.

KIM, S.-Y. 2011. Bayesian Model for Cost Estimation of Construction Projects. Journal of the Korea Institute of Building Construction, 11, 91-99.

KING, R., MORGAN, B., GIMENEZ, O. \& BROOKS, S. 2009. Bayesian analysis for population ecology, CRC Press.

KUHNERT, P. M. 2011. Four case studies in using expert opinion to inform priors. Environmetrics, 22, 662-674.

KUHNERT, P. M., MARTIN, T. G. \& GRIFFITHS, S. P. 2010. A guide to eliciting and using expert knowledge in Bayesian ecological models. Ecology Letters, 13, 900-914.

KUHNERT, P. M., MARTIN, T. G., MENGERSEN, K. \& POSSINGHAM, H. P. 2005. Assessing the impacts of grazing levels on bird density in woodland habitat: a Bayesian approach using expert opinion. Environmetrics, 16, 717-747.

KULLDORFF, M. 2006. Satscan user guide for version 7.0. Available: http://www.satscan.org.

KULLDORFF, M. 2011. SaTScan user guide for version 9.0. Available: http://www.satscan.org.

KULLDORFF, M., HEFFERNAN, R., HARTMAN, J., ASSUNCAO, R. \& MOSTASHARI, F. 2005. A space-time permutation scan statistic for disease outbreak detection. PLoS medicine, 2, e59.

KULLDORFF, M., TANGO, T. \& PARK, P. J. 2003. Power comparisons for disease clustering tests. Computational Statistics \& Data Analysis, 42, 665-684.

KYALE, D. M., NGENE, S. \& MAINGI, J. 2011a. Biophysical and human factors determine the distribution of poached elephants in Tsavo East National Park, Kenya. Pachyderm, 48-60. 
KYALE, D. M., NGENE, S. \& MAINGI, J. 2011b. Biophysical and human factors determine the distribution of poached elephants in Tsavo East National Park, Kenya. Pachyderm, 49, 48-60.

KYANDO, M., IKANDA, D. \& RØSKAFT, E. 2017. Hotspot elephant-poaching areas in the Eastern Selous Game Reserve, Tanzania. African Journal of Ecology.

KYANDO, M. T. 2014. The Assessment of elephant poaching in the population of the Selous Game Reserve, Tanzania. Institutt for biologi.

LAW, J. \& CHAN, P. W. 2012. Bayesian Spatial Random Effect Modelling for Analysing Burglary Risks Controlling for Offender, Socioeconomic, and Unknown Risk Factors. Applied Spatial Analysis and Policy, 5, 73-96.

LAW, J. \& HAINING, R. 2004. A Bayesian Approach to Modeling Binary Data: The Case of High-Intensity Crime Areas. Geographical Analysis, 36, 197-216.

LAW, J., HAINING, R., MAHESWARAN, R. \& PEARSON, T. 2006. Analyzing the relationship between smoking and coronary heart disease at the small area level: a Bayesian approach to spatial modeling. Geographical Analysis, 38, 140-159.

LAW, J. \& QUICK, M. 2013. Exploring links between juvenile offenders and social disorganization at a large map scale: a Bayesian spatial modeling approach. Journal of Geographical Systems, 15, 89-113.

LAW, J., QUICK, M. \& CHAN, P. 2014. Bayesian spatio-temporal modeling for analysing local patterns of crime over time at the small-area level. Journal of quantitative criminology, 30, 57-78.

LAW, J., QUICK, M. \& CHAN, P. W. 2015. Analyzing hotspots of crime using a Bayesian spatiotemporal modeling approach: a case study of violent crime in the Greater Toronto Area. Geographical Analysis, 47, 1-19.

LEUTHOLD, B. M. \& LEUTHOLD, W. 1978. Ecology of the giraffe in Tsavo East National Park, Kenya. African Journal of Ecology, 16, 1-20.

LI, G., HAINING, R., RICHARDSON, S. \& BEST, N. 2014. Space-time variability in burglary risk: a Bayesian spatio-temporal modelling approach. Spatial Statistics, 9, 180-191.

LINDSEY, P., BALME, G., BECKER, M., BEGG, C., BENTO, C., BOCCHINO, C., DICKMAN, A., DIGGLE, R., EVES, H. \& HENSCHEL, P. 2012. Illegal hunting and the bush-meat trade in savanna Africa: drivers, impacts and solutions to address the problem. Panthera/Zoological Society of London. Wildlife Conservation Society report, New York, 74.

LITOROH, M., OMONDI, P., KOCK, R. \& AMIN, R. 2012. Conservation and Management Strategy for the Elephant in Kenya. Kenya Wildlife Service, Nairobi.

LIU, Y., WANG, X., LIU, Y., SUN, D., DING, S., ZHANG, B., DU, Z. \& XUE, F. 2013. Detecting Spatial-temporal clusters of HFMD from 2007 to 2011 in Shandong province, China. PloS one, 8, e63447. 
LUAN, H., LAW, J. \& QUICK, M. 2015. Identifying food deserts and swamps based on relative healthy food access: a spatio-temporal Bayesian approach. International journal of health geographics, 14, 1.

MACNAB, Y. C. 2004. Bayesian spatial and ecological models for small-area accident and injury analysis. Accident Analysis \& Prevention, 36, 1019-1028.

MADHUSUDAN, M. \& KARANTH, K. U. 2002. Local hunting and the conservation of large mammals in India. AMBIO: A Journal of the Human Environment, 31, 49-54.

MAINGI, J. K., MUKEKA, J. M., KYALE, D. M. \& MUASYA, R. M. 2012. Spatiotemporal patterns of elephant poaching in south-eastern Kenya. Wildlife Research, 39, 234-249.

MAISELS, F., STRINDBERG, S., BLAKE, S., WITTEMYER, G., HART, J., WILLIAMSON, E. A., ABA'A, R., ABITSI, G., AMBAHE, R. D. \& AMSINI, F. 2013. Devastating decline of forest elephants in Central Africa. PloS one, 8, e59469.

MARTIN, T. G., BURGMAN, M. A., FIDLER, F., KUHNERT, P. M., LOW-CHOY, S., MCBRIDE, M. \& MENGERSEN, K. 2012. Eliciting expert knowledge in conservation science. Conservation Biology, 26, 29-38.

MARTIN, T. G., KUHNERT, P. M., MENGERSEN, K. \& POSSINGHAM, H. P. 2005. The power of expert opinion in ecological models using Bayesian methods: impact of grazing on birds. Ecological Applications, 15, 266-280.

MCCARTHY, M. A. 2007. Bayesian methods for ecology, Cambridge University Press.

MCCULLAGH, P. \& NELDER, J. A. 1989. Generalized linear models, CRC press.

MENG, C. Y. \& DEMPSTER, A. P. 1987. A Bayesian approach to the multiplicity problem for significance testing with binomial data. Biometrics, 301-311.

MENNIS, J. \& GUO, D. 2009. Spatial data mining and geographic knowledge discovery-An introduction. Computers, Environment and Urban Systems, 33, 403-408.

MURRAY, J. V., GOLDIZEN, A. W., O'LEARY, R. A., MCALPINE, C. A., POSSINGHAM, H. P. \& CHOY, S. L. 2009. How useful is expert opinion for predicting the distribution of a species within and beyond the region of expertise? A case study using brush-tailed rock-wallabies Petrogale penicillata. Journal of Applied Ecology, 46, 842-851.

NAIMI, B. 2013. Uncertainty analysis for species distribution models [Online]. Available: http://usdm.r-forge.r-project.org/, http://r-gis.net.

NGENE, S., NJUMBI, S., NZISA, M., KIMITEI, K., MUKEKA, J., MUYA, S., IHWAGI, F. \& OMONDI, P. 2013. Status and trends of the elephant population in the Tsavo-Mkomazi ecosystem. S urvival, 37.

NGENE, S. M. 2010. Why elephant roam, University of Twente, Faculty of Geo-information Science and Earth Observation. 
NGENE, S. M. 2013. Status and trends of the elephant population in the Tsavo-Mkomazi ecosystem. Pachyderm, 38-50.

NIELSEN, S. E., HERRERO, S., BOYCE, M. S., MACE, R. D., BENN, B., GIBEAU, M. L. \& JEVONS, S. 2004. Modelling the spatial distribution of human-caused grizzly bear mortalities in the Central Rockies ecosystem of Canada. Biological Conservation, 120, 101-113.

NTZOUFRAS, I. 2011. Bayesian modeling using WinBUGS, John Wiley \& Sons. NYIRENDA, V. R., LINDSEY, P. A., PHIRI, E., STEVENSON, I., CHOMBA, C., NAMUKONDE, N., MYBURGH, W. J. \& REILLY, B. K. 2015. Trends in Illegal Killing of African Elephants (Loxodonta africana) in the Luangwa and Zambezi Ecosystems of Zambia. Environment and Natural Resources Research, 5, 24.

OMONDI, P. \& NGENE, S. The National Elephant Conservation and Management Strategy (2012-2021) at a Glance. The George Wright Forum, 2012a. George Wright Society, 90.

OMONDI, P. \& NGENE, S. The National Elephant Conservation and Management Strategy (2012-2021) at a Glance. The George Wright Forum, 2012b. JSTOR, 90-92.

ONYANGO, P. O. \& LESOWAPIR, B. 2016. Demography of a population with a long history of poaching and the utility of the individual identification technique as a tool for monitoring intermittently studied elephant populations. African journal of ecology, 54, 357-364.

OSBORNE, H. 2000. The seasonality of nineteenth-century poaching. The Agricultural History Review, 27-41.

OUKO, E. 2013. Where, when, and why are there elephant poaching hotspots in Kenya. Thesis, University of Twente.

PITTIGLIO, C. 2012. Human-wildlife interface in African Savanna: quantifying landscape fragmentation for predicting wildlife distribution and human-wildlife conflicts.

PORTER, M. D. \& BROWN, D. E. 2007. Detecting local regions of change in high-dimensional criminal or terrorist point processes. Computational statistics \& data analysis, 51, 2753-2768.

PRESS, S. J. 2009. Subjective and objective Bayesian statistics: principles, models, and applications, John Wiley \& Sons.

QUICK, M. \& LAW, J. 2013. Exploring Hotspots of Drug Offences in Toronto: A Comparison of Four Local Spatial Cluster Detection Methods 1. Canadian Journal of Criminology and Criminal Justice/La Revue canadienne de criminologie et de justice pénale, 55, 215-238.

RASHIDI, P., SKIDMORE, A., WANG, T., DARVISHZADEH, R., NGENE, S. \& VRIELING, A. 2017. Assessing trends and seasonal changes in elephant poaching risk at the small area level using spatio-temporal Bayesian modeling. International journal of geographical information science, 1-15. 
RASHIDI, P., WANG, T., SKIDMORE, A., MEHDIPOOR, H., DARVISHZADEH, R., NGENE, S., VRIELING, A. \& TOXOPEUS, A. G. 2016. Elephant poaching risk assessed using spatial and non-spatial Bayesian models. Ecological Modelling, 338, 60-68.

RASHIDI, P., WANG, T., SKIDMORE, A., VRIELING, A., DARVISHZADEH, R., TOXOPEUS, B., NGENE, S. \& OMONDI, P. 2015. Spatial and spatiotemporal clustering methods for detecting elephant poaching hotspots. Ecological Modelling, 297, 180-186.

RESTREPO, A. C., BAKER, P. \& CLEMENTS, A. C. 2014. National spatial and temporal patterns of notified dengue cases, Colombia 2007-2010. Tropical Medicine \& International Health, 19, 863-871.

REUTTER, B. A., HELFER, V., HIRZEL, A. \& VOGEL, P. 2003. Modelling habitat-suitability using museum collections: an example with three sympatric Apodemus species from the Alps. Journal of Biogeography, 30, 581-590.

RICHARDSON, S., ABELLAN, J. J. \& BEST, N. 2006. Bayesian spatio-temporal analysis of joint patterns of male and female lung cancer risks in Yorkshire (UK). Statistical methods in medical research, 15, 385-407.

RUTLEDGE, D. T., LEPCZYK, C. A., XIE, J. \& LIU, J. 2001. Spatiotemporal dynamics of endangered species hotspots in the United States. Conservation Biology, 15, 475-487.

SÁNCHEZ-MERCADO, A., FERRER-PARIS, J. R., YERENA, E., GARCÍA-RANGEL, S. \& RODRÍGUEZ-CLARK, K. M. 2008. Factors affecting poaching risk to vulnerable Andean bears Tremarctos ornatus in the Cordillera de Merida, Venezuela: space, parks and people. Oryx, 42, 437-447.

SCHOOT, R., KAPLAN, D., DENISSEN, J., ASENDORPF, J. B., NEYER, F. J. \& AKEN, M. A. 2014. A gentle introduction to Bayesian analysis: applications to developmental research. Child development, 85, 842860.

SHAFFER, M. J. \& BISHOP, J. A. 2016. Predicting and Preventing Elephant Poaching Incidents through Statistical Analysis, GIS-Based Risk Analysis, and Aerial Surveillance Flight Path Modeling. Tropical Conservation Science, 9, 525-548.

SHARMA, K., WRIGHT, B., JOSEPH, T. \& DESAI, N. 2014. Tiger poaching and trafficking in India: Estimating rates of occurrence and detection over four decades. Biological Conservation, 179, 33-39.

SI, Y., SKIDMORE, A. K., WANG, T., DE BOER, W. F., DEBBA, P., TOXOPEUS, A. G., LI, L. \& PRINS, H. H. 2009. Spatio-temporal dynamics of global H5N1 outbreaks match bird migration patterns. Geospatial Health, 4, 65-78.

SIBANDA, M., DUBE, T., BANGAMWABO, V. M., MUTANGA, O., SHOKO, C. \& GUMINDOGA, W. 2016. Understanding the spatial distribution of elephant (Loxodonta africana) poaching incidences in the mid- 
Zambezi Valley, Zimbabwe using Geographic Information Systems and remote sensing. Geocarto International, 31, 1006-1018.

SKIDMORE, A. K. 1989. An expert system classifies eucalypt forest types using thematic mapper data ans a digital terrain model. Photogrammetric Engineering and Remote Sensing, 55, 1449-1464.

SMITH, R. J. \& KASIKI, S. 2000. A spatial analysis of human-elephant conflict in the Tsavo ecosystem, Kenya. IUCN/Species Survival Commission African Elephant Specialist Group, Human-Elephant Conflict Task Force, Gland, Switzerland.

SPIEGELHALTER, D. J., BEST, N. G., CARLIN, B. P. \& VAN DER LINDE, A. 2002. Bayesian measures of model complexity and fit. Journal of the Royal Statistical Society: Series B (Statistical Methodology), 64, 583639.

SPINAGE, C. A. 1973. A review of ivory exploitation and elephant population trends in Africa. African Journal of Ecology, 11, 281-289.

STIGLER, S. M. 1986. Laplace's 1774 memoir on inverse probability. Statistical Science, 359-363.

SUN, D., TSUTAKAWA, R. K., KIM, H. \& HE, Z. 2000. Spatio-temporal interaction with disease mapping. Statistics in medicine, 19, 20152035.

TAKAHASHI, K., YOKOYAMA, T. \& TANGO, T. 2005. FleXScan user guide for version 3.1.2. Available: http://www.niph.go.jp/soshiki/gijutsu/download/flexscan/.

TANGO, T. 2010. Statistical methods for disease clustering, Springer.

TANGO, T. \& TAKAHASHI, K. 2005. A flexibly shaped spatial scan statistic for detecting clusters. International journal of health geographics, 4, 11.

TANGO, T. \& TAKAHASHI, K. 2012. A flexible spatial scan statistic with a restricted likelihood ratio for detecting disease clusters. Statistics in Medicine, 31, 4207-4218.

THOGMARTIN, W. E., SAUER, J. R. \& KNUTSON, M. G. 2004. A hierarchical spatial model of avian abundance with application to Cerulean Warblers. Ecological Applications, 14, 1766-1779.

TORABI, M. \& ROSYCHUK, R. 2011. An examination of five spatial disease clustering methodologies for the identification of childhood cancer clusters in Alberta, Canada. Spatial and Spatio-temporal Epidemiology, 2, 321-330.

TORABI, M. \& ROSYCHUK, R. J. 2012. Hierarchical Bayesian spatiotemporal analysis of childhood cancer trends. Geographical Analysis, 44, 109120.

TYRRELL, J. \& COE, M. 1974. The rainfall regime of Tsavo National Park, Kenya and its potential phenological significance. Journal of Biogeography, 187-192.

VIRA, V., EWING, T. \& MILLER, J. 2014. Out of Africa: mapping the global trade in illicit elephant ivory. Available at media1. s-nbcnews. 
com/i/MSNBC/Sections/NEWS/OutofAfrica_Report. pdf. Accessed January, 11, 2015.

WANG, L.-Y., ZHANG, W.-Y., DING, F., HU, W.-B., MAGALHAES, R. J. S., SUN, H.-L., LI, Y.-X., ZOU, W., WANG, Y. \& LIU, Q.-Y. 2013. Spatiotemporal Patterns of Japanese Encephalitis in China, 20022010. PLoS neglected tropical diseases, 7, e2285.

WASSER, S., BROWN, L., MAILAND, C., MONDOL, S., CLARK, W., LAURIE, C. \& WEIR, B. S. 2015. Genetic assignment of large seizures of elephant ivory reveals Africa's major poaching hotspots. Science, 349, 84-87.

WHITE, N. 2013. The" White Gold of Jihad": violence, legitimisation and contestation in anti-poaching strategies. New York Times, 30, 09.

WITTEMYER, G., NORTHRUP, J. M., BLANC, J., DOUGLAS-HAMILTON, I., OMONDI, P. \& BURNHAM, K. P. 2014. Illegal killing for ivory drives global decline in African elephants. Proceedings of the National Academy of Sciences, 111, 13117-13121.

WU, W., GUO, J., GUAN, P., SUN, Y. \& ZHOU, B. 2011. Clusters of spatial, temporal, and space-time distribution of hemorrhagic fever with renal syndrome in Liaoning Province, Northeastern China. BMC infectious diseases, 11, 229.

$X U, B .2008$. Spatial and temporal analysis of hemorrhagic disease in whitetailed deer in Southeast USA. PhD thesis, University of Georgia, Athens.

YUAN, Y. Computing direct and indirect standardized rates and risks with the STDRATE procedure. Proceedings of the SAS Global Forum 2013 Conference, Cary, NC: SAS Institute Inc. Available at http:/support. sas. com/resources/papers/proceedings11/423-2013. pdf, 2013. Citeseer.

ZAFRA-CALVO, N., LOBO, J., PRADA, C., NIELSEN, M. R. \& BURGESS, N. D. 2018. Predictors of elephant poaching in a wildlife crime hotspot: The Ruvuma landscape of southern Tanzania and northern Mozambique. Journal for Nature Conservation, 41, 79-87. 


\section{Summary}

Poaching of elephants is an increasingly rampant problem both in Kenya and across Africa. It is a key driver of elephant population decline in certain regions of Africa. Quantifying spatial and temporal dynamics of elephant poaching risk at different scales provides the information needed for setting conservation priorities as well as for concentrating management resources where they are most needed. However, few studies exist that are aimed at quantifying the spatial and spatiotemporal patterns linked to the criminal act of wildlife poaching. Obtaining an absolute measure of poaching levels based on direct observation is practically impossible due to the covert nature of poaching. Detailed data are scarce, and many poaching reports are collected incidentally and may be only indirectly obtained. Such reports may be challenging to analyze because of the absence of sampling design and uncertainty concerning locations. It is therefore important to apply methods that can overcome the scarce data problem, which emerges when unstable estimations occur due to low counts of incidents and high sampling variation.

Using different spatial and spatio-temporal modelling methods, with the ability to estimate poaching risk in areas with zero counts by borrowing information from neighboring areas and experts, we investigated how elephant poaching risk may change at different locations, times or for combinations of space and time at a local and national level, and we tried to identify key factors influencing elephant poaching risk. Applying this kind of modelling, which provides a flexible framework for borrowing information over space and time from adjacent areas by using spatial and temporal random effects, provides an effective way to form estimates for poorly sampled areas.

Poaching data were obtained from the Kenya Wildlife Service's database on elephant mortality. Based on the literature and prior scoping discussion, we selected the potential risk factors associated with poaching. Thirty experts from the Kenya Wildlife Service were interviewed regarding elephant and poaching These factors included: (1) distance to roads, (2) distance to settlements, (3) distance to rivers and streams, (4) density of waterholes, (5) elevation, (6) slope, (7) mean normalized difference vegetation index (NDVI), (8) standard deviation of NDVI, (9) elephant population density, (10) livestock density, (11) distance to international border, and (12) seasonal timing of elephant poaching (i.e., poaching probabilities in the dry and wet seasons).

Our results indicate that although hotspot predictions varied for the different methods, some areas were consistently identified as encompassing poaching hotspots. Moreover, our analysis at national level shows that high poaching risk areas in Kenya have varied annually, shifting from the south-east to the west between 2002 and 2012. They are shifting from areas with high 
recorded elephant poaching incidents to areas where minimal poaching incidents have been historically reported. The results also demonstrate that the Tsavo ecosystem is the main persistently high-risk area at national level in Kenya between 2002 and 2012. It was also found that the mean trend in elephant poaching is increasing in the Tsavo ecosystem over time. The results further showed that two blocks, located in the Tsavo west national park and the Taita ranches, have been consistently identified as poaching hotspots irrespective of the model used. Furthermore, our results indicate that areas with the highest poaching risk differ between dry and wet seasons.

In addition, the results revealed that adding risk factors enhances the model fit for assessing poaching risk. Furthermore, results obtained from the poaching risk factor analysis indicated that similarities occurred between risk factors detected at the local and national level, but also that some differences emerged. For example, the seasonal timing of elephant poaching, density of waterholes, distance to a road, and distance to an international border are all key factors persistently influencing elephant poaching risk at local and national level in Kenya. Distance to an international border seems to have the greatest influence on elephant poaching at the local level, while the distance to a road is most influential at the national level, with a variation greater than other risk factors. Moreover, it was found that distance to settlements was significantly identified as a key factor that influences the spatial patterns of elephant poaching risk at the national level while was not significant at the local level. On the other hand, livestock density was a significant predictor, which significantly influenced the spatial variation in trends regarding elephant poaching risk over time at a local level but was not significant at the national level.

These findings can be used to guide the deployment of policing resources in areas with relatively increasing poaching trends, or to improve or alter management actions. The Kenyan Wildlife Service (KWS) should continue to carry out frequent surveillance and intensify patrolling within and around the detected elephant poaching hotspots especially targeting the areas which exist along international borders and areas with human settlements in and around them. The findings could also be incorporated in future national and regional management programs to further -reduce the poaching of elephants. 


\section{Samenvatting}

Het stropen van olifanten is een steeds groter wordend probleem, zowel in Kenia als in heel Afrika. Stroperij is een belangrijke oorzaak van de achteruitgang van de olifantenpopulatie in bepaalde regio's van Afrika. Het kwantificeren van de ruimtelijke en temporele dynamiek van het risico van olifantstroperij op verschillende schaalniveaus biedt de informatie die nodig is voor het in stand houden van de diersoort, alsmede voor het bepalen van hulp op het gebied van management waar deze het meest nodig zijn. Er bestaan echter weinig studies die zijn gericht op het kwantificeren van de ruimtelijke en ruimte-temporele patronen die verband houden met de criminele daad van het stropen van wilde dieren. Het verkrijgen van een absolute maat voor het niveau van stroperij op basis van directe waarneming is praktisch onmogelijk vanwege de verborgen aard van stroperij. Gedetailleerde gegevens zijn schaars en veel stroperij rapportages worden incidenteel verzameld en kunnen alleen indirect worden verkregen. Dergelijke rapporten kunnen een uitdaging zijn om te analyseren vanwege de afwezigheid van een steekproef basis alsmede de onzekerheid over locaties. Het is daarom belangrijk om methoden toe te passen die het schaarse gegevensprobleem kunnen oplossen, vooral wanneer onstabiele schattingen worden gedaan als gevolg van de lage aantallen incidenten tegenover de hoge variatie van het aantal genomen monsters.

Onderzocht is, hoe het risico van olifanten stroperij kan veranderen op verschillende locaties, tijden of een combinatie hiervan op beide nationaal en lokaal niveau. Hiervoor werden verschillende ruimtelijke en ruimte-temporele modellerings-methoden gebruikt, met de mogelijkheid om stropersrisico's te schatten in gebieden met nul-tellingen door informatie te lenen van aangrenzende gebieden en experts. Daarnaast is er geprobeerd om de belangrijkste factoren te identificeren die van invloed zijn op het risico van olifanten stroperij. Het toepassen van deze type modellering, dat een flexibel raamwerk biedt met behulp van ruimtelijke en temporele willekeurige effecten, biedt een effectieve manier om schattingen te maken voor de slecht ingeschatte/gecontroleerde gebieden.

Stroperijgegevens werden verkregen uit de database van de Kenya Wildlife Service over olifanten sterfte. Op basis van de literatuur en een eerdere verkennende discussie zijn potentiële risicofactoren voor stroperij geselecteerd op basis van discussies met experts en eerder onderzoek. Dertig deskundigen van de Kenya Wildlife Service werden geïnterviewd over olifanten en stroperijen. Deze factoren omvatten: (1) afstand tot wegen, (2) afstand tot nederzettingen, (3) afstand tot rivieren en beken, (4) dichtheid van waterpoelen, (5) hoogte, (6) helling, (7) gemiddelde genormaliseerde verschil-vegetatie-index (NDVI), (8) standaardafwijking van NDVI, (9) olifant populatiedichtheid, (10) veebezetting, (11) afstand tot internationale grens, 
en (12) seizoensgebonden timing van olifantstroperij (dwz stroperskansen in de droge- en natte seizoenen).

Onze resultaten geven aan dat, hoewel hot spot voorspellingen variëerden voor de verschillende methoden, sommige gebieden consequent werden geïdentificeerd als omvattende stropers hot spots. Bovendien laat onze analyse op nationaal niveau zien dat streken met hoge stropersrisico's in Kenia jaarlijks variëren, en verschuiven van het zuid-oosten naar het westen tussen 2002 en 2012. Ze verplaatsen zich van gebieden met hoge geregistreerde olifanten stroperij incidenten naar gebieden waar historisch gezien minimale stroperij incidenten zijn gerapporteerd. De resultaten tonen ook aan dat het Tsavo-ecosysteem tussen 2002 en 2012 het belangrijkste persistente hoog-risicogebied op nationaal niveau in Kenia is. Ook werd vastgesteld dat de gemiddelde trend in olifantstroperij in de loop van de tijd toeneemt in het Tsavo-ecosysteem. De resultaten toonden verder aan dat twee gebieden, gelegen in het Tsavo West National Park en de Taita Ranches, consequent zijn geïdentificeerd als stropers hotspots, ongeacht het model dat gebruikt werdt. Bovendien geven onze resultaten aan dat gebieden met het hoogste stroperij risico verschillen tussen droge en natte seizoenen.

Bovendien toonden de resultaten aan dat het toevoegen van risicofactoren het model, dat geschikt is voor het beoordelen van het risico op stroperij, verbetert. Bovendien gaven de resultaten van de risicofactor-analyse aan dat er overeenkomsten waren tussen op lokaal en nationaal niveau gedetecteerde risicofactoren, maar ook dat er enkele verschillen naar voren kwamen. Bijvoorbeeld, de seizoensgebonden timing van de olifanten stroperij, veelvuldigheid van water bronnen, afstand tot een weg en afstand tot een internationale grens zijn allemaal belangrijke factoren die het risico van stroperij op lokaal en nationaal niveau in Kenia blijven beïnvloeden.

De factor van de afstand tot een internationale grens lijkt de grootste invloed te hebben op het stropen van olifanten op lokaal niveau, terwijl de afstand tot een weg het meest invloedrijke is op nationaal niveau, met een grotere variatie dan andere risicofactoren. Bovendien werd vastgesteld dat afstand tot nederzettingen significant werd geïdentificeerd als een sleutelfactor die de ruimtelijke patronen van het risico van olifantstroperij op nationaal niveau beïnvloedt, terwijl deze op lokaal niveau niet significant was. Anderzijds was de veebezetting een significante voorspeller, die de ruimtelijke variatie in trends ten aanzien van het risico van olifantenstroperij, over een bepaalde tijd, op lokaal niveau significant beïnvloedde, maar op nationaal niveau niet significant was.

Deze bevindingen kunnen worden gebruikt als een richtlijn voor de inzet van politiemiddelen in gebieden met relatief toenemende stroperij, of om managementacties te verbeteren of te wijzigen. De Keniaanse Wildlife Service (KWS) moet frequente bewaking blijven uitvoeren en de patrouilles in 
en om de gedetecteerde olifantstrop hotspots intensiveren, met name gericht op de gebieden langs internationale grenzen en gebieden met menselijke nederzettingen in en rondom hen. De bevindingen kunnen ook worden opgenomen in toekomstige nationale en regionale beheersprogramma's om het stropen van olifanten verder te verminderen. 
Appendix Table A1: VIFs of the remaining variables after excluding the collinear variables

\begin{tabular}{lc}
\hline Explanatory variables & VIF \\
\hline Distance to road & 1.087 \\
Waterhole density & 1.388 \\
Distance to river & 1.607 \\
Probability of Elephant poaching in wet season & 1.307 \\
Probability of Elephant poaching in dry season & 1.309 \\
Standard deviation of NDVI & 1.316 \\
Elephant population density & 1.277 \\
Distance to international border & 1.566 \\
Livestock density & 1.733 \\
\hline
\end{tabular}


Appendix Table A2: Descriptive statistics for elephant poaching incidents between 2002 and 2012 within the defined blocks in the Greater Tsavo ecosystem.

\begin{tabular}{|c|c|c|c|c|}
\hline Blocks & Mean & $\mathrm{Sd}$ & Max & Min \\
\hline 1 & 1.09 & 2.9 & 10 & 0 \\
\hline 2 & 1.27 & 2.7 & 8 & 0 \\
\hline 3 & 1.90 & 3.20 & 8 & 0 \\
\hline 4 & 4.09 & 7.15 & 24 & 0 \\
\hline 5 & 0.63 & 2.01 & 7 & 0 \\
\hline 6 & 6.63 & 11.09 & 35 & 0 \\
\hline 7 & 2.18 & 4.70 & 14 & 0 \\
\hline 8 & 3.72 & 6.68 & 20 & 0 \\
\hline 9 & 3 & 5.02 & 14 & 0 \\
\hline 10 & 8.06 & 20.11 & 70 & 0 \\
\hline 11 & 4.09 & 7.03 & 21 & 0 \\
\hline 12 & 11.45 & 17.39 & 45 & 0 \\
\hline 13 & 14.54 & 26.51 & 84 & 0 \\
\hline 14 & 2 & 4.74 & 16 & 0 \\
\hline 15 & 1.18 & 2.51 & 7 & 0 \\
\hline 16 & 0.54 & 1.72 & 6 & 0 \\
\hline 17 & 1.45 & 4.59 & 16 & 0 \\
\hline 18 & 0.81 & 2.58 & 9 & 0 \\
\hline 19 & 1.09 & 3.44 & 12 & 0 \\
\hline 20 & 0.18 & 0.57 & 2 & 0 \\
\hline 21 & 2 & 3.33 & 9 & 0 \\
\hline 22 & 2.90 & 5.66 & 19 & 0 \\
\hline 23 & 0 & 0 & 0 & 0 \\
\hline 24 & 3.90 & 9.42 & 32 & 0 \\
\hline 25 & 0 & 0 & 0 & 0 \\
\hline 26 & 0 & 0 & 0 & 0 \\
\hline 27 & 1.09 & 3.44 & 12 & 0 \\
\hline 28 & 0 & 0 & 0 & 0 \\
\hline 29 & 0 & 0 & 0 & 0 \\
\hline 30 & 3.09 & 6.21 & 21 & 0 \\
\hline 31 & 0.81 & 2.58 & 9 & 0 \\
\hline 32 & 1.63 & 3.49 & 10 & 0 \\
\hline 36 & 0 & 0 & 0 & 0 \\
\hline 37 & 3.45 & 6.28 & 19 & 0 \\
\hline
\end{tabular}


Appendix Table A3: Descriptive statistics for elephant poaching incidents in in the dry seasons between 2002 and 2012 within the defined blocks in the Greater Tsavo ecosystem.

\begin{tabular}{|c|c|c|c|c|}
\hline Blocks & Mean & $\mathrm{Sd}$ & Max & Min \\
\hline 1 & 0.18 & 0.38 & 1 & 0 \\
\hline 2 & 0.18 & 0.38 & 1 & 0 \\
\hline 3 & 0.18 & 0.38 & 1 & 0 \\
\hline 4 & 0.27 & 0.44 & 1 & 0 \\
\hline 5 & 0.09 & 0.28 & 1 & 0 \\
\hline 6 & 0.81 & 1.33 & 4 & 0 \\
\hline 7 & 0.18 & 0.57 & 2 & 0 \\
\hline 8 & 0.81 & 1.74 & 6 & 0 \\
\hline 9 & 0.36 & 0.64 & 2 & 0 \\
\hline 10 & 1 & 1.9 & 5 & 0 \\
\hline 11 & 0.36 & 0.88 & 3 & 0 \\
\hline 12 & 1.09 & 1.92 & 6 & 0 \\
\hline 13 & 1.18 & 2.28 & 6 & 0 \\
\hline 14 & 0.36 & 0.64 & 2 & 0 \\
\hline 15 & 0.18 & 0.38 & 1 & 0 \\
\hline 16 & 0.09 & 0.28 & 1 & 0 \\
\hline 17 & 0.27 & 0.61 & 2 & 0 \\
\hline 18 & 0 & 0 & 0 & 0 \\
\hline 19 & 0 & 0 & 0 & 0 \\
\hline 20 & 0 & 0 & 0 & 0 \\
\hline 21 & 0.36 & 0.48 & 1 & 0 \\
\hline 22 & 0.45 & 0.89 & 3 & 0 \\
\hline 23 & 0 & 0 & 0 & 0 \\
\hline 24 & 0.36 & 1.14 & 4 & 0 \\
\hline 25 & 0 & 0 & 0 & 0 \\
\hline 26 & 0 & 0 & 0 & 0 \\
\hline 27 & 0.18 & 0.57 & 2 & 0 \\
\hline 28 & 0 & 0 & 0 & 0 \\
\hline 29 & 0 & 0 & 0 & 0 \\
\hline 30 & 0.36 & 0.64 & 2 & 0 \\
\hline 31 & 0.09 & 0.28 & 1 & 0 \\
\hline 32 & 0.18 & 0.38 & 1 & 0 \\
\hline 36 & 0 & 0 & 0 & 0 \\
\hline 37 & 0.45 & 0.78 & 2 & 0 \\
\hline
\end{tabular}


Appendix Table A4: Descriptive statistics for elephant poaching incidents in the wet seasons between 2002 and 2012 within the defined blocks in the Greater Tsavo

\begin{tabular}{|c|c|c|c|c|}
\hline Blocks & Mean & $\mathrm{Sd}$ & Max & Min \\
\hline 1 & 0 & 0 & 0 & 0 \\
\hline 2 & 0 & 0 & 0 & 0 \\
\hline 3 & 0.09 & 0.28 & 1 & 0 \\
\hline 4 & 0.27 & 0.61 & 2 & 0 \\
\hline 5 & 0 & 0 & 0 & 0 \\
\hline 6 & 0.18 & 0.38 & 1 & 0 \\
\hline 7 & 0.18 & 0.57 & 2 & 0 \\
\hline 8 & 0 & 0 & 0 & 0 \\
\hline 9 & 0.09 & 0.28 & 1 & 0 \\
\hline 10 & 0.45 & 1.15 & 4 & 0 \\
\hline 11 & 0.09 & 0.28 & 1 & 0 \\
\hline 12 & 0.54 & 1.15 & 4 & 0 \\
\hline 13 & 1.18 & 1.64 & 4 & 0 \\
\hline 14 & 0 & 0 & 0 & 0 \\
\hline 15 & 0 & 0 & 0 & 0 \\
\hline 16 & 0 & 0 & 0 & 0 \\
\hline 17 & 0 & 0 & 0 & 0 \\
\hline 18 & 0 & 0 & 0 & 0 \\
\hline 19 & 0.09 & 0.28 & 1 & 0 \\
\hline 20 & 0 & 0 & 0 & 0 \\
\hline 21 & 0 & 0 & 0 & 0 \\
\hline 22 & 0 & 0 & 0 & 0 \\
\hline 23 & 0 & 0 & 0 & 0 \\
\hline 24 & 0.09 & 0.28 & 1 & 0 \\
\hline 25 & 0 & 0 & 0 & 0 \\
\hline 26 & 0 & 0 & 0 & 0 \\
\hline 27 & 0 & 0 & 0 & 0 \\
\hline 28 & 0 & 0 & 0 & 0 \\
\hline 29 & 0 & 0 & 0 & 0 \\
\hline 30 & 0.18 & 0.38 & 1 & 0 \\
\hline 31 & 0 & 0 & 0 & 0 \\
\hline 32 & 0 & 0 & 0 & 0 \\
\hline 36 & 0 & 0 & 0 & 0 \\
\hline 37 & 0.09 & 0.28 & 1 & 0 \\
\hline
\end{tabular}


Appendix Table A5: Posterior summaries for $B$ coefficients of the explanatory variables and precision of area-specific trends in spatio-temporal Bayesian modelling Explanatory variables mean B (credible interval: $2.5 \%$, $97.5 \%$

Probability of elephant poaching in $0.62(0.022,1.237)$

wet season

Probability of elephant poaching in

$0.55(-0.016,1.147)$

dry season

Livestock density

$1.07(0.246,2.211)$

Waterhole density

$0.77(0.054,1.288)$

Elephant population density

$0.92(-0.331,1.933)$

Distance to road

$0.55(0.004,1.144)$

Distance to rivers and streams

$0.61(-0.460,1.408)$

Standard deviation (STD) of NDVI

$1.04(-1.373,3.495)$

Distance to international border

$1.49(0.421,2.711)$

Prec delta: precision of area-specific trends 


\section{Appendix figure B1:}

model

for(j in 1:Time)

t[i] $<-$ j

$\mathrm{m} \_\mathrm{t}<-$ mean(t[1:Time])

for(i in $1: \mathrm{N})$

for(j in 1:Time)

O[i,j] dpois (lambda[i,j])

$\log (\operatorname{lambda}[i, j])<-$ logg.expec.e[i,j]

+ alpha $+s[i]+u[i]+$ beta $^{*}\left(t[i]-m \_t\right)+$ delta[]$^{*}\left(t[i]-m \_t\right)$

$\mathrm{u}[\mathrm{i}] \sim \operatorname{dnorm}(\mathrm{O}$, prec u $)$ hotspot[i] <- step(-delta[i])

$\mathrm{s}[1: \mathrm{N}] \sim$ car.normal(adj], weights[, num, prec.s)

delta[1:N] car.normal(adj], weights[, num[, prec.delta)

alpha $\sim$ dflat ()

beta $\sim$ dnorm $(0,0.001)$

prec.s $\sim$ dgamma $(0.5,0.0005)$

prec.u $\sim$ dgamma $(0.5,0.0005)$

prec.delta $\sim$ dgamma $(0.5,0.0005)$

for( $k$ in 1:sumNumNeigh)

weights $[k]<-1$

\}

WinBUGS code for Model 1.1 


\section{Biography}

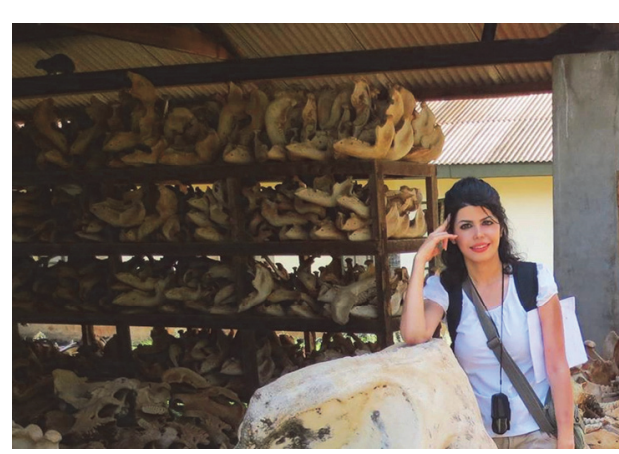

Parinaz Rashidi was born on 31th July 1982 in Iran. She studied natural resource engineering environment at the Gorgan University of Agricultural Science and Natural Resource, Iran, and received a B.Sc. in September 2006. She obtained her M.Sc. in the same field from the University of Tehran in February 2009. Her M.Sc. research focused on determining systematic selection of conservation patches in Golestan Province, Iran. After graduation she collaborated with Putra University, Malaysia, on a number of papers for two years. In 2012, she was awarded a European Commission Erasmus Mundus scholarship to pursue her doctoral research at the Faculty of Geo-information Science and Earth Observation (ITC) at the University of Twente, the Netherlands, resulting in the following publications and culminating in this thesis.

\section{Scientific publications:}

Rashidi, P., Wang, T.J., Skidmore, A.K., Vrieling, A., Darvishzadeh, R., Toxopeus, A.G., Ngene, S.M. and Omondi, P. (2015) Spatial and spatiotemporal clustering methods for detecting elephant poaching hotspots. In: Ecological modelling, 297, 180-186.

Rashidi, P., Wang, T.J., Skidmore, A.K., Mehdipoor. H., Darvishzadeh, R., Ngene, S.M., Vrieling, A., Toxopeus, A.G. (2016) Elephant poaching risk assessed using spatial and non-spatial Bayesian models. Ecological Modelling, 338, 60-68.

Rashidi, P., Skidmore, A., Wang, T., Darvishzadeh, R., Ngene, S., Vrieling, A., 2017. Assessing trends and seasonal changes in elephant poaching risk at the small area level using spatio-temporal Bayesian modelling. International journal of geographical information science, 1-15.

Rashidi, P., Wang, T.J., Skidmore, A.K., Darvishzadeh, R., Ngene, S.M (2018) Areas at high risk of elephant poaching shift from the south-east to the west of Kenya during 2002-2012. In review: AMBIO

\section{International conferences:}

Rashidi, P., Wang, T.J., Skidmore, A.K., Vrieling, A., Darvishzadeh, R., Toxopeus, A.G., Ngene, S.M. Elephant poaching hotspots: a comparison of spatial clustering methods. Zoological Society of London symposium : remote 
sensing for conservation: uses, prospects and challenges, 22-23 May 2014, London, United Kingdom.

Rashidi, P., Wang, T.J., Skidmore, A.K., Darvishzadeh, R. Ngene, S.M. A Bayesian spatial approach for identifying elephant poaching hotspots. Space Technology and Applications for Wildlife Management and Protecting Biodiversity, 27-30 Jun 2016, Nairobi, Kenya 